\title{
AN ARCHITECTURE OF DISASSEMBLY AND CYCLICAL MATERIAL LIFE
}

\author{
by
}

Danya Sturgess, B.Arch, University of Waterloo, 2009

\author{
A thesis \\ presented to Ryerson University \\ In partial fulfillment of the \\ requirements for the degree of \\ Master of Architecture \\ In the program of \\ Architectural Science \\ Toronto, Ontario, Canada, 2012 \\ (C) Danya sturgess 2012
}





\section{Author's declaration for electronic submission of a thesis}

I hereby declare that I am the sole author of this thesis. This is a true copy of the thesis, including any required final revisions, as accepted by my examiners.

I authorize Ryerson University to lend this thesis to other institutions or individuals for the purpose of scholarly research.

I further authorize Ryerson University to reproduce this thesis by photocopying or by other means, in total or in part, at the request of other institutions or individuals for the purpose of scholarly research.

I understand that my thesis may be made electronically available to the public. 



\section{An Architecture of Disassembly and Cyclical Material Life Master of Architecture 2012 \\ Danya Sturgess \\ Architectural Science \\ Ryerson University}

\section{Abstract}

This thesis explores disassembly as architectural expression and liberator of components for reuse and recycling in order to diminish material waste when the building is deemed obsolete. It questions that contemporary buildings be built for permanence, but proposes instead that they be able to be modified and taken apart in order to provide material for the next generation of buildings instead of the landfill. It examines the history and theory of joints and connections in architecture and the possibilities these offer for disassembly. It examines production and construction methods pertaining to disassembly and reversible joints, as well as the implications of an architecture that strives to express its construction and material being. Principles of disassembly and component reuse are established through the study of temporary, prefabricated, modular, and waste-as-material precedents. The principles are utilized in the design project, which aims to create an architecture expressing the assembly of parts in addition to the whole while significantly contributing to a reduction of material waste. 



\section{Acknowledgements}

I would like to thank my tireless supervisor Dr. Mark Gorgolewski, to whom I am indebted for his ideas, time, and thoughtful commentary. His vast knowledge and enthusiasm continued to motivate, encourage, and inspire me at weekly meetings over the past eight months.

I am grateful as well to my second advisor, Professor Vincent Hui, for his perceptive and focused guidance. His tough-love approach kept me working hard.

I have to thank Professor Arthur Wrigglesworth for his energetic reception and criticism at presentations of the work, as well as Richard Witt and Chloe Town for the insightful discussion and comments generated at the final public presentation.

I am also indebted to my many Ryerson colleagues who supported and suffered alongside me in the studio - it was a great relief to know I was never alone.

Finally, I owe a deep thanks to my partner, John, for his constant support and optimism - and his willingness to let me ignore him for days at a time.

I offer my kind regards to all those who supported me in any respect during the completion of this lengthy project. 



\section{Contents}

1 Introduction

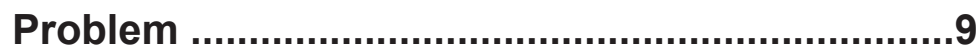

2 Background and literature review ....................15

2.1 Design with reused material

2.2 Design for disassembly

2.3 Tectonics and the building as autonomous form

2.4 The architectural joint

$2.5 \quad$ Fabrication and assembly

2.6 Building typologies for impermanence

3

Precedent review ...............................................69

3.1 Mechanical joinery

3.2 Pre-fabrication

3.3 Design for disassembly

3.4 Layering assemblies

3.5 Portable and temporary structures

3.6 Building with standardized elements

3.7 Case studies for disassembly

4 Design exploration

4.1 System design proposal

4.2 Commercial agenda

4.3 System design

4.4 Site specific design

Wellesley St W and Sherbourne St site

Danforth Ave and Playter Blvd site

5 Conclusions

Appendices. 209

References 



\section{List of figures}

Fig 1.1 Resource extraction - Mallet, Mark. (2011) Is Green Mining Possible?, retrieved from http://www.greenlivingonline.com/, Nov 4, 2011.

Fig 1.2 Demolition - Dallas Contracting Co., (2011) Building Demolition, retrieved from http://www.dallascontracting. com, Nov 4, 2011.

Fig 1.3 Material waste - Your Kloset, (2011) Landfill-landscape, retrieved from http://www.yourkloset.com, Nov 4, 2011.

Fig 1.4 Parthenon - Camarillo Dunn, Jerry Jr. (2011) The Parthenon and the Acropolis, retrieved from http://tlc.howstuffworks.com, Nov 4, 2011.

Fig 1.5 Crystal Palace -7 CCV (2010, Jul 17) A relaxing way to Crystal Palace, retrieved from http://www.7ccv.com/tag/ crystal-palace, Nov 4, 2011.

Fig 1.6 Sanaa Art Gallery - blog.betaflop.de (2008, Feb) Day 114: New York City (3), retrieved from http://blog.petaflop.de/2008/02/05/day-114-new-york-city-3/, Nov 30, 2011.

Fig 1.7 Renzo Piano, Tjibaou Centre - Buchanan, Peter. (1993) Renzo Piano Building Workshop: complete works v.2, London: Phaidon Press.

Fig 1.1.1 Traditional Architecture Cycle, drawn by author

Fig 1.1.2 Revised Architecture Cycle, drawn by author

Fig 1.1.3 Principles, drawn by author

Fig 2.1.1 Material Reuse with Villa Welpeloo, drawn by author

Fig 2.1.2 Biological and industrial nutrient cycle, drawn by author

Fig 2.1.3 Design4deconstruction. (2011) British Pavilion at Expo '92, Seville, Spain - Architect. Retrieved from http://www. design4deconstruction.org/, Nov 22, 2011.

Fig 2.1.4 Nicholas Grimshaw and Partners British Pavilion interior - Design4deconstruction. (2011) British Pavilion at Expo '92, Seville, Spain - Architect. Retrieved from http://www. design4deconstruction.org/, Nov 22, 2011.

Fig 2.2.1 Shigeru Ban Centre d'Interpretation - Miyake, Riichi. (2010) Shigeru Ban Paper in Architecture, Luna, Ian \& Gould, Lauren A. (Ed.) New York: Rizzoli International Publications, Inc.

Fig 2.2.2 MIT Building 20 - MIT Institute Archives. (1998) Celebrating the History of Building 20, retrieved from http:// libraries.mit.edu/archives/mithistory/building20/index. 

Fig 2.2.3 Layered Assembly Sketch, drawn by author

Fig 2.3.1 Shigeru Ban Haesley Nine Bridges Clubhouse (2012) Shigeru Ban in conferenza a Ferrara, "Works and humanitarian activities," retrieved from http://www.materialdesign.it/it/post-it/shigeru-ban-in-conferenza-a-ferraraworks-and-humanitarian-activities-_13_59.htm, May 1, 2012.

Fig 2.3.2 Renzo Piano Tjibaou - Buchanan, Peter. (1993) Renzo

Piano Building Workshop: complete works v.2, London: Phaidon Press.

Fig 2.3.3 Yukiharu Suzuki \& Assoc, Barn House - modern residential design. (2010) Barn Home Design by Yukiharu Suzuki \& Associates. Retrieved from http://www.modresdes.com/2010/08/barn-home-design-by-yukiharu-suzukiassociates/, Nov 24, 2011.

Fig 2.3.4 Kengo Kuma, Bamboo House - inhabitat. (2006) Great (Bamboo) Wall. Retrieved from http://inhabitat.com/ great-bamboo-wall/, Nov 24, 2011.

Fig 2.4.1 Renzo Piano, UNESCO Laboratory Workshop - Buchanan, Peter. (1993) Renzo Piano Building Workshop: complete works v.2, London: Phaidon Press.

Fig 2.4.2 Francois de Menil, Byzantine Fresco Chapel Museum - Ojeda, Oscar Riera \& Pasnik, Mark. (2003) Elements: Architecture in Detail, Rockport Publishers: Massachusetts. 164.

Fig 2.4.3 Olson Sundberg Kundig Allen, Mission Hill Family Estate Winery - Ojeda, Oscar Riera \& Pasnik, Mark. (2003) Elements: Architecture in Detail, Rockport Publishers: Massachusetts. 114.

Fig 2.4.4 African Nomadic Frame - Prussin, Labelle. (1995) African Nomadic Architecture: Space, Place and Gender, Smithsonian Institution Press and The National Museum of African Art: Washington and London.

Fig 2.4.5 Demountable foundation sketch, drawn by author

Fig 2.4.6 Demountable foundation sketch 2, drawn by author

Fig 2.4.7 Crystal Palace Roof - The Crystal Palace Museum. (2011) Artifacts From The Crystal Palace: Black \& White Photographs, retrieved from www.crystalpalacemuseum. org.uk, Dec 7, 2011.

Fig 2.4.8 Doric Column Assembly - Miller, Stephen G. (1990)

Nemea: A Guide to the Site and Museum. Berkeley: University of California Press. retrieved from http://publishing.cdlib.org/ucpressebooks/ view?docld=ft1q2nb0x1; chunk.id=d0e5888;doc. view=print, Mar 28, 2012.

Fig 2.4.9 Le Corbusier, Villa Savoye - Wikipedia. (2011) Villa Sa- 

voye, retrieved from en.wikipedia.org/wiki/Villa_Savoye, Nov 22, 2011.

Fig 2.4.10 Zaha Hadid, Abu Dhabi Performing Arts Centre - dezeen. (2007) Zaha Hadid in Abu Dhabi update, retrieved from www.dezeen.com, Nov 22, 2011.

Fig 2.4.11 Renzo Piano, UNESCO Lab Workshop Joint - Buchanan, Peter. (1993) Renzo Piano Building Workshop: complete works v.2, London: Phaidon Press.

Fig 2.4.12 Peter Marino and Assoc, Datascape Corporation Ojeda, Oscar Riera \& Pasnik, Mark. (2003) Elements: Architecture in Detail, Rockport Publishers: Massachusetts. 46.

Fig 2.5.1 Andrew Kudless, Manifold detail (2012) Matsys, retrieved from http://matsysdesign.com/category/information/exhibitions/, May 2, 2012.

Fig 2.5.2 Renzo Piano and Richard Rogers, Pompidou Center (2010) Architectural Design In Steel Frame Design, In Architecture-Structure. Retrieved from http://tukangarsitek.blogspot.com/2010/11/architectural-design-in-steelframe.html, Dec 7, 2011.

Fig 2.5.3 Herzog and DeMeuron Bird's Nest model - Iwamoto, Lisa. (2009) Digital Fabrications: Architectural and Material Techniques. New York: Princeton Architectural Press. 016.

Fig 2.5.4 Andrew Kudless, Manifold - Iwamoto, Lisa. (2009) Digital Fabrications: Architectural and Material Techniques. New York: Princeton Architectural Press. 086.

Fig 2.5.5 Shigeru Ban, Nemunoki Children's Museum of Art - Miyake, Riichi. (2010) Shigeru Ban Paper in Architecture, Luna, Ian \& Gould, Lauren A. (Ed.) New York: Rizzoli International Publications, Inc. 67.

Fig 2.5.6 Andrew Kudless, P_Wall - Iwamoto, Lisa. (2009) Digital Fabrications: Architectural and Material Techniques. New York: Princeton Architectural Press. 115.

Fig 2.6.1 East York Bungalow renovations, drawn by author

Fig 3.1.1 Shigeru Ban, temporary Artek Pavilion - UPM. (2012) Images for media, retrieved from http://www.upmprofi.com/ en/media/photo-gallery/Pages/default.aspx, May 2, 2012.

Fig 3.1.2 Stan Allen, Infobox - Dezeen magazine. (2011, Nov 17) Taichung Infobox by Stan Allen, dezeen magazine. Retrieved from www.dezeen.com, Nov 28, 2011.

Fig 3.1.3 Stan Allen, Infobox Detail - Dezeen magazine. (2011, Nov 17) Taichung Infobox by Stan Allen, dezeen magazine. Retrieved from www.dezeen.com, Nov 28, 2011.

Fig 3.1.4 DSA+s Architects Bamboo Restaurant - Architecture, 

Modern Home \& Interior Design, Furniture. (2010, Nov) Outdoor Bamboo Restaurant. Retrieved from www.archplanner.com, Nov 28, 2011.

Fig 3.1.5 DSA+s Architects Bamboo Restaurant Detail - Architecture, Modern Home \& Interior Design, Furniture. (2010, Nov) Outdoor Bamboo Restaurant. Retrieved from www. archplanner.com, Nov 28, 2011.

Fig 3.1.6 SSM Architekten, Kunsthaus - Saieh, Nico. (2008, Aug 14) Kunsthaus Art House Extension/ssm Architekten, archdaily. Retrieved from www.archdaily.com, Nov 28, 2011.

Fig 3.1.7 SSM Architekten, Kunsthaus detail - Saieh, Nico. (2008, Aug 14) Kunsthaus Art House Extension/ssm Architekten, archdaily. Retrieved from www.archdaily.com, Nov 28, 2011.

Fig 3.1.8 Gregg Fleishman, Disaster house - Fleishman, Gregg, (2011) Humanizing the Factory Produced House. Retrieved from www.greggfleishman.com, Nov 28, 2011.

Fig 3.1.9 Shigeru Ban Tea House - Miyake, Riichi. (2010) Shigeru Ban Paper in Architecture, Luna, lan \& Gould, Lauren A. (Ed.) New York: Rizzoli International Publications, Inc.

Fig 3.1.10 Suyama Peterson Deguchi, Mount Vernon cabin interior - Remodelista. (2011, March 21) Architect Visit: Suyama Peterson Deguchi Architects in Seattle, retrieved from www.remodelista.com, Nov 28, 2011.

Fig 3.1.11 Gaia, Glencoe Visitor Center interior- Design4deconstruction. (2011) Glencoe Visitor Center, Glencoe, Scotland - Gaia Architects. Retrieved from http://www. design4deconstruction.org/, Nov 22, 2011.

Fig 3.1.12 Shigeru Ban, Paper dome - Miyake, Riichi. (2010) Shigeru Ban Paper in Architecture, Luna, Ian \& Gould, Lauren A. (Ed.) New York: Rizzoli International Publications, Inc.

Fig 3.1.13 Renzo Piano, IRCAM detail - Ermanno, Ranzani. (1990, Feb) Ampliamento dell'Ircam a Parigi, in Domus [38] -47.

Fig 3.1.14 Curved brick wall sketch, drawn by author

Fig 3.1.15 Shigeru Ban Vasarely Pavilion - Miyake, Riichi. (2010) Shigeru Ban Paper in Architecture, Luna, lan \& Gould, Lauren A. (Ed.) New York: Rizzoli International Publications, Inc. p.106-109.

Fig 3.1.16 Shigeru Ban Canal Boathouse Museum - Miyake, Riichi. (2010) Shigeru Ban Paper in Architecture, Luna, Ian \& Gould, Lauren A. (Ed.) New York: Rizzoli International Publications, Inc. p.106-109.

Fig 3.2.1 Huang and Dempsey, [c]space pavilion exterior detail SDA (2008) DRL10 [C]SPACE PAVILION, retrieved from http://synthesis-dna.com/project-example-1/, May 2, 

2012.

Fig 3.2.2 Huang and Dempsey, [c]space pavilion - Kallaway (2012) Architectural Association School of Architecture, retrieved from http://mediacentre.kallaway.co.uk/architectural-association-school-picture-library1.asp, May 2, 2012.

Fig 3.2.3 Flatform Installation - Marble Fairbanks. (2011) Flatform, Home Delivery: Fabricating the Modern Dwelling. Retrieved from www.marblefairbanks.com, Oct 27, 2011.

Fig 3.2.4 Bead Brick high rise - Muslimin, Rizal. (2010) Bead Brick, retrieved from http://www.brickstainable.com/currentwinners/technical-design.html, Dec 9, 2011.

Fig 3.2.5 Bead Brick arrangements - Muslimin, Rizal. (2010) Bead Brick, retrieved from http://www.brickstainable.com/current-winners/technical-design.html, Dec 9, 2011.

Fig 3.3.1 Nicholas Grimshaw, Igus Headquarters and Factory facade detail - CSI Ltd (2012) retrieved from http://csicsf.com/, May 2, 2012.

Fig 3.3.2 The Adaptable House axonometric detail - 4d Architects, (2011) The Adaptable House, retrieved from www.4darchitects.nl, Nov 24, 2011.

Fig 3.3.3 The Adaptable House exterior - 4d Architects, (2011) The Adaptable House, retrieved from www.4darchitects.nl, Nov 24, 2011.

Fig 3.3.4 Glencoe Visitor Centre - Gaia Group. (2011) Design Excellence Providing Access and Conservation, retrieved from www.gaiagroup.org, Nov 22, 2011.

Fig 3.3.5 Glencoe Visitor Centre, glazed link - Gaia Group. (2011) Design Excellence Providing Access and Conservation, retrieved from www.gaiagroup.org, Nov 22, 2011.

Fig 3.3.6 Station Z Memorial interior - Werner Sobek. (2011) Station Z, retrieved from www.wernersobek.de, Dec 9, 2011.

Fig 3.3.7 IGUS Factory exterior -Kronenberg, Robert. (2000) Portable Architecture, Second Edition. Oxford: Architectural Press.

Fig 3.3.8 IGUS Factory interior -Kronenberg, Robert. (2000) Portable Architecture, Second Edition. Oxford: Architectural Press.

Fig 3.3.9 IGUS Factory detail drawing -Kronenberg, Robert. (2000) Portable Architecture, Second Edition. Oxford: Architectural Press.

Fig 3.4.1 Essex House - Bahamon, Alejandro \& Sanjines, Maria Camila. (2010) Rematerial: From Waste to Architecture. WW Norton \& Co.

Fig 3.4.2 Steenwijk Community Centre exterior - Marx \& Steketee. 

tee. (2011) Toga Nu, Steenwijk. Retrieved from www. mrxnstkt.nl, Dec 9, 2011.

Fig 3.4.3 Steenwijk Community Centre interior - Marx \& Steketee. (2011) Toga Nu, Steenwijk. Retrieved from www.mrxnstkt.nl, Dec 9, 2011.

Fig 3.4.4 Racine Art Museum detail- Bahamon, Alejandro \& Sanjines, Maria Camila. (2010) Rematerial: From Waste to Architecture, WW Norton \& Co.

Fig 3.4.5 Racine Art Museum facade- Bahamon, Alejandro \& Sanjines, Maria Camila. (2010) Rematerial: From Waste to Architecture, WW Norton \& Co.

Fig 3.4.6 Mechanical acces panel - Durmisevic, Elma \& Linthorst, Patrick. (2000) Industrialization of Housing (Building with systems), The Netherlands: Delft University of Technology,

Fig 3.5.1 Renzo Piano, IBM Travelling Exhibition exterior detail Arquitectura + Historia (2010) SC 137: El Pabellón IBM de Renzo Piano Reelaborado por el Studio Gang en Chicago, retrieved from http://arquitecturamashistoria. blogspot.ca/2010/08/sc-137-el-pabellon-ibm-de-renzopiano.html, May 2, 2012.

Fig 3.5.2 The Nomad Contemporary Yurt interior- NOTCOT (2008) The Nomad Yurt by Ecoshack, http://www.notcot. com/archives/2008/03/the-nomad-yurt.php, Nov 4, 2011.

Fig 3.5.3 The Nomad Contemporary Yurt kit- NOTCOT (2008) The Nomad Yurt by Ecoshack, http://www.notcot.com/ archives/2008/03/the-nomad-yurt.php, Nov 4, 2011.

Fig 3.5.4 Shigeru Ban Artek Pavilion - Miyake, Riichi. (2010) Shigeru Ban Paper in Architecture, Luna, Ian \& Gould, Lauren A. (Ed.) New York: Rizzoli International Publications, Inc. p.106-109.

Fig 3.5.5 Renzo Piano, IBM Traveling Pavlion detail - Vidani, Peter (2012) Arquitectura en Movimiento, retrieved from www.arquitecturaenmovimiento.tumblr.com, Mar 27, 2012

Fig 3.5.6 Renzo Piano, IBM Traveling Pavilion - NCSEA (2007) The Imaginative Engineer, In Structure Magazine, retrieved from www.structuremag.org, Mar 27, 2012.

Fig 3.6.1 2012 Architects, Villa Welpeloo facade - Paperblog (2012) Villa Welpeloo par 2012 Architects, retrieved http://www. paperblog.fr/2706036/villa-welpeloo-par-2012-architects/, May 2, 2012.

Fig 3.6.2 2012 Architects, Villa Welpeloo - 2012 Architecten (2012) Villa Welpeloo, retrieved from www.2012architecten.nl, Mar 25, 2012.

Fig 3.6.3 Azkoitia Museum - Bahamon, Alejandro \& Sanjines, Ma- 

ria Camila. (2010) Rematerial: From Waste to Architecture, WW Norton \& Co.

Fig 3.6.4 Curved standardized material sketch, drawn by author

Fig 3.6.5 Curved standardized material sketch, drawn by author

Fig 3.6.6 Palette Structure - Bahamon, Alejandro \& Sanjines, Maria Camila. (2010) Rematerial: From Waste to Architecture, WW Norton \& Co.

Fig 3.6.7 Planar material sketch, drawn by author

Fig 3.6.8 Planar material sketch, drawn by author

Fig 3.7.1 Werner Sobek, R128 House exterior - 1 Kind Design. (2011) Off-the-grid green house with glass facade, retrieved from http://www.1kindesign.com/2011/03/25/offthe-grid-green-house-with-glass-facade/, Mar 28, 2012

Fig 3.7.2 R128 House structural detail - Stang, Alanna and Hawthorne, Christopher. (2005) The Green House: New Directions in Sustainable Architecture. New York: Princeton Architectural Press.

Fig 3.7.3 R128 House kitchen - Stang, Alanna and Hawthorne, Christopher. (2005) The Green House: New Directions in Sustainable Architecture. New York: Princeton Architectural Press.

Fig 3.7.4 Kieran and Timberlake, Loblolly House - Kieran, Stephen and Timberlake, James. (2008) Loblolly House: Elements of a New Architecture. New York: Princeton Architectural Press.

Fig 3.7.5 Loblolly House scaffolding detail - Kieran, Stephen and Timberlake, James. (2008) Loblolly House: Elements of a New Architecture. New York: Princeton Architectural Press.

Fig 3.7.6 Loblolly House service block - Kieran, Stephen and Timberlake, James. (2008) Loblolly House: Elements of a New Architecture. New York: Princeton Architectural Press.

Fig 3.7.7 MEC Burlington exterior - Cowling, Dan. (2010) Mountain Equipment Co-op: New store tests design for recoverability, SAB Magazine, retrieved from www.sabmagazine.com, Nov 30, 2011.

Fig 3.7.8 MEC Burlington interior - Cowling, Dan. (2010) Mountain Equipment Co-op: New store tests design for recoverability, In SAB Magazine, retrieved from www.sabmagazine.com, Nov 30, 2011.

Fig 4.1.1 Anderson, Mark \& Anderson, Peter. (2007) Prefab Prototypes: site-specific design for offsite construction, New York: Princeton Architectural Press. 

Fig 4.2.1 Suburban retail concept, drawn by author

Fig 4.2.2 Suburban retail parking, drawn by author

Fig 4.2.3 Commercial infill concept, drawn by author

Fig 4.3.1 Toronto urban block size, drawn by author

Fig 4.3.2 Parking bay dimension concept, drawn by author

Fig 4.3.3 Screw pile detail, drawn by author

Fig 4.3.4 Timber cross bracing concept, drawn by author

Fig 4.3.5 Timber beam detail, drawn by author

Fig 4.3.6 Structural joinery, drawn by author

Fig 4.3.7 Skin concept, drawn by author

Fig 4.3.8 Roof panel exploded, drawn by author

Fig 4.3.9 Wall panel exploded, drawn by author

Fig 4.3.10 Floor panel exploded, drawn by author

Fig 4.3.11 Service-washroom and circulation cores concept, drawn by author

Fig 4.3.12 Service plenum perspective, drawn by author

Fig 4.3.13 Furnishings exploded, drawn by author

Fig 4.3.14 Bay assembly exploded, drawn by author

Fig 4.3.15 Process cycles at obsolescence, drawn by author

Fig 4.4.1 Site plan for Wellesley St E and Sherbourne Ave site, drawn by author

Fig 4.4.2 Commercial land-use map for the Sherbourne Ave site, drawn by author

Fig 4.4.3 Commercial square footage map for the Sherbourne Ave site, drawn by author

Fig 4.4.4 Site photo from February 2012, taken by author

Fig 4.4.5 Site photo from February 2012, taken by author

Fig 4.4.6 Assembly process images, drawn by author

Fig 4.4.7 Building massing on site, drawn by author

Fig 4.4.8 Ground floor plan, drawn by author

Firg 4.4.9 Upper floor plan, drawn by author

Fig 4.4.10 Wellesley St E and Sherbourne Ave corner perspective, $\mathrm{XXV}$ 

drawn by author

Fig 4.4.11 Sherbourne St looking North towards Wellesley St E, drawn by author

Fig 4.4.12 Upper floor interior view towards Sherbourne-Wellesley corner, drawn by author

Fig 4.4.13 Disassembly process images, drawn by author

Fig 4.4.14 Danforth Ave and Playter Blvd site plan, drawn by author

Fig 4.4.15 Assembly process images, drawn by author

Fig 4.4.16 Ground floor plan, drawn by author

Fig 4.4.17 Upper floor plan, drawn by author

Fig 4.4.18 Danforth Ave perspective looking east, drawn by author

Fig 4.4.19 Danforth Ave perspective looking west, drawn by author

Fig 4.4.20 Exterior perspective of south entry to building, drawn by author

Fig 4.4.21 Aerial view of the disassembly process, drawn by author

Fig 4.4.22 Conventional material cycle with waste, drawn by author

Fig 4.4.23 Demolition material cycle, drawn by author

Fig 4.4.24 Disassembly of conventional building material cycle, drawn by author

Fig 4.4.25 New material cycle with reusable and recyclable materials, drawn by author 



\section{List of appendices}

Appendix 1 Material volume estimate analysis for Sherbourne St and Wellesley St East building iteration, created by author 


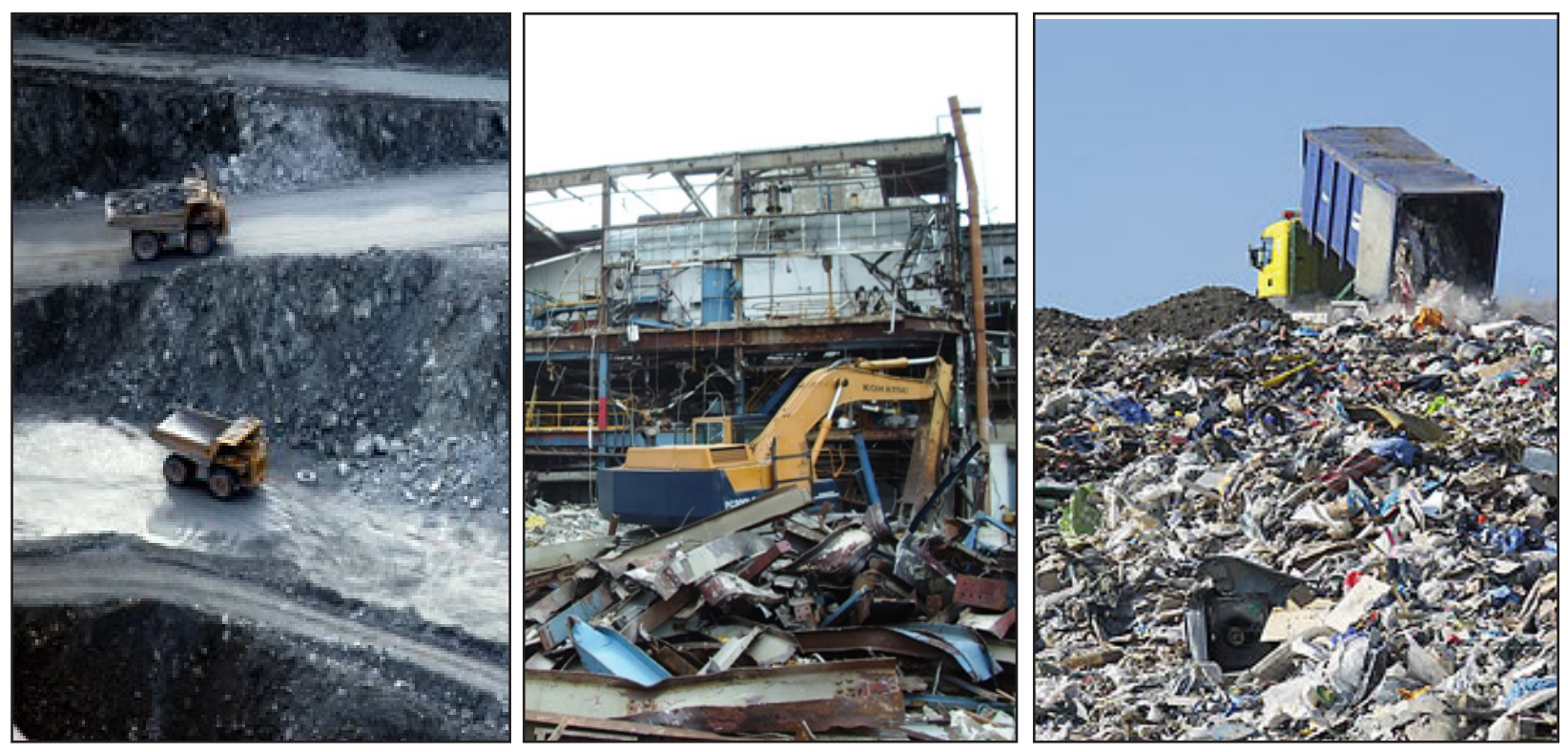

\section{Introduction}

Fig 1.1 Resource extraction

Fig 1.2 Building demolition

Fig 1.3 Material dumping
The thesis study began with the desire to address the problem of material waste in architecture. The consumption of earth's resources is essential for the economic prosperity of developed society, but increased rates of consumption and growth in world population put high demand on all earthly goods (Durmisevic \& Brouwer, 2002)(Ashby, 2009, p.7). The construction industry is the second most massive consumer of material resources in the world (Berge, 2009, p.6). The greatest amount of waste is generated at the end of a building's life - when they are demolished to make way for new creations. Typically this act of destruction is undertaken with little attempt to recover parts for reuse and relegates material to landfills (Durmisevic \&Yeang, 2009, p.136). In Canada, construction and demolition creates 9.3 million tonnes of waste each year, and in 2008 data shows that only $12 \%$ was recycled or reused. (Ontario Waste Management Association, 2005) Although materials often outlive the building use, architects rarely design to consider their fate after the building life is over (Berge, 2009, p.6) (Mori, 2003, p.30). Contrary to the reality, architecture is perceived as permanent, while building materials are viewed as disposable. To sustain the quality of life on earth it is critical to conserve and effectively use resources (Durmisevic \& Bouwer, 

2002). Disposing of good material is impractical since harvesting and processing resources generally requires more energy than recycling or reusing that which has already been sourced (Ashby, 2009, p.72). The concept of constructing with reused materials is not currently practical or widespread since designs do not accommodate disassembly and easy means of liberating their components.

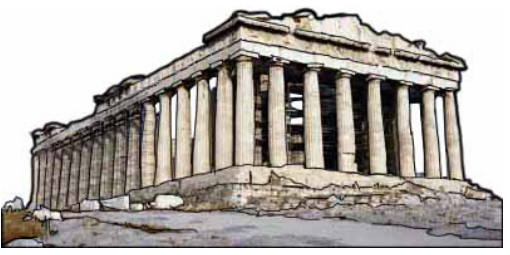

There are two approaches to using material effectively: the one is to design for endurance and lasting building life, while the other is to design for a limited existence with the intention of material reuse. Traditionally architecture has been considered a permanent and lasting fixture that acts as a reminder of the zeitgeist from when it was conceived. However it is almost impossible to foresee which buildings will be preserved, maintained and treasured while others are taken down and replaced. Contemporary architecture is often impermanent despite its intentions, and is not necessarily an enduring solution. Current construction practices usually aim to create buildings with the material life of at least 50

Fig 1.4 Parthenon as enduring Fig 1.5 Crystal Palace as impermanent years, but many buildings are demolished after only 15 (Durmisevic \& Yeang, 2003, p.134). Demolitions and renovations typically account for more projects than new builds each year. In the United States, 1.75 billion square feet of building stock are torn down each year, 5 billion are renovated, and 5 billion are built new (Architecture 2030, 2011). Programmatic needs change, technical innovations render obsolete older systems, and materials are damaged and deteriorate. A 2011 CBC article described how the vast fields of new condominium buildings with window wall cladding in Canada are destined to need entirely new skin and mechanical systems within 25 years (CBC, 2011). There is constant growth and change to the fabric of the built environment as needs and lifestyles change. Elma Durmisevic and Jan Brouwer (2002) describe how buildings are changed based upon "user requirements,... degradation of materials and more technology dependent components."In the research paper "Understanding Obsolescence: A Conceptual Model for Buildings," the authors claim that obsolescence leading to demolition 



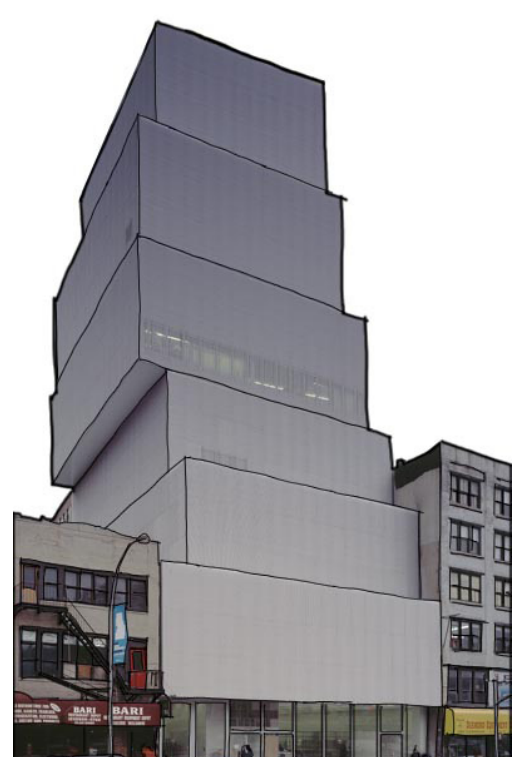

\section{VS}

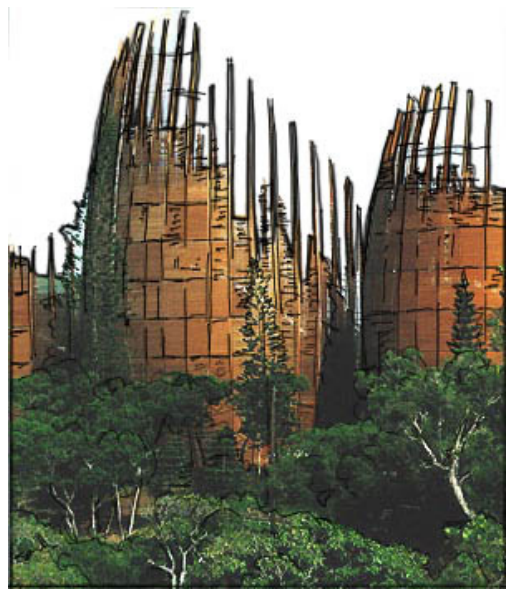

Fig 1.6 SANAA, Contemporary Art Gallery avoids the expression of construction, structure and material Fig 1.7 Renzo Piano, Tjibaou Cultural Centre, expresses a study of vernacular construction with contemporary method and materials can arise at small scale within "building materials, parts and elements, building construction systems (structure, fabric, mechanical and electrical, etc.)" or at the scale of an entire building, block or neighbourhood (Thomsen and van der Flier, 2011, p.353). Buildings can be rendered obsolete due to physical factors such as poor design and material wear, behavioural factors such as change in use, damage by occupants, or external factors such as changing physical and behavioural conditions in the surrounding environment such as new technologies, traffic, nearby buildings and social deprivation. The physical factors of the building can be controlled through design and management, but behavioural factors tend to be beyond control of the owner, and external factors are too complex to be tackled by the owner or foreseen by the architect (Thomsen and van der Flier, 2011). These factors make it near impossible to design a lasting building, but designing a solution that is capable of change and adaptation could extend usefulness. In the book "Cradle to Cradle", William McDonough and Michael Braungart question the desire to build lasting forms. They believe that to build for permanence is arrogant and selfish, and that we should allow future generations to conceive and create their own products and architectures.

"Maybe we want our things to live forever, but what do future generations want? What about their right to the pursuit of life, liberty, and happiness, to a celebration of their own abundance of nutrients, of materials, of delight?"

(McDonough \& Braungart, 2002, p.114)

Futurists Sant Elia and Marinetti stated as far back as 1914: "The life of

a house will not be as long as it is with us, every generation will want to build its own town" (Universitat Stuttgart, p.43). It is irrational to expect that solutions derived based upon the flows, knowledge and data of today will be successful and functional in the years to come. Architects must come to accept that their creations are not permanent, but the management of the materials that composes them has a lasting effect.

A secondary architectural issue is that of tectonics. Architecture is the 

art of building, yet most contemporary edifices are dislocated from the expression of construction. Architecture abstracted to imagery has no substance or meaning with respect to construction and withholds the evidence of effort and skill from perception. For a user to take pleasure in a work of architecture they must comprehend its matter, its weight, and its rigidity. Respecting and comprehending material qualities can elevate the building beyond simple form to poetics, and create compelling tectonic architecture. There is power in the essential elements of architecture: light, shadow, material, structure, texture and detail, and there is satisfaction in gaining an understanding of the effort involved in designing and making a building through its tectonic language. Disassembly architecture should be a tectonic expression of assembly, disassembly, and impermanence through joinery. 


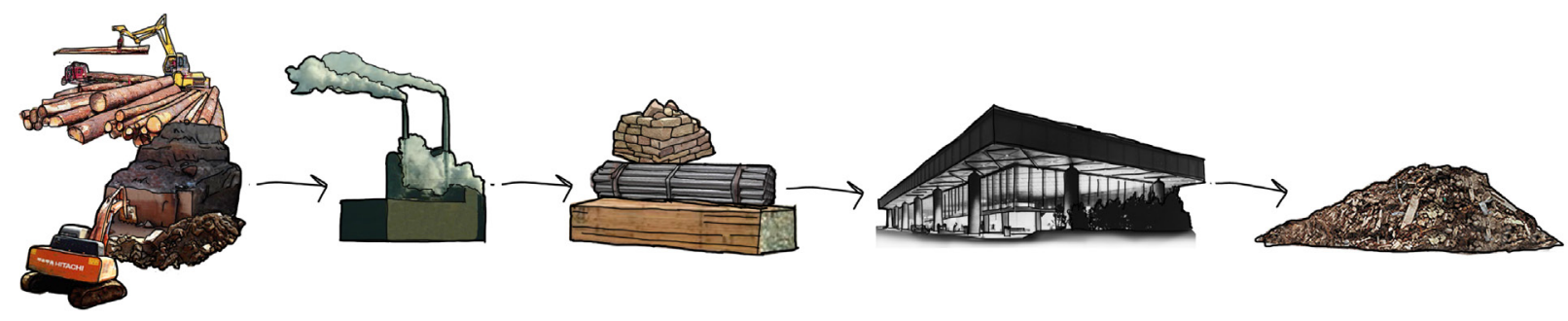

\subsection{Problem}

Fig 1.1.1 Traditional Architecture Cycle with I.M. Pei's demolished JKK Terminal
Contemporary architecture leads to wasteful use of material while there is rising demand for construction materials. Buildings today are often impermanent, yet even design for disassembly often does not conceive of material life after the building. Design for disassembly attempts to mimic traditional construction techniques while hiding or only subtly exposing connections, avoiding a radical reconfiguration of architectural expression. Many current architects try to avoid the expression of assembly in architecture by favouring abstraction and absent details that create environments without evidence of the effort involved in construction and devoid of material honesty. 



\section{Position}

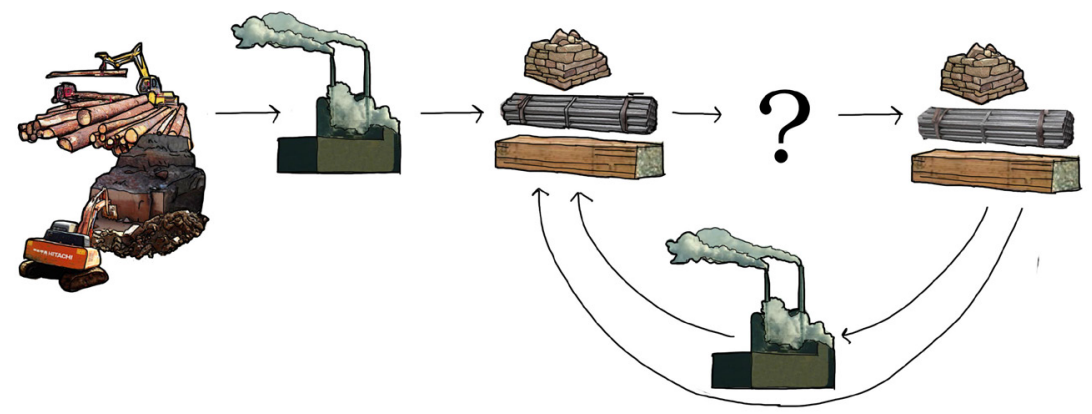

Fig 1.1.2 Proposed Architecture It is critical to use resources effectively. Contemporary architecture Cycle needs to reduce material waste by designing to liberate materials at the end of use. Material life cycle can be extended by changing linear flow into cyclic flow through reuse or recycling of components. A focus on creating an impermanent but durable assembly can create architecture that can be taken apart and components reused. The built form will be about the assemblage of pieces, expressing the details that allow the materials to be separated. Architecture is not a product, but a process of design, making, use, adaptation and unmaking. New architecture needs to embrace its impermanence, with an expression of the act of construction through visible joinery and a promotion of the reuse and recycling of materials. Disassembly also means the building components can be modified and updated when problems or new solutions arise. Architecture as autonomous form can be visually interesting using only basic elements such as structure, material, and detail that reflect the act of construction. 



\section{Principles}

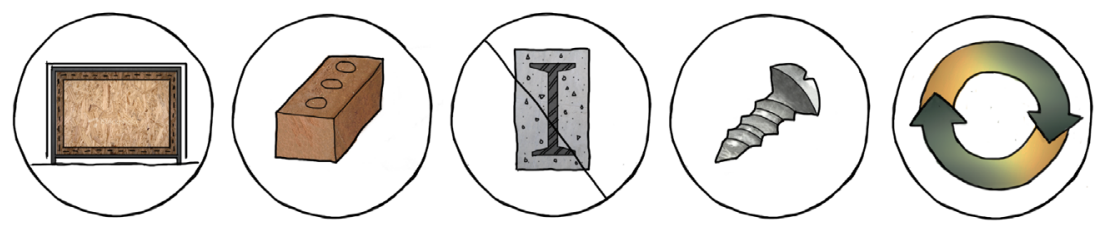

Fig 1.1.3 Principles

Research into disassembly architecture, building with material reuse, and reversible joinery among other things led to several principles to explore in the design project. Layering of assemblies requires building with separate conditions of site, structure, skin, services and finishes so that parts can be updated without compromising the longevity of other layers. Working with uncut standard forms ensures materials are more likely to be reused. Employing homogeneous materials instead of composites allows for the separation of components into base materials for recycling or reuse. Creating non-permanent, reversible connections also allows for easier recycling and reuse, and easier disassembly of the whole building. Selecting materials based upon the expected lifetime of the assembly or building by balancing functional and technical life spans, as well as using recyclable components when compelled to cut or customize, ensures that material lives are most suited to their function.

In terms of architectural expression, to show the making of the architectural object, assembly will be demostrated through deliberate joinery. A built form would express the assemblage of pieces and connections that allows materials to be separated. It would have details that display the effort of assembly and the properties of materials. It would explore prefabrication of components and connectors to improve disassembly, and highlight joinery and the expression of assembly. 



\section{Background and literature review}





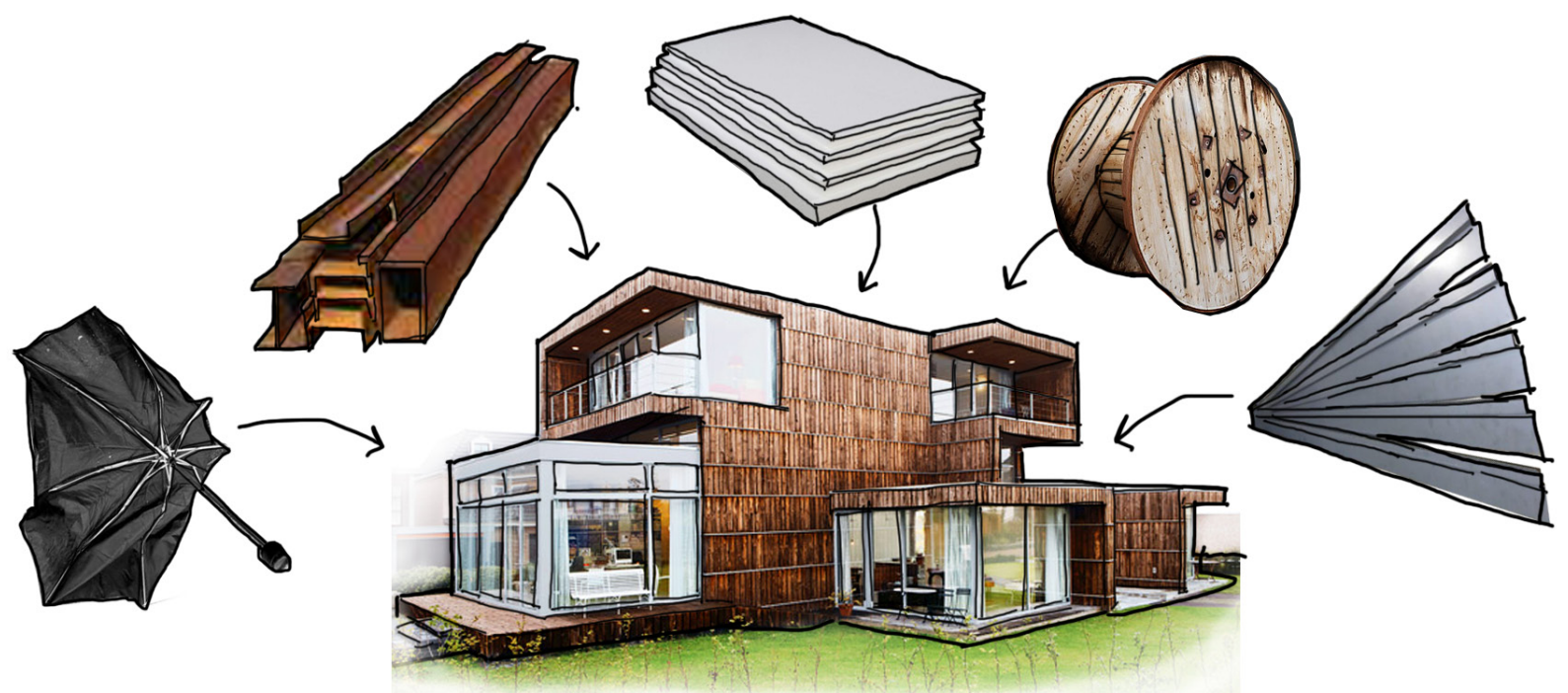

\subsection{Design with reused material}

Fig 2.1 (Page 9-10) aged metal surface

Fig 2.1.1 Reused materials in Villa Welpeloo by 2012 Architects involved significant energy input and reconfiguration to obtain the desired component arrangements
Many designers and architects have embraced the practice of design with used components and materials. This practice extends material life by diverting it from the landfill for the duration of its use. However, it cannot become successful until design practices adjust to enable it as an endeavour. Elma Durmisevic and Ken Yeang, (2009, p.134) authors of "Designing for Disassembly (DfD)," state that buildings are not designed to accommodate deconstruction that will liberate their components for reuse - they are currently conceived as integrated systems in closed structures. Demolition is still the most practiced method of taking down a building whose usefulness has ended, and it ensures that potentially reusable materials are contaminated or lost.

William McDonough and Michael Braungart of "Cradle to Cradle" (2002) believe that there are two types of material flows in human society that must be kept independent, that of biological nutrients and technical nutrients. The first allows for biological decomposition at the end of its life, while the second can be recycled into industrial systems. They have found that mixtures of the materials mean that neither can be reused once the useful life of the product has come to an end, since then they 


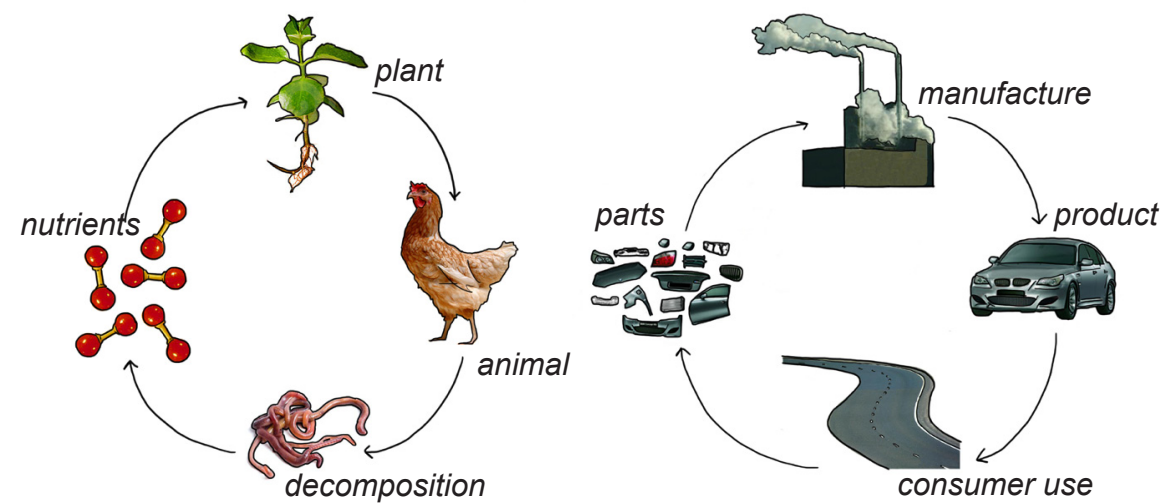

Fig 2.1.2 The separate material cycles: biological nutrient cycle and industrial nutrient cycle

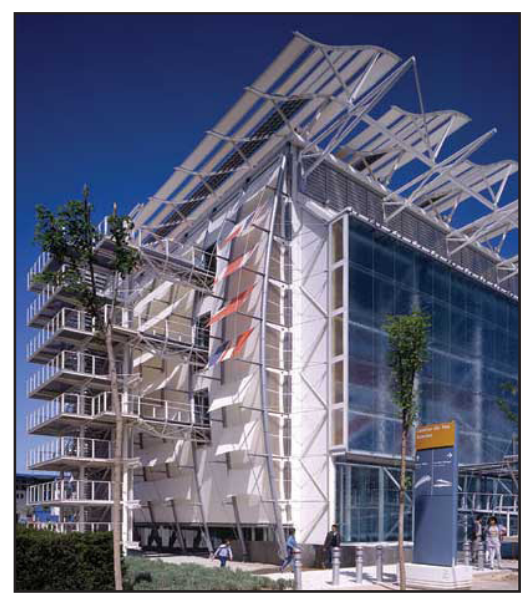

Fig 2.1.3 Nicholas Grimshaw and Partners, British Pavilion, 1992

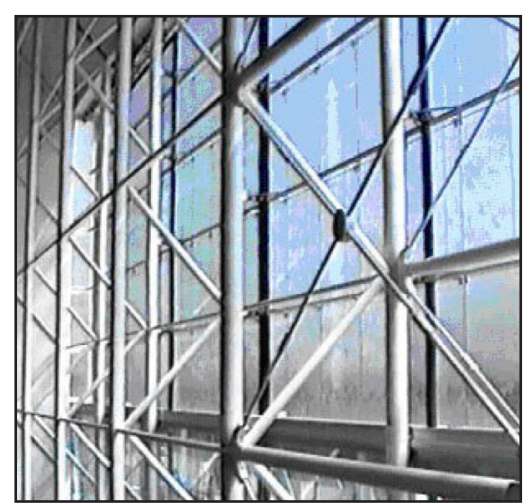

Fig 2.1.4 British Pavilion interior pinned connections on steel struc- can neither biodegrade nor be recycled. Bill Addis, who wrote "Building With Reclaimed Components and Materials: A Design Handbook for Reuse and Recycling," expands on the importance of this idea, as design where materials are joined together in ways that allow them to be easily separated helps facilitate recycling and reuse (Addis, 2006, p.19).

Designing with reused materials favours standard forms and generic materials because they are available in larger quantities for construction, such as old tires and wood skids. Custom forms do not offer as many possibilities for new projects - and are often scrapped, even when originally intended for reuse. The British Pavilion by Nicholas Grimshaw and Partners, for the Seville Exhibition in1992, was purchased for reconstruction at a hotel in Asia, but the plan failed due to code issues. Pin joint connections and tubular steel allowed the vast majority of the structure to come apart easily. The only bolts connected columns to piles that formed a permanent foundation for a temporary structure. The entire steel structure was recycled in England, while the piles, concrete ground and mezzanine floor slabs, and plasterboard shaft wall were demolished (Design4deconstruction, 2011). Shipping the building to Asia from England for reuse would not be an ideal use of energy; building components would ideally be able to be reused local to their original built form. More generic and ubiquitous materials and components are more likely to be in demand for reuse.

In the book "Green building: project planning \& cost estimating," there 

are said to be over 1,600 construction material reuse stores throughout the United States and Canada. The authors found that the most sought after salvaged materials tended to be finish and structural woods, windows, doors, cabinets and casework, masonry, metals of almost any sort, lighting and plumbing fixtures, and often ceiling tiles and carpet (R.S.Means, 2011). Specialty recovery companies placed particular focus on high-end commodities, such as high-quality lumber and antique doors, as well as low-value generic components like strip flooring, windows and roof joists.

If reuse and recycling is to become standard practice to extend construction material life then building detailing and design will need to incorporate the means for easy separation of parts, and material properties would need to be considered to facilitate recycling. For reuse, standard forms with minimal manipulations would have to be favoured over custom shapes and components, and durable, high-quality materials would be encouraged to promote markets for reclamation. 



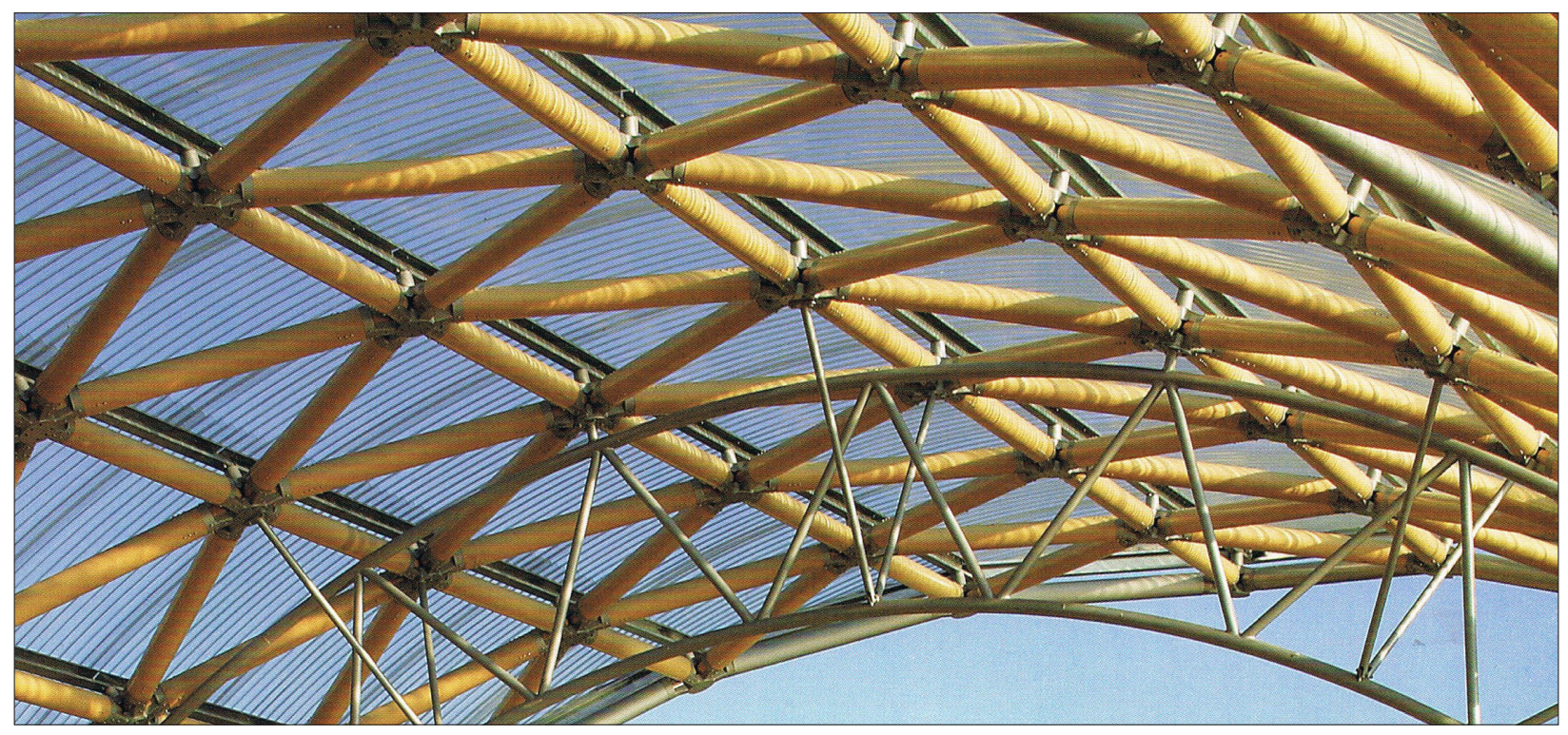

\subsection{Design for disassembly}

Fig 2.2.1 Shigeru Ban, Centre d'Interpretation is designed to come apart using custom joinery so that parts can be replaced over time
The concept of design for disassembly creates an architecture that is inherently impermanent. The impermanent building could last anywhere from 1 day to 1000 years, but it is understood that it will not stand forever. Impermanent structures are designed differently from permanent structures through assembly methods, materials, and site relationships. For buildings of very short duration, such as nomadic structures, foundations are often unnecessary. The temporary building is not affixed to a particular location, but can still be shaped by them:

"...It befits a temporary provision symbiotic on an enduring site to practice two modes of economy: the first is to be in itself as economical as is functionally/physically possible; the second is conservation and exploitation of the configuration of its site - unlike a new building on its assigned plot, it must respect its supporting site's independence and continuence, use it as a borrowed resource - but not passively: to solve its economics design-intelligence must replace the routine choices an empty plot allows, must notice opportunities the existing site presents: features to be exploited but not changed (Carr-Smith, 2009)."

Impermanent architecture has been considered contradictory, since architecture is dominated by characteristic permanence and lasting solutions. However, designing for permanence is impractical and often impossible. We can only hypothesize the effect an intervention will have, and hope our work will be accepted and lasting. An example of the un- 



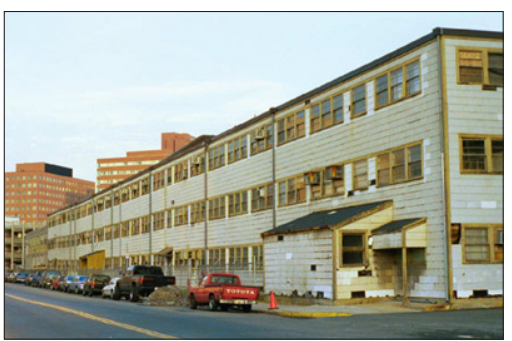

Fig 2.2.2 Don Whitson, MIT Building 20

predictability of building life stood on MIT campus. Building 20 was designed and built rapidly in 1943 with the intent of temporality as it was slated for demolition after the war. It ended up lasting over 35 years because it was so beloved for its flexibility, roughness and functionality (Brand, 1994, p.24). .

\begin{abstract}
"Temporary is permanent, and permanent is temporary. Grand, final-solution buildings obsolesce and have to be torn down because they were too overspecified to their original purpose to adapt easily to anything else. Temporary buildings are thrown up quickly and roughly to house temporary projects. Those projects move on soon enough, but they are immediately supplanted by other temporary project-of which, it turns out, there is an endless supply (Brand, 1994, p.28)."
\end{abstract}

What is the implication of impermanence upon architecture? The deficiency of an impermanent building lies in the potential loss of its physical presence over time, which removes cultural and historical legacy from the built environment. It is a loss that permanently-built architecture also frequently undergoes despite the intentions of the architect, since obsolescence is frequently unpredictable. Change is inevitable in the built world and nothing is truly permanent. The most lasting part of architeture is the materails used to construct. Even if the design fails and the building is destroyed, the materials remain. Buildings that have lasted hundreds or thousands of years have not done so without transformation. They are no longer the true imaginings of their originators, having acquired the additions to permit functionality in present day. Architecture that has been withheld the transformations of time becomes an artifact, incapable of functioning in present day, but maintaining a connection to cultures past. Architecture must continue to adapt and change if it is to maintain usefulness. Stagnation leads to obsolescence and relegation to a cultural artefact. Impermanent buildings accept change and can achieve other architectural aspirations comparable to those designed for permanence. They can contribute to memory, fulfill uses, and delight aesthetically and spiritually. In addition, impermanent buildings have the power to achieve something more than those built with the intent to 



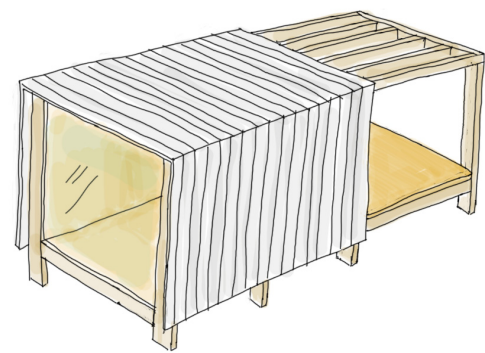

Fig 2.2.3 Concept sketch for layered cladding, structure and finishes last forever. The architect and writer Christopher Alexander claims that every time we build we make "nine mistakes for every success," so the more complete an architectural reality we present, the more opportunity there is for feedback to learn, to correct that which fails to perform the way it should and to improve (Brand, 1994, p.63).

“. ...Indeterminability emerges in the meeting of experience, time and context; the outcome of this conflation is impossible to predict. Irregularities, instabilities and deviance which appear in a given place, which disturb and transform an expected physical order, give rise to shocks, random encounters and accidents (Levesque, 2008)..."

The liberation that arises from impermanence is that of experimentation. The architecture can become a form of physical research, whose performance in context can lead to revisions and new iterations. The impermanent building is a full-scale model that can be scrutinized, revised and rebuilt. The architect Renzo Piano believes that most experimental and unusual architecture is made possible through temporary or impermanent briefs, and he "views impermanent buildings as just another part of mainstream architecture (Kronenberg, 2000, p.18)." Buildings designed for disassembly accept impermanence in architecture, and understand that management of materials and resources has a lasting effect. They are designed for partial or entire deconstruction, in order to replace materials and systems that have worn or become obsolescent, to move to a new location, to grow or shrink, or to disappear entirely into their component parts.

There are valuable principles to take away from the disassembly rhetoric including the concept of layered assemblies, and using dry connections. Layered assemblies divide the building into separate parts - shell, structure, services, finishes, furnishings - and limit their overlap so that each can be modified as necessary without impacting others, since they can last for different lengths of time (Durmisevic \& Yeang, 2009). Frank Duffy and Stewart Brand both believe in the concept of dividing a build- 

ing into separate systems and limiting their interaction (Brand, 1994, p.14). This concept counters designs where systems are integrated, preferring to separate them. Duffy distinguishes the layers as "Shell, Services, Scenery and Set," while Brand expands the layers to include "Site, Structure, Skin, Services, Space Plan and Stuff" (Brand, 1994, p.17). Elma Durmisevic and Jan Brouwer describe the layers as subassemblies that have different functional and life cycle expectancies. By keeping them independent they can be replaced without influencing transformation of the whole structure (Durmisevic \& Brouwer, 2002).

Using dry connections means adhesives and other permanent means of fastening are avoided to construct details with components that can be disconnected for reuse or recycling. Dry connections also begin to refer to the idea of avoiding composite materials and advocating for 'pure' materials. The concept of using 'pure' materials to maximize material life comes from Michael Braungart and William McDonough of "Cradle to Cradle (2002)." Their definition of pure materials can be described as homogeneous material compositions with finishes or additives that do not compromise their ability to be reused or recycled. If composites cannot be separated into 'pure' materials for reuse or recycling or even down-cycling, they are forced into the waste stream.

Barbara Knecht, who wrote an article entitled "Designing for Disassembly and Deconstruction," claims that for a building to be successful in accommodating disassembly it should try to build as little as is necessary to achieve the design, that details should avoid permanent connections and composite components, and that mechanical systems should not be bound to structure, but accessible for maintenance and updating ( 2004, p.183). Knecht's statement to 'build as little as necessary' verges on anti-architectural, but could be interpreted as envisioning a minimal and reductionist aesthetic. The suggestion of dislocating mechanical systems from structure could also be adapted to include electrical, communication networks and plumbing. Durmisevic and Yeang (2009) offer 

further suggestions, such as separating levels of material, creating subassemblies, and using dry mechanical connections. In "Dynamic Versus Static Building Structures," Durmisevic and Brouwer (2002) describe the various life cycles of materials in contemporary buildings. They claim that there are three scenarios, the first is where the functional durability of the material is short compared to its technical life cycle, the second is where the functional durability is expected to be longer than the technical life cycle, and the third is where functional and technical life cycles are equivalent. Technical life cycle can be considered the expected length of time the building will be used for its intended purpose.

1. Functional lifecycle $<$ technical lifecycle

2. Functional lifecycle $>$ technical lifecycle

3. Functional lifecycle $=$ technical lifecycle

The first scenario would ideally be disassembled into reusable or recyclable materials, the second should be composed of replaceable and recyclable materials and the third should be fully recyclable. Durmisevic and Brouwer (2002, p.14) claim that a significant part of our built environment falls into the first scenario, that the second scenario involves monuments that are critical to maintain and the third scenario includes temporary buildings that should be designed for recycling. They believe the more separate life cycle layers a building is designed to accommodate the more likely it is open to transformation and longer life before obsolescence (Durmisevic and Brouwer, 2002).

Designing for permanence is impractical because change is inevitable. Buildings are required to adapt over time, whether designed with lasting or temporary construction methods. An acceptance of impermanence and the flexibility of design for disassembly allows for architecture to take on a more responsive and experimental approach, and avoid stagnation and obsolescence. Through the separation of systems, the use of pure materials and dry impermanent connections, and the selection of material based upon expected lifetime of the building, design for disassembly allows for entire deconstruction or even partial deconstruction to 

material based upon expected lifetime of the building, design for disassembly allows for entire deconstruction or even partial deconstruction to permit the building to grow, shrink or re-locate, and it allows materials and systems to be replaced and manipulated without the premature destruction of the entire building. 



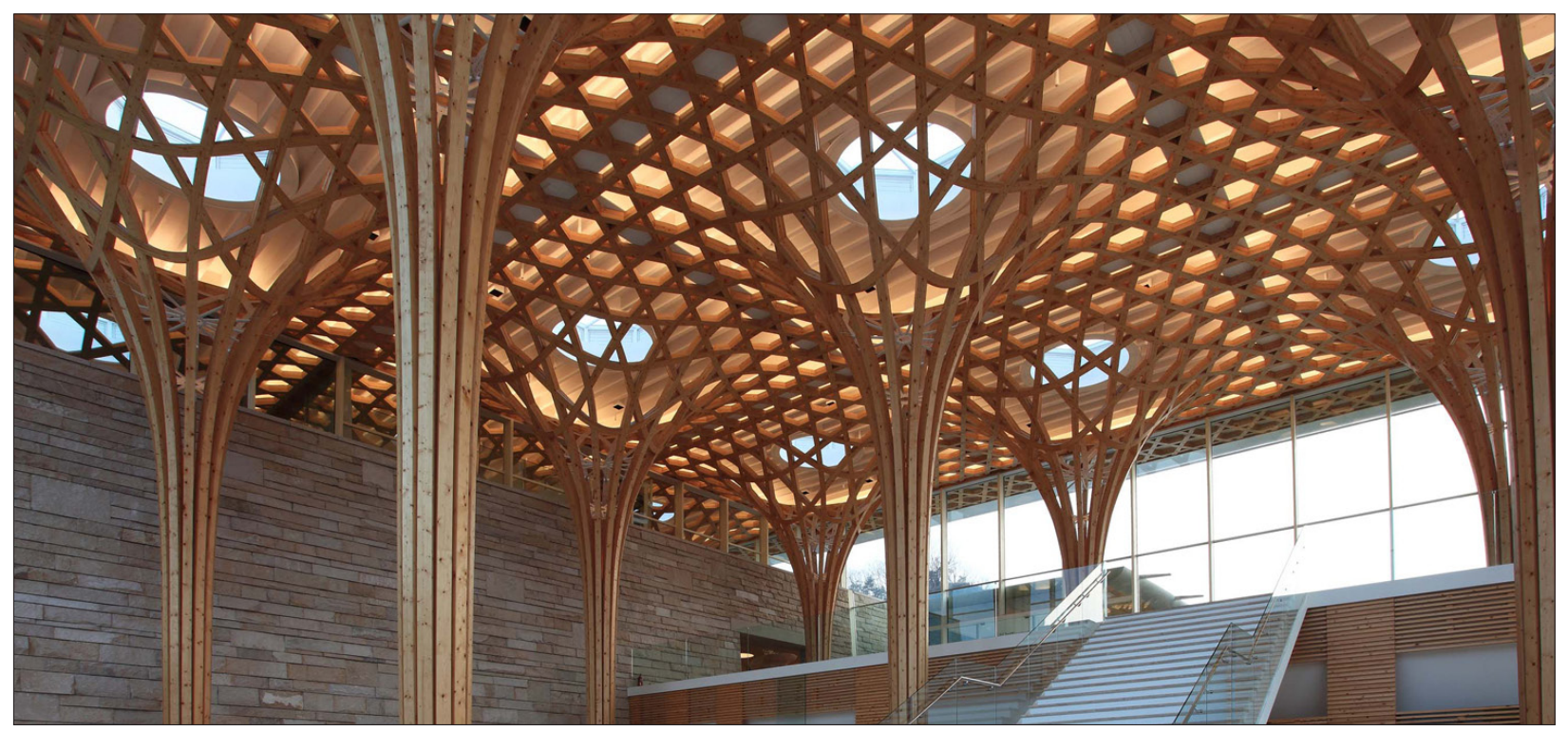

\subsection{Tectonics and building as autonomous form}

Fig 2.3.1 Shigeru Ban's Haesley Nine Bridges Clubhouse is expressive of material properties and structure - a heavy stacked wall of stone beneath a flexible web of timber members bent into elegant posts
An architecture that explores the expression of assembly of materials and visible demountable joinery is inherently tectonic. Tectonic architecture expresses essential characteristics of construction and buildings, such as structure, material and the process of making, to create powerful architecture. Kenneth Frampton describes tectonic architecture as a "poetic manifestation of structure...as an act of making and revealing (Frampton, 2008, p.519)." It communicates the building as autonomous form and expression of construction, and architecture as an act of making. Concern for detailed connections and material is an exploration of the basic elements of architecture. It is important to explore the argument for tectonic architecture and how it creates powerful buildings in order to develop a successful architecture of joinery, material and assembly.

Tectonic design has historically been undertaken for diverse reasons. Architects who embraced tectonic expression often were rejecting the impression of architecture as a sculpture or image, wanted to express the process of construction in the final form, or sought to understand and demonstrate the properties of buildings such as structure, material and 



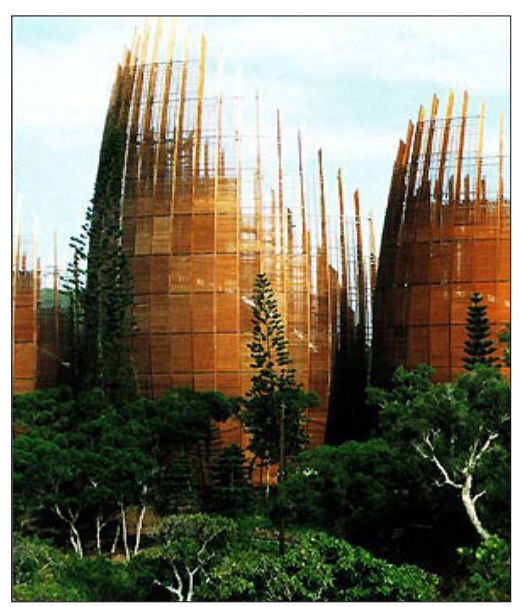

Fig 2.3.2 Renzo Piano, Tjibaou Cultural Center was a study of vernacular construction expressed through structure and material detail. A proponent of phenomenology, architect Juhani Pallasmaa believed that architecture detached from the truths of construction created buildings that were "stage sets for the eye, devoid of the authenticity of material and tectonic logic (Pallasmaa, 2008, p.565)..." Mies van der Rohe argued for the restoration of architecture as building, and to reclaim it from "aesthetic speculators." (Frampton, 2001, p.161) It was inappropriate for the skilled architect to design architecture as sculpture. Mies believed that novel form could arise from exploring the issues of building, but could not be the goal of architectural work (Frampton, 2001, p.161). Aesthetic projects were seen to have no substance or meaning with respect to building, but just reduced architecture to imagery. The rejection of scenographic architecture, which condenses architecture to a final image by hiding any evidence of the process of making, is not uncommon since it avoids a sense of effort, process and construction (Frampton, 2008, p.518). A response to scenographic architecture is to create buildings that express their construction method. The embellishment and expression of the basic elements of architecture can pull the user from the state of distraction typical of the contemporary world by heightening the awareness of place, experience and self in the space (Caldwell, 2007, p.vii). There is an inherent physicality in a crafted building with its own properties and characteristics that can reconnect the visitor to their own body and self-conscious (Frampton, 2008, p.522).

Tectonic architecture can be powerful to encounter and the perception of the means of construction creates a richer experience and appreciation. There is strength in the essential elements of architecture: material, structure, joint, and construction, and there is satisfaction in gaining an understanding of the effort involved in designing and making a building through its tectonic language. For a user to take pleasure in a work of architecture Arthur Schopenhauer wrote that they had to understand its matter, and properties such as weight, rigidity and cohesion. He believed that: 



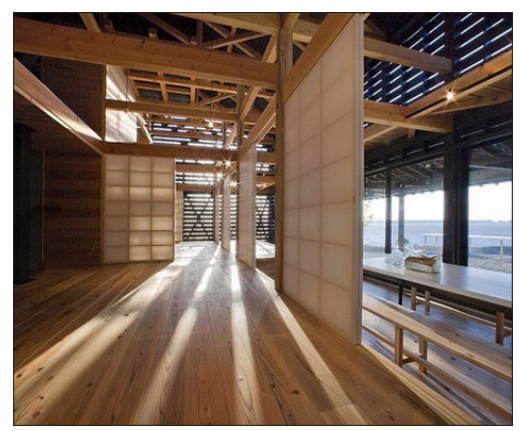

Fig 2.3.3 Yukiharu Suzuki \& Assoc, Barn House uses a beautifully detailed timber structure and rich natural materials as architectural expression
"... if we were 'told clearly that the building, the sight of which please[d] us, consisted of entirely different materials of very unequal weight and consistency, but not distinguishable to the eye, the whole building would become as incapable of affording us pleasure as would a poem in an unknown language (Weston, 2003, p.44)..."

Architect Juhani Pallasmaa argued for the use of natural materials since they allow users to become "convince[d] of the veracity of matter (Pallasmaa, 2008, p.565)." He thought they offered another level of depth beyond their physical presence since they could express their age, history, birth and human use. However, industrial materials can offer a sense of nostalgia and history. Exposed rivets and cylinder glass windows act as reminders of older methods of construction and assembly, and of the work involved in construction:

"...The massed rivets of plated-steel structures greatly add to the impression of strength, and also offer the satisfying feelings of being able to grasp how, and with what effort, the structure was assembled. This satisfaction is not so readily afforded by many modern structures, where welding frequently eliminates more expressive joints (Weston, p.155)..."

Pallasmaa claimed that materials act in conjunction with time, light, shadow, transparency, texture and detail to produce a complete architectural experience (Pallasmaa, 2008, p.565). Honest material use is critical to create compelling tectonic architecture. Respecting and comprehending material qualities can elevate the building beyond simple form to poetics. German philosopher Martin Heidegger claimed that the properties of materials were expressed for the first time in ancient Greek temples, as they were "worked, assembled and presented in such a way that they ask[ed] us to pay attention to their individual qualities: in its presence, we [felt] that we [saw] stone as stone-and as something marvellous (Weston, 2003, p.44)." The structural engineer Cecil Balmond (2008) believed that structure could also be the animator of architecture and give it richness. He explained that "new structure animates geometry... buildings become rhythm and sequence and clash and confrontation (Balmond, 2008, p.558)." Architect Peter Zumthor believed 

that appreciation for a work was influenced by the expression of skill and effort, owing to his profound respect for the "art of joining" by craftsmen and engineers. He rejected the pursuit of novel form in contemporary architecture and instead worked with the essential characteristics of architecture to create powerful spaces (Weston, 2003, p.205). The use of structure, detail, material, and construction can create powerful architecture.

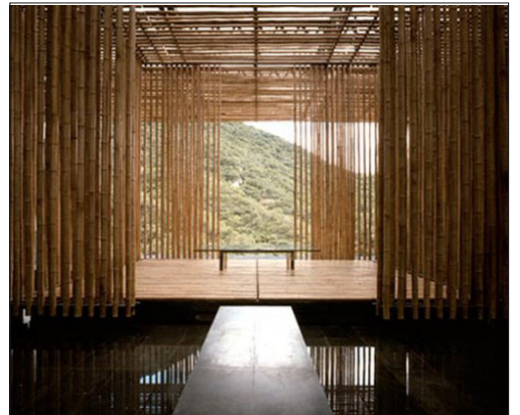

Fig 2.3.4 Kengo Kuma, Bamboo House uses the qualities of bamboo as architectural expression
An architecture that aims to be respectful of material and expressive of joinery and assembly is tectonic in nature. It uses the basic elements of architecture in order to create an appreciation of the means of assembly and the final built form. It turns architectural works into autonomous forms to be appreciated for the visible effort and skill needed for their realization. When matter and the means of making are made visible the user takes more pleasure in discovering a work of architecture. When the basic elements of architecture are embellished for expression, they can heighten the awareness of place, experience and the self in the space. For the thesis study it will be important to create details that display the effort of assembly and the properties of materials, to embellish joinery and the expression of disassembly. 


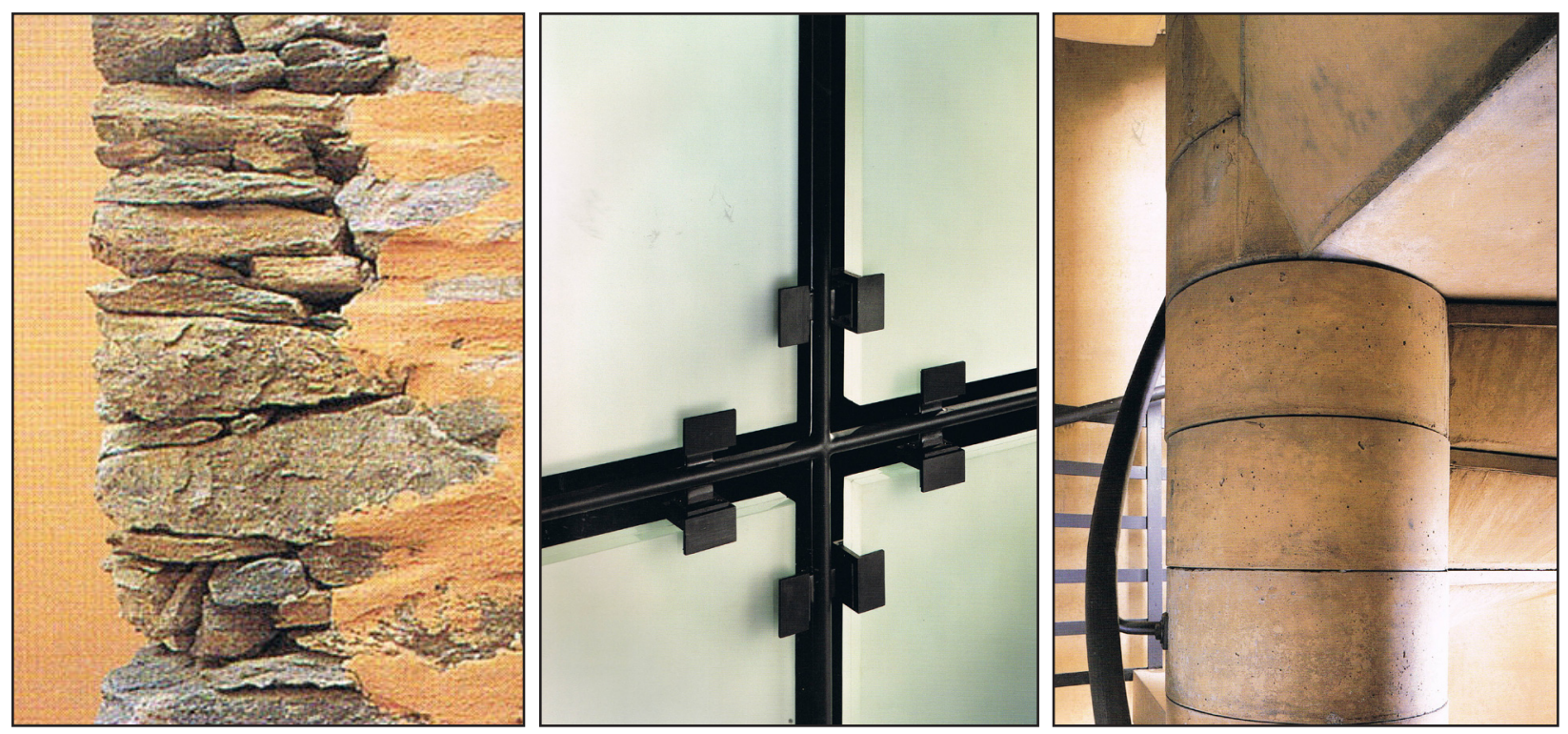

\subsection{The architectural joint}

Fig 2.4.1 Renzo Piano, UNESCO Laboratory Workshop, dry stone stacked joints with stucco overlap Fig 2.4.2 Francois de Menil, Byzantine Fresco Chapel Museum, metal and glass expressed joinery

Fig 2.4.3 Olson Sundberg Kundig Allen, Mission Hill Family Estate Winery, stair structure seam of hidden joint
In "The Tell-the-Tale Detail," Marco Frascari believed that "the art of detailing [was] really the joining of materials, elements, components, and building parts in a functional and aesthetic manner (Frascari, 2008, p.501)." The detail was always a joint, a connector between two parts (Frascari, 2008). Architects Kieran and Timberlake believed that without separation there would be no need for joining, and "separation in architecture arises from the characteristics of the materials to be assembled into a building or from the evolution of the site (Kieran and Timberlake, 2002, p.51)." Joining was the way to assemble separate pieces into buildings (Kieran and Timberlake, 2002). It could express the meaning of man-made objects, giving order and intelligibility to the world (Frascari, 2008). The Beaux-Arts tradition developed a representation of designed or surveyed buildings called the "analytique" which would focus on capturing the details graphically, in order to determine the overall language of the building (Frascari, 2008). French theoreticians developed the term "architecture parlante", which meant that details were essentially the words that were used to compose the sentence of the building and give it character (Frascari, 2008, p502).

The earliest reversible joints were knots tied in nomadic building forms 



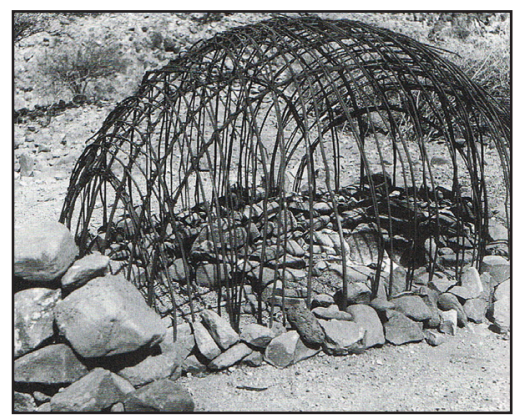

Fig 2.4.4 Frame of African nomadic building

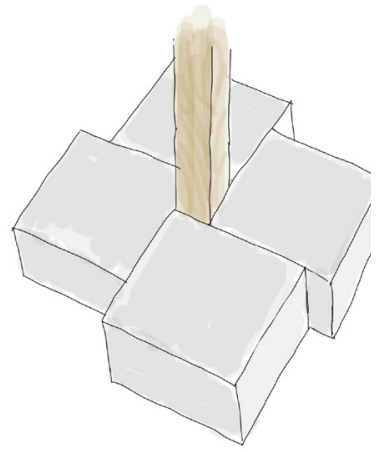

Fig 2.4.5 Demountable foundation sketch

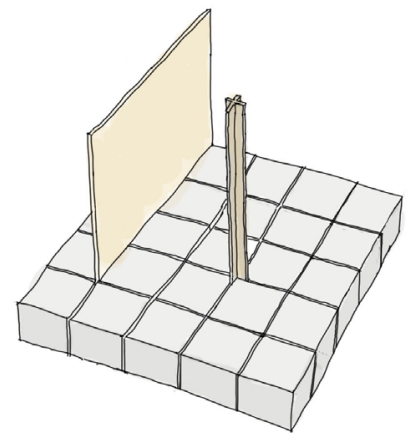

Fig 2.4.6 Demountable foundation

(Frampton, 2008, p.524). The structures were fully demountable and portable in their component parts, were essential and minimal for lightness, and employed locally available materials. In the American tipi, timber posts delineated the space and formed the structure, skins or reed mats acted as an outer membrane laid over the timbers, ropes held the skins down, and wooden pegs and rope bound the timber poles together (Laublin, 1977). In some African nomadic structures, if the ground was too tough to bury frame supports, rocks were piled around the base to hold the structure in place (Prussin, 1995, p.156). The stones formed a natural and demountable foundation for the frame. Gottfried Semper believed it was the joint between the heavy base or podium, and the light frame that was the essence of architecture (Frampton, 2008, p.522). Primitive nomadic architecture required disassembly to allow users to pack up their belongings and relocate for resources. Nomadic construction techniques are appropriate precedents for an architecture of disassembly, cyclical material life, and tectonic expression. Joinery and construction expressed the impermanence and portability of the traditional design. Industrial prefabrication and design for speed assembly could also lead to impermanent architecture. Joseph Paxton's Crystal Palace, initially assembled in England in 1851 for the temporary housing of the Exhibition of the Industry of all Nations, was an early design that showcased the deconstructive possibilities of prefabrication. The original proposal for a permanent structure of brick and stone in Hyde Park was quickly overturned when Paxton came forward with a design for a structure of iron and glass that could be speedily assembled and removed afterward, (Citizendium, 2010). The experimental building was assembled from standardized machine made parts, including 300,000 uniform panes of glass, in a repeated bay system in only nine months (Alfred, 2009). The iron columns and girders with mechanical joints sat on a concrete foundation - which was a permanent construction that would require demolition (Alfred, 2009). Despite its temporary intent, the building was dismantled, modified to increase its height, then relocated and re-assembled as a destination outside of London (Citizendium, 



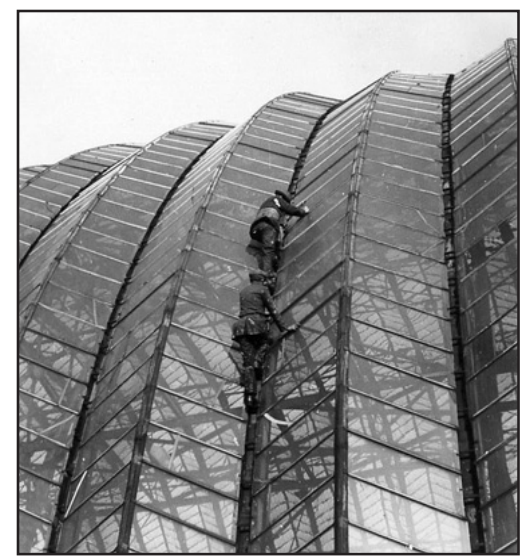

Fig 2.4.7 The glass roof of the Crystal Palace

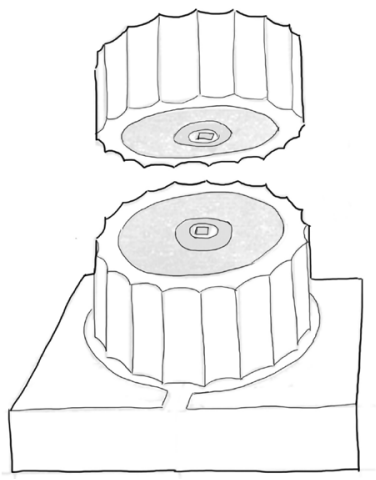

Fig 2.4.8 Doric column assembly

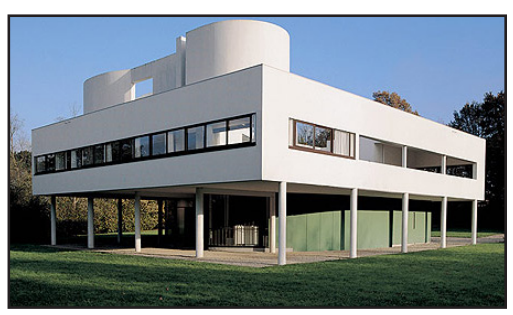

Fig 2.4.9 Le Corbusier, Villa Savoye, demonstrates an absence of evidence of assembly in its detailing
2010). The Crystal Palace demonstrated the flexibility, easy disassembly and re-assembly of a building designed for impermanence, using standardized parts and mechanical joinery.

There have been different periods in the history of architectural movements when craftsmanship and construction was expressed and also when connections and the evidence of assembly were hidden (Daniels, 48). Despite the appearance of heavy permanence, some classical constructions allowed for disassembly through their realization. Doric Greek columns were cylinders of stacked stone with hidden wood dowel joints to hold them in place, and contained both absent and expressive joints (Miller, 1990). They appeared as monolithic forms with only a seam denoting the hidden joint and how it was built. The lack of permanent connections meant that forms could be taken apart, allowing for the reuse of marble and steel from classical buildings. The intention for the column was likely to be a lasting form considering its monolithic and solid expression, but limitations of construction methods led to impermanence. The International Style Movement deliberately hid construction details, with the intent to dematerialize and express the building as an idealized image (Daniels, 48). The pure aesthetic of the Modernist forms were not designed with time or change in mind, and their lack of material honesty led to buildings that have weathered and decomposed in unflattering ways (Weston, 2003). The absent or abstract detail allowed the building to be perceived as a unified whole, and were considered the opposite of the expressive or articulated detail. When the articulated detail showed its consideration of material, weight, connection and assembly, the abstract detail denied those characteristics with an "absence of weight, an indifference to material, a lack of apparent connection, and an apparent disregard for the elements (Ford, (2009), p.11)." The post-postmodern approach was to create seamless forms and hide any sense of assembly or parts. Many architects designed monolithic forms out of an assembly of parts, but risked damage and wear by avoiding articulated joints:

"...Seemlessly unseen, these details revelled in the fact that "ignorance is bliss" when it comes to expressing how materials connect with each other when they are assembled... The problematic aspect of gloss-over detailing is that over time, almost all such 



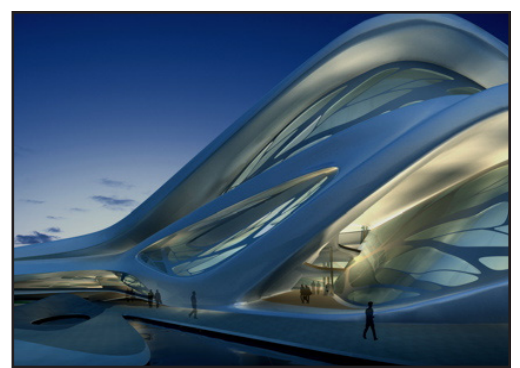

Fig 2.4.10 Zaha Hadid, Dubai Arts Center attempts to create seamless joints for a continuous form

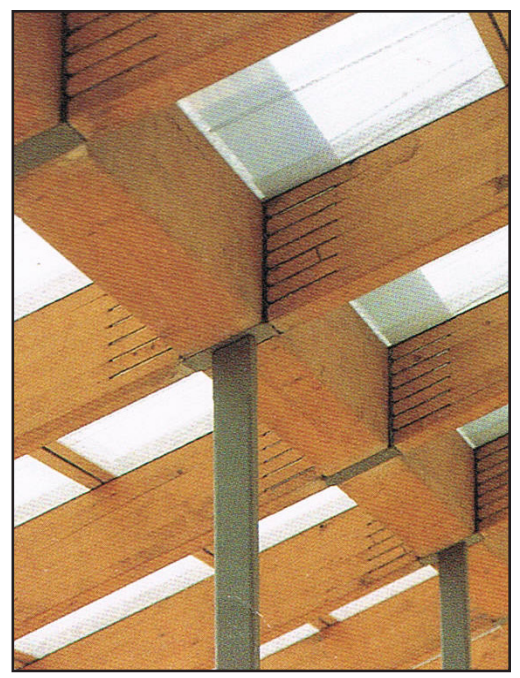

Fig 2.4.11 Renzo Piano, UNESCO Laboratory Workshop, the joint connecting column to beam blends steel into timber structure detailing has a propensity to evidence its inherent dishonesty. Materials have different expansion coefficients, they accept or reject water to varying degrees, some materials propagate organic or biological infestations while others preempt them, and oxidation and galvanic action are always waiting patiently to undo the best laid plans an architect can come up with. Rather than age gracefully, most of these examples are inevitably fated to lose their battle with the elements and time far more rapidly than those who express both materiality and use the knowledge of weatherability as a design criteria rather than subordinated "baggage" (Dickinson, 1997, p.ix)."

Joints between materials are also often hidden through the use of baseboards and moldings. Alternatively, many modern architects decided to emphasize keeping materials apart with 'shadow gaps' between doors, skirtings and walls to demonstrate and emphasize the assembly (Weston, 2003, p.153). In the essay "Detail and Articulation," Yolande Daniels argues that internalizing the details in seamless architecture is foolish because the intelligence of the system is hidden and suppressed (Daniels, 2003).

Detailing the joints between different surfaces and materials demands a surprising amount of time on most architectural projects and is an essential task of the architect (Weston, 2003). The conception is practical and formal, and can determine the success or failure of a building design (Frascari, 2008, p.501). Kent Bloomer of Yale University considers detailing to be "the most undervalued opportunity in the profession." He believes that although buildings are traditionally approached as a "top down" design problem, they should be designed from the bottom up, and allow the different scales to inform each other (Dickinson, 1997, p.xix). Marco Frascari wrote that through their own order, details could impose order and meaning of the entire construction and that "the understanding and execution of details constitute[d] the basic process by which the architectural practice and theories should be developed (Frascari, 2008, p.501)." In the eighteenth century, members of the École des Beaux Arts described the architectural detail like a word in a language. Through its selection and ordering it gave character to a piece of writing, just as building character is shaped by the meaning and order of its details 

(Weston, 2003, p.148). In, "The Architectural Detail: Dutch Architects Visualise their Concept" Ben van Berkel and Caroline Bos, of UN Studio, are quoted as having stated that well conceived and realized details help to extend the appreciation of architecture:

"Long after the idiomatic treatment of the whole has been exhausted, details can provide new insights and surprising discoveries that determine the vitality of a building (Melet, 2002, p.7)."

Careful joining and detailing should be demonstrated to impart the effort and skill involved in realizing disassembly architecture.

By failing to control the appearance of joints architect Edward Ford (2009) believed that buildings could visually come apart into their components. If the quantity of parts became too large and visually complicated it was difficult to perceive the whole. There are countless connections in a building, and they should not all be treated the same way. Ford described mandatory joints from material properties as a series of challenges that the architect had to overcome. He lamented over the need for control joints in materials such as stucco, concrete, masonry, and drywall that could create a condition of "panelization" of surfaces (Ford, 2009, p.145). Richard Weston-architect, landscape architect, professor and author-explained in his book "Materials, Form and Architecture" that our vision is "acutely sensitive to joints in or between materials, and the effects of even the slightest systematic marks in a surface can be considerable (2003, p.152)." It is important to decide what joints to emphasize, and which to downplay in demountable architecture the expression of joints should not be universally bold. Edward Ford believed that joints were allowed to speak the most powerfully when they were singular, accompanied by a series of hidden or subtle joints. A crafted joint presented the building as an assembly and explained how it was put together. A joint was a reminder that the building was made of parts brought together with intent to form space (Ford, 2009). If joints were intended to be read, they often had to be visually reinforced. 



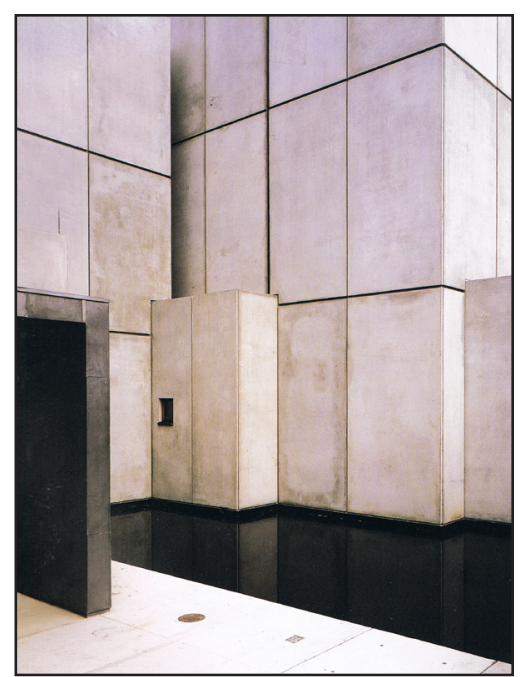

Fig 2.4.12 Peter Marino and Assoc., Datascape Corporation displays the intentional panelization of a surface through shadows of joints
Joints between flush stone panels or precast concrete forms could become invisible, while reminders of formwork in cast-in-place concrete were nearly impossible to conceal (Ford, 2009). Kahn would enhance poured concrete joints by making them deeper, wider or larger, and making them an ornament captured by light and shadow, that reminded the viewer of the construction process. As a component of tectonic architecture the joint can draw attention to the physical qualities of the building, such as weight, rigidity, and strength, heightening an awareness of the place and body within the space.

The joint is a key component of disassembly construction that has powerful theoretical roots, is a critical and time consuming detailing practice and raises a series of issues and choices for the architect. The joint can allow buildings to be demountable and impermanent. The expressive or articulated joint can demonstrate material properties, weight, and assembly, and extend the appreciation and enjoyment of a building. A designed joint can provide the order for a larger scale of assembly. However, joints can also dissolve a building into its component parts when their visibility is not controlled, reducing the conception of the whole. A possible strategy for disassembly and material life cycle architecture could be to articulate joints based upon the expected endurance of components and layers. For example, more rugged and heavy connections could be used to affix the long lasting structure and site layers, while more delicate and minimal joints could be easily removed for shorter lasting layers such as finishes. Achieving a balance between visually reinforced and reduced joints is critical to maintain the appearance of an autonomous form, while also achieving an expression of assembly. 



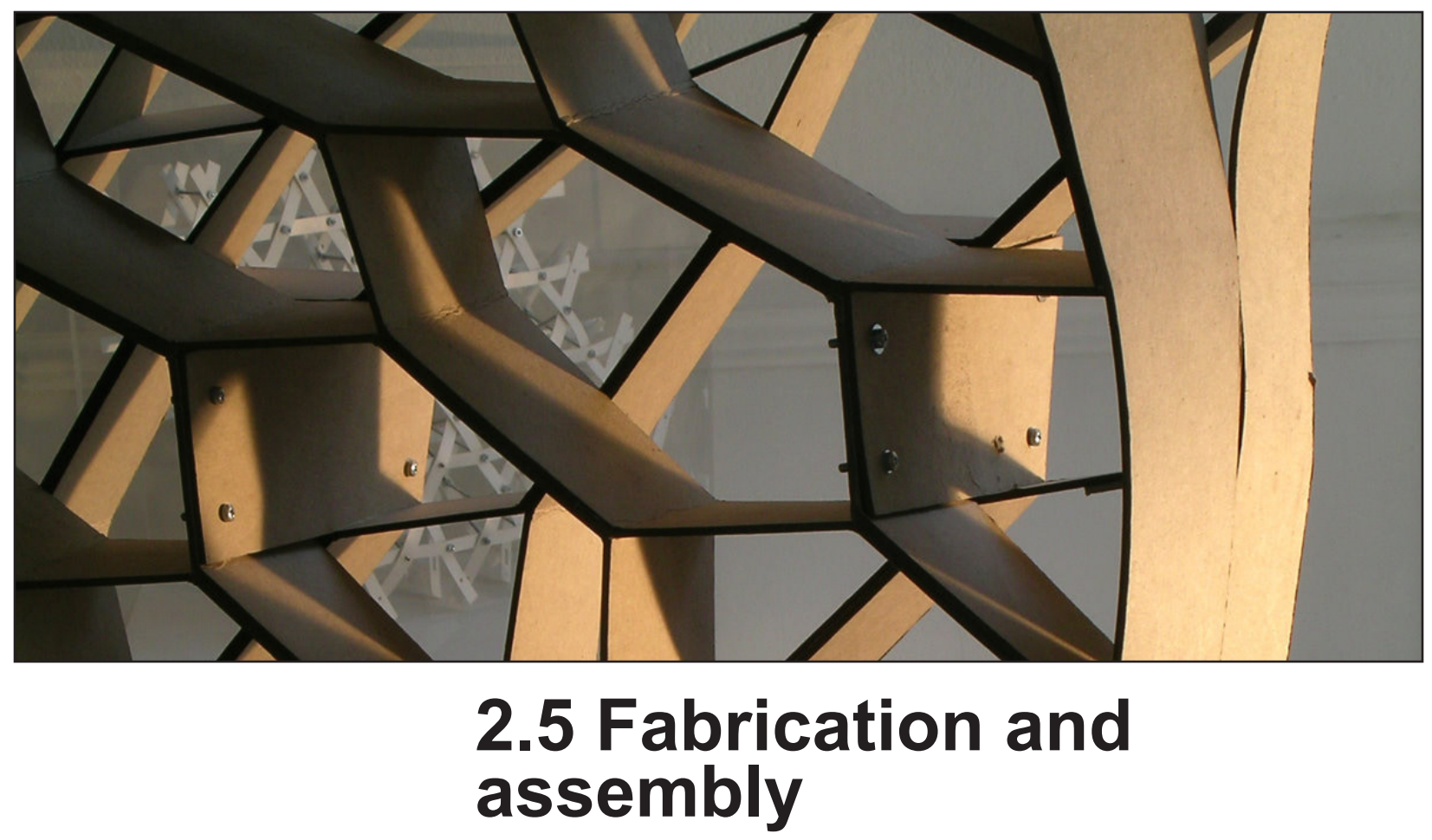

Fig 2.5.1 Andrew Kudless, Manifold, The rhetoric against tectonic architecture and visible joinery has been is a study in folded planar material assembled with simple bolted connections

bolstered by the high cost of skilled craftsmanship in the trades and the dislocation of the contemporary architect from the act of building. The architect creates the image and meaning, but often does not execute the creation of their design in reality. Nader Tehrani, in the introduction to Michael Cadwell's book "Strange Details," describes this disconnect as "somewhat like permitting the writer to use a certain vocabulary, but disassociating it from the very alphabet from which the text emerges (Cadwell, 2007, p.ix)." The relatively recent rise of digital fabrication has permitted the architect to regain some ground in constructing. Drawing software can be immediately connected to fabrication tools, removing the contractor as the mediator between the architect and the building (Cadwell, 2007). This new process can re-establish the architect as master builder and the building as tectonic assembly. Architects can combine the specificity of factory customization, the efficiency of standardization and the speed of prefabrication, in the creation of reusable and recyclable components for disassembly architecture.

Architecture no longer needs to be an expression of construction, but 



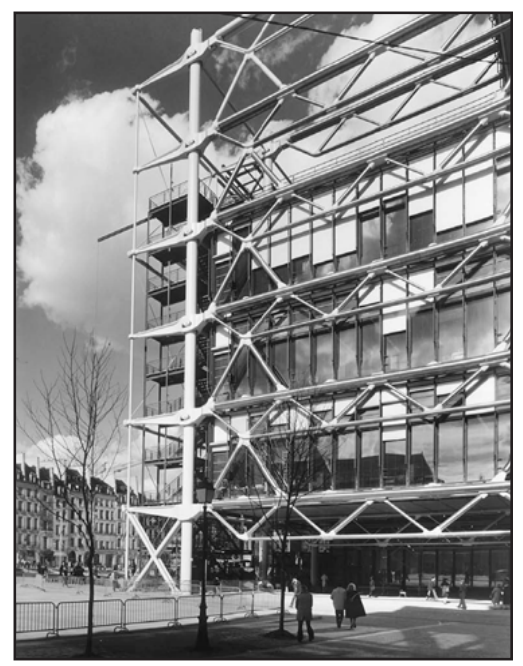

Fig 2.5.2 Renzo Piano, Pompidou Centre

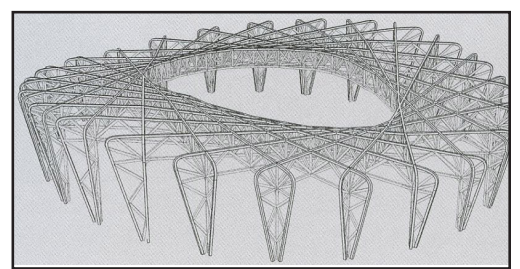

Fig 2.5.3 Herzog and DeMeuron, Olympic Stadium in Beijing is a sectioned structure achieving a nonrectilinear form can be an assembly. Buildings are increasingly constructed from components and assemblies that are prefabricated off-site, with little manipulation in situ (Weston, p.149). Architect team Kieran and Timberlake (2008) laud the benefits of assembly over construction. They describe how construction is time consuming, while assembly is fast; how construction is complex, requires skill, training and specialized tools, while assembly depends upon precise factory cut, pre-fitted, drilled and jigged components put together with written instructions. (2008, p.80) Assemblies are also more readily reversible and can be disassembled "as quickly, or more quickly, than assembled (Kieran and Timberlake, 2008, p.81)." Fabricated connectors, such as steel plates, and bolts have supplanted costly craftsmanship and joinery by hand. Massive cast-steel 'gerberettes' in the Pompidou Centre in Paris elegantly join columns to beams, and celebrate the beauty of assembly, joinery and structure (Weston, p.151). The structural engineer for the project, Peter Rice, stated that the central design characteristic was "making the joint the essence of the solution." He wanted to create a structural design that was more articulated of its method of making, instead of the ubiquitous continuous welded structure in contemporary works (Ford, 2009, p.148).

What used to be time-consuming and skilled work that limited the appeal of expressive architectural details is now easily obtained through fabrication techniques. Full-scale parts can be created from diverse materials such as metals, woods and plastics from the digital model of the building (Iwamoto, 2009, p.005). In the book "Digital Fabrications: Architectural and Material Techniques," Lisa Iwamoto (2009) divides digital fabrication into five different techniques: sectioning, tessellating, folding, contouring and forming. Sectioning, folding and forming appear to be the methods adaptable to architecture of disassembly and cyclical material life, with a tectonic expression. Sectioning is typically a structural conception that involves the creation of ribs - acting as beams or columns - reminiscent of ship and aircraft construction (Iwamoto, 2009, p.010). Sectioning is often used to achieve complex forms, 

since it is simply a process of deriving two dimensional cuts through a 3 dimensional model. The cross sections are then joined to create a skeleton of the form. The drawback to this type of digital construction is that sections are often cut from panelized materials, creating a lot of waste for non-rectilinear forms. The model of Herzog and DeMeuron's Bird's Nest Stadium, shows how bent lines of truss along sections could be used to achieve a lightweight complex form, instead of cut planar material which would likely be more wasteful and heavy.

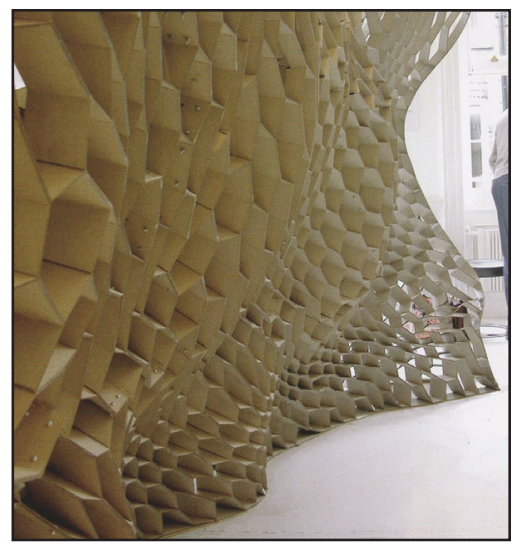

Fig 2.5.4 Andrew Kudless, Manifold, 2004

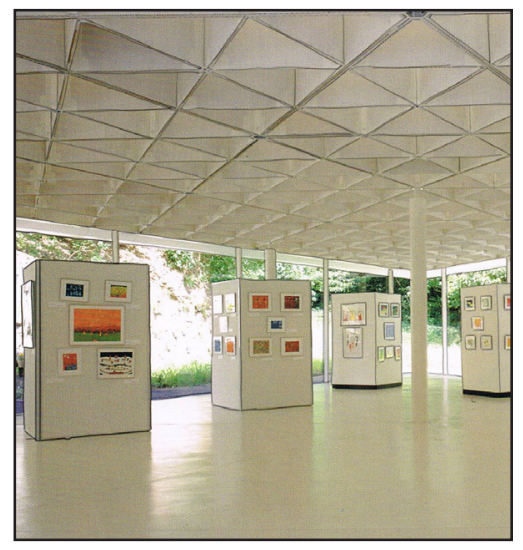

Fig 2.5.5 Shigeru Ban, Nemunoki Children's Museum of Art, 1999

Folding is also a fabrication method that favours planar material, but demands that it be pliable to bend without breaking (Iwamoto, 2009). Materials are somewhat limited, with precedents using cardboard, sheet metal, thick paper and fabric. "When folds are introduced into otherwise planar materials, those materials gain stiffness and rigidity, can span distance, and can often be self-supporting (Iwamoto, 2009, p.062)." Folding can also create continuity of surface through material language, allowing floors to become walls and ceilings. The process takes twodimensional surfaces, and through creasing, folding and wrapping turns them into three-dimensional forms. A number of software programs offer tools for transforming a model into two-dimensional information, and laser cutters, water-jets and plasma cutters are used to cut and perforate the material (Iwamoto, 2009). The concept of folding could extend to non-pliable materials if material was cut instead of scored at seams and connected into forms with joinery. Shigeru Ban's Nemunoki Children's Museum of Art uses the same structural method in its roof as Andrew Kudless's digitally-produced Manifold project, but is better suited to extending material life and expressive joinery. Nemunoki has standardized cardboard panels, and uses repetitive custom joinery, made visible to visitors at the bottom edge to connect the panels together. The Manifold project hides bolted connectors on the interior surface of the honeycomb system.

Forming is the final method of fabrication that has potential for reusable 



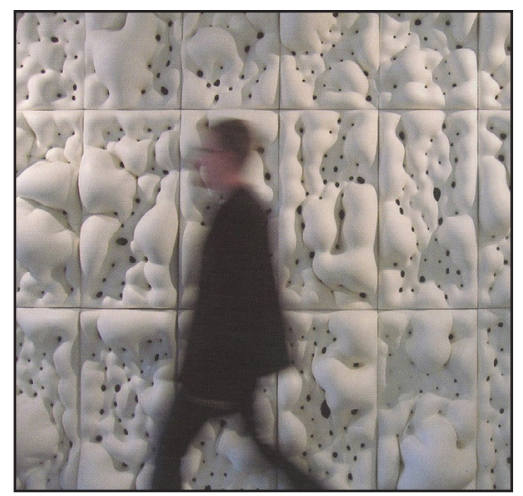

Fig 2.5.6 Andrew Kudless, P-wall, 2006 components. It allows the creation of parts from customized molds or forms (Iwamoto, 2009). Forms made with digital milling or rapid-prototyping machines could be used to mass produce standardized hardware, joints, and panels (Iwamoto, 2009). Andrew Kudless's P_Wall project created a custom acoustic panel with plaster and elastic fabric. The project shows how new standardized components could be created using form-making techniques. The system created in this project is only reusable in its panel form, and cannot be recycled or even down-cycled once it obsolesces or is damaged (reduced to a poorer quality material assembly, such as the transformation of lumber into MDF). It is not an ideal mass produced material for cyclical material life, and will ultimately produce significant waste. For architecture of disassembly and cyclical material life, it should be ensured that prefabricated components are either recyclable or reusable, considering demand and obsolescence are unknown.

Off-site fabrication has replaced handcraftsmanship and construction. Buildings are assembled from many parts. To simplify and speed the process, the design can call upon precise factory prepared pieces, often digitally produced, that are typically more open to disassembly than traditional construction, but not necessarily to reuse. Digital fabrication offers several methods that could be adopted for the study of an architecture of disassembly and material life cycle, including forming, sectioning and folding. Although prefabrication has been prone to wasteful designs and the creation of components not ideal for extending material life cycle, an awareness of the demand for component reuse and material life cycles can ensure that customized forms do not end up as waste. 



\subsection{Building typologies for impermanence}

Certain building typologies and systems are more predisposed to adopting principles of disassembly and cyclical material life. If the life of a building is forecast to be limited, it should be designed to allow its material components to endure in another form or be recycled. Retail architecture, domestic architecture, and temporary buildings are a few examples that lend themselves to principles of disassembly because of their often shortened existences or predisposition to change.

Retail architecture can be based upon trends and fluctuating economic factors. "...The exigencies of pushing products mean that the life span of a boutique or showroom may not be more than a few seasons (Barrenech, 2005, p.15)." Minsuk Cho, of the firm Mass Studies, felt shocked to see a shop design, his first project in Korea, torn down and replaced by a larger building two years after realization (Cho, 2010, p.202). Retail projects are often quickly conceived and created:

"Whether a store lasts two years or two decades, it captures the architectural sensibilities of an era more plainly than maybe any other building type. Retail is about creating an environment reflective of the here and now: current trends, movements, aesthetic directions, whatever is in the air at a given moment (Barrenech, 2005, p.15)."

'“Freshening up' a store facade, usually on a five year basis, is a common tenant lease requirement to keep a centre looking new (Platt, 25)."

Often stores aim to draw new clients and visitors into the space through novel displays and eye-catching design. High quality materials and detail design can impart good branding for the company and product.

"Commercial buildings have to adapt quickly, often radically, because of intense competitive pressure to perform, and they are subject the rapid advances that occur in any industry. Most businesses either grow or fail. If they grow, they move; if they fail, they're gone. Turnover is a constant. Commercial buildings are forever metamorphic (Brand, 1994, p.7)..." 

According to Durmisevic and Brouwer (2002) a short functional life of architecture would be best served by recyclable and reusable materials since their technical lives would outlast the architectural iteration.

The changeability of office buildings would be focused on an interior architecture, concerned with layout, systems and finishes. During the lifetime of an office building, there are typically ten or more tenant companies, and each new inhabitant demands a complete remodelling (Brand, 1994). The short functional life of interior office architecture, including the layers of furnishings, finishes and services, means that it should be composed of reusable or recyclable materials that could have further use after the office was remodelled. The office building structure could be used until it reached the end of its technical life, in which case it would ideally be fully recyclable since it could serve no further material purpose in new buildings. The structure, services and skin would need to allow flexibility of uses.

Migrant worker settlements grow and disappear at resource extraction sites. Workers migrate to often isolated and rural sites for as long as the economic draw sustains them. The life of the architecture at a forestry camp, mining village or oil field, such as Fort McMurray, is temporary unless it develops another means of economic survival. Disassembly and design for material life cycle would avoid creating permanent buildings that will be abandoned and decay once workers have moved on. They would ideally be assembled of reusable or recyclable materials that would be easy to remove from the site for new purposes.

Domestic buildings are the steadiest changing type of architecture (Brand, 1994). The home is constantly required to adapt to family growth, desires and changes in taste. The relationship between occupant and home is intimate, and one must adapt to the other. Often the changes are minor, such as updates to resolve annoyances. 

"Homes are the domain of slowly shifting fantasies and rapidly shifting needs. The widows parent moves in; the teenager moves out; finances require letting out a room (new door and outside stair); accumulating stuff needs more storage (or public storage frees up some home space); a home office or studio becomes essential. Meanwhile, desires accumulate for a new deck, a hot tub, a modernized kitchen, a luxurious bathroom, a walk-in closet, a hobby refuge in the garage, a kid refuge in the basement or attic, a whole new master bedroom (Brand, 1994, p.10)..."

Fig 2.6.1 Typical exterior renovations to post-war bungalows in East York

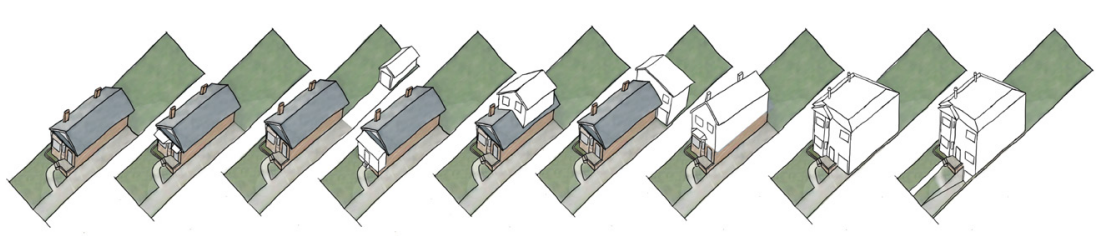

The home also changes occupants approximately every 6 to 8 years, while most apartments receive new tenants every 3 (Brand, 1994, p.87). Every new occupant arrives with a new outlook to how the home should function and they typically demand a renovation. Typically there are two separate renovations for every home transfer; the previous occupants attempt to increase the selling price with new features and finishes, while the new occupants update for their requirements and aesthetic sense (Brand, 1994). The domestic building, single family or multiple, would benefit from disassembly principles. Stewart Brand's layers of building assembly: site, structure, skin, services, space plan and stuff all risk change through demands put upon a single-family home. Since domestic buildings are likely to obsolesce before they have met the end of their technical lifecycle, they would ideally be assembled of reusable or recyclable materials.

The functional life of a building should drive the type of materials specified and the method of assembly. Because change is inevitable, and buildings are required to adapt to maintain functionality, even buildings lasting for hundreds of years could adopt concepts of impermanence. For any building, system or component that is impermanent, disassembly and the architecture of joinery and material life is an appropriate response. 



\section{Precedent review}

This section will explore architectural issues that surface with the intentions of disassembly and cyclical material life. The analysis of built projects shows the strengths and weaknesses of diverse strategies. Most projects are only used to observe a selected phenomena, and do not strive to achieve the same goals as the thesis study. 



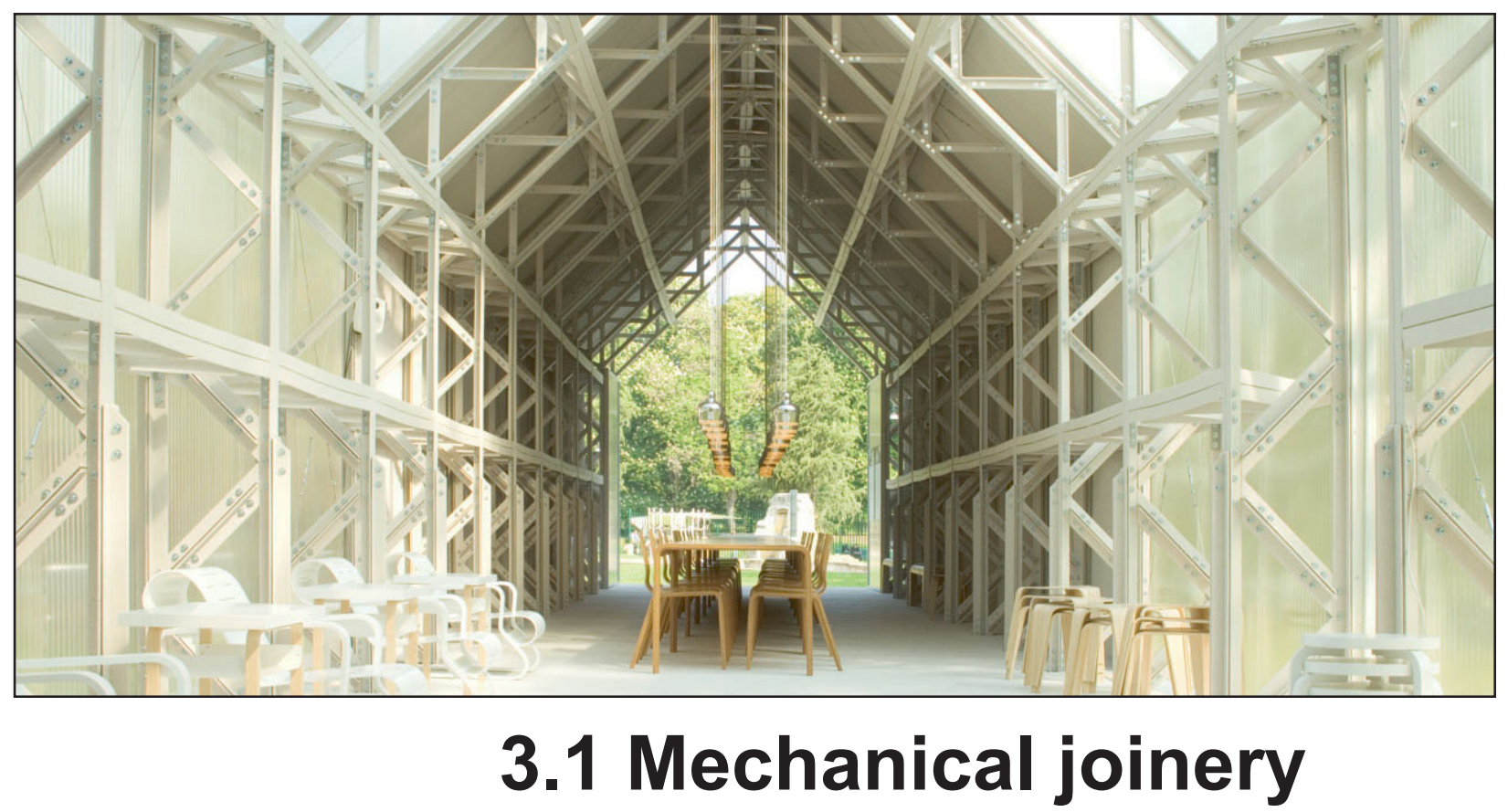

Fig 3.1 (Page 37-38) worn wood slat The following taxonomy describes mechanical, and typically reversible, surface

Fig 3.1.1 Shigeru Ban, temporary Artek Pavilion at the 2007 Milan Furniture Fair is designed for construction and deconstruction with lightweight members and bolted connections

joinery from a variety of projects, some of which are temporary and others with unstated longevity. The method of fixing components together is a major factor in whether they can be reused and recycled. Non-mechanical joinery, such as mortars and adhesives make assemblies difficult, time-consuming and expensive to take apart and often necessitate significant cleaning (Berge, 2009). The problem with adhesives and laminates also extends to the recycling of materials.

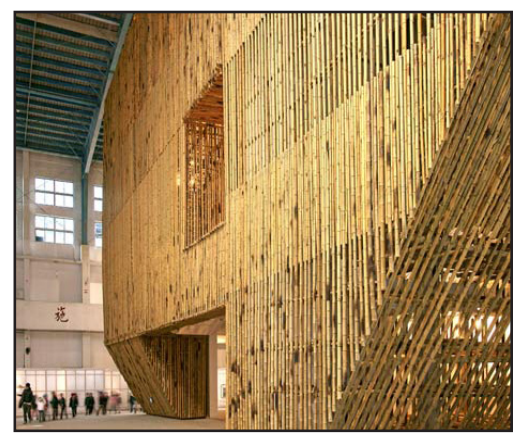

Fig 3.1.2 Stan Allen, Infobox, 2011

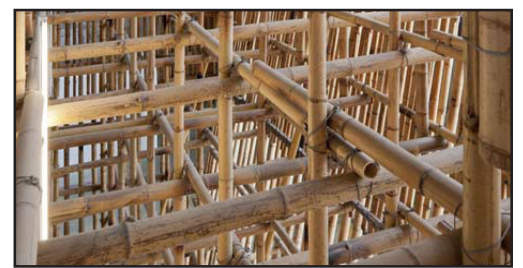

Fig 3.1.3 Stan Allen, Infobox detail

\begin{abstract}
"Pure wood waste can be ground and recycled as raw material for various building boards, such as particle boards and oriented strand boards. It can also be energy recycled to good effect. However, glues, surface treatments and impregnating agents often turn these products into hazardous waste (Berge, 2009, 173)."
\end{abstract}

To be recycled, many materials have to maintain their original chemical compositions or be easily stripped of additives. Mechanical joinery is ideal for both reuse and recycling.

Tied joints can use fabric, rope, and wire, are reminiscent of some nomadic structures and are inherently impermanent in appearance. The Taichung Infobox in Taiwan by Stan Allen, is a temporary space to display a master plan, models and drawings for a site being constructed 



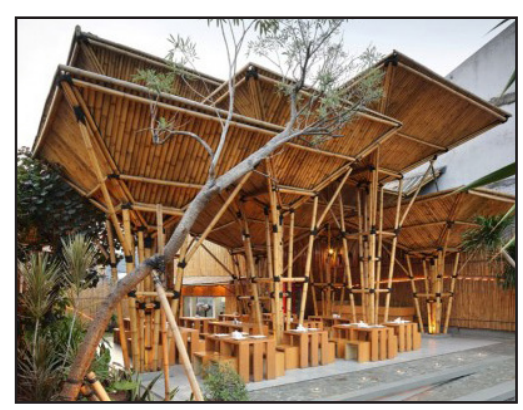

Fig 3.1.4 DSA+s Architects, Bamboo restaurant, 2010

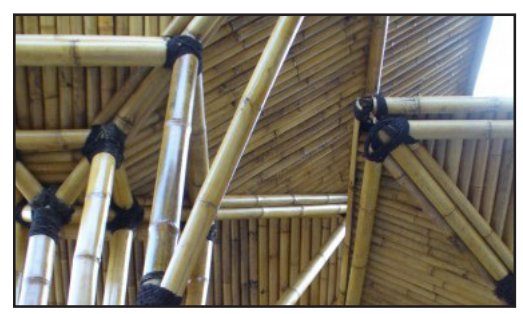

Fig 3.1.5 DSA+s Architects, Bamboo restaurant detail

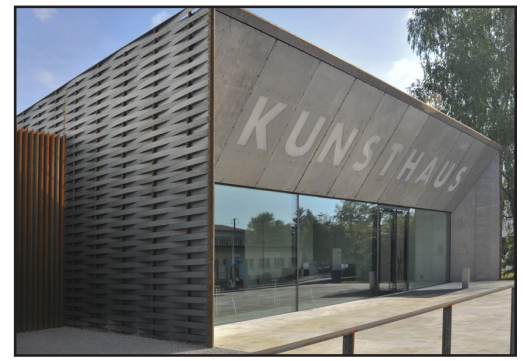

Fig 3.1.6 SSM Architekten, Kunsthaus entry

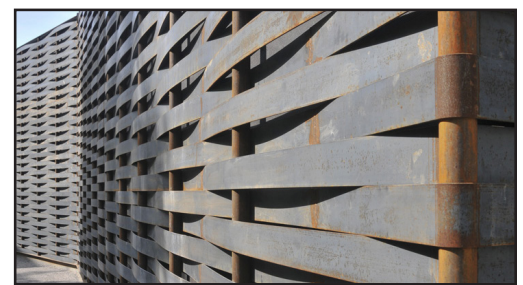

Fig 3.1.7 DSA+s Architects, Bamboo detail

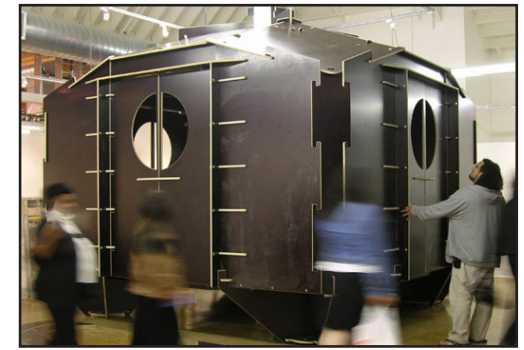

Fig 3.1.8 DH1 Disaster House 2006

nearby. The bamboo construction is held together with nearly invisible metal wire in a very lightweight latticework technique that focuses on expressing the mass of bamboo instead of the joinery. The creators claim the parts are to be recycled once the Infobox is taken down. (dezeen, 2011). In contrast, a temporary bamboo restaurant in Jakarta, designed by DSA+s Architects, expresses tied joints distinctly through dark colouration. The client wanted a design that was easy to assemble and disassemble (Architecture, Modern Home \& Interior Design, Furniture, 2010). The joints are visibly reversible since they are built from a fabriclike material which would likely only last a limited number of years or would require replacement. The restaurant is essentially composed of a concrete plinth with a series of bamboo columns that become generous capitals forming protective roofs. The concrete slab limits the disassembly of the restaurant and the expression of impermanence of the roof structure above.

Woven connections use the pressure of materials against one another to hold them in place. An art gallery extension in Genchen, Switzerland completed in 2008 by SSM Architekten employs weaving as its method of joinery for the exterior cladding. Steel rods act as a framework for pliable steel bands to wrap around (Saieh, 2008). Weaving is a labour-intensive process, so would benefit from off-site prefabrication. It requires pliable materials and structural members, and more delicate materials applications such as screens of wood or bamboo, are usually relegated to interior purposes or sheltered from weather on the exterior.

Architect Greg Fleishmann explores intersecting notch connections using plywood panels in California, for temporary housing, children's playgrounds, sukkahs and pavilions (Fleishman, 2011). The shear strength of plywood creates a very strong slotted joint, and the notch can be extremely precise when factory-cut. The forms are highly expressive of their assembled nature, and are reminiscent of a child's building toy. The slotted joint would be best applied as a structural connection as 



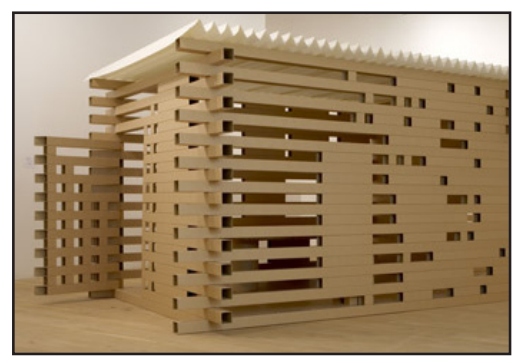

Fig 3.1.9 Shigeru Ban, Cardboard Tea House, 2008

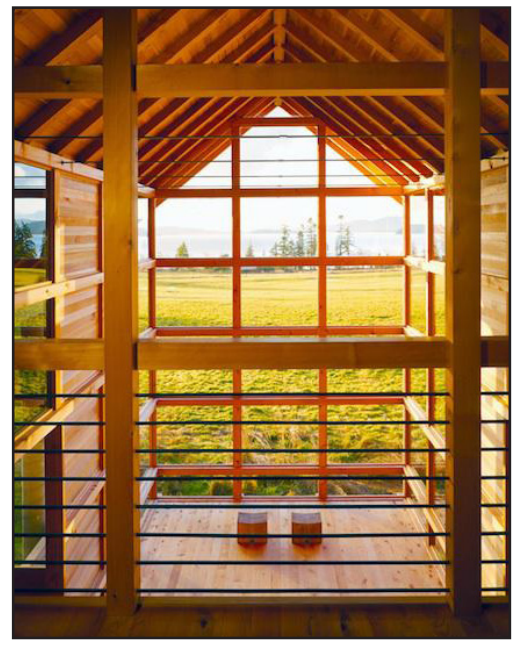

Fig 3.1.10 Suyama Peterson Deguchi, Mount Vernon cabin

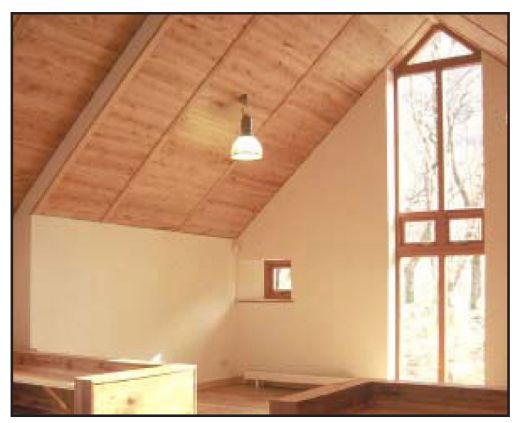

Fig 3.1.11 Gaia Architects, Glencoe Visitor Center opposed to within the finish layer since it requires intersecting materials instead of co-planar - reminiscent of beams and columns. In Shigeru Ban's temporary installation, the Cardboard Tea House, the notch or slot joint becomes the generator of the architectural language. The overlapping joint extends into the material expression and becomes the structure, language for openings and the enclosure. The project is tectonically satisfying because it demonstrates how it was constructed and how it works through its visual language. The details are very simple, but repetition creates ornamentation and expressive openings that offer varying density across the different surfaces. The project would not allow for reuse of material because it is highly customized for its intended purpose, but if the cardboard was still a pure material, the house could be entirely recycled.

Tongue and groove joints are common in panelized finish surfaces such as floors, ceilings and exterior cladding. They form tight, precise joints for continuous surfaces, but are usually accompanied by permanent connections to hold them tightly together. Nailing or adhering would not be required if panels were fitted within a framework that held them in the desired form.

Seattle architecture firm Suyama Peterson Deguchi utilize blind mortise and tenon joints for the timber in their Mount Vernon cabin (Remodelista, 2011). The tenon does not extend to the other side of the stile, so the timber pieces appear to just butt up against one another in an invisible, friction-fit, and impermanent joint (Woodwork Details, 2007). The detail is minimal and removes focus from the joinery and act of assembly. The invisible connection makes the timber appear to defy gravity, which is not ideal for successful tectonic expression that relies upon the demonstration of effort and weight in addition to material properties.

Gaia Architects employed a modified lap joint to reduce the number of fixings to hold floor and ceiling boards in place in the Glencoe Visitor 



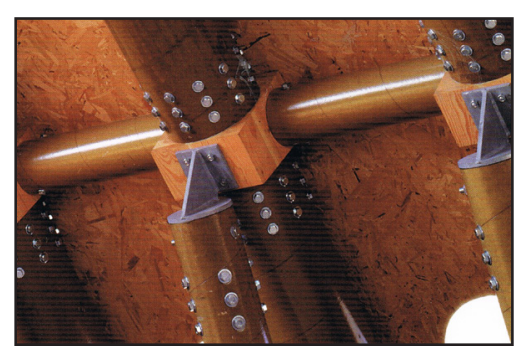

Fig 3.1.12 Shigeru Ban, Paper Dome, Japan, 1998

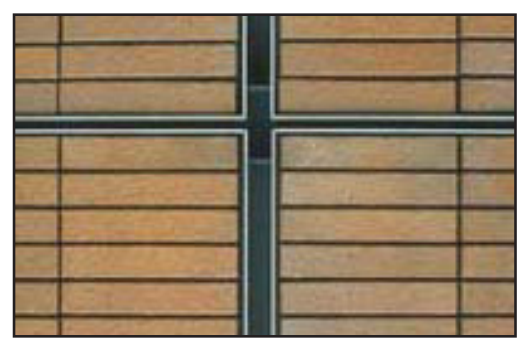

Fig 3.1.13 Renzo Piano, IRCAM extension facade detail

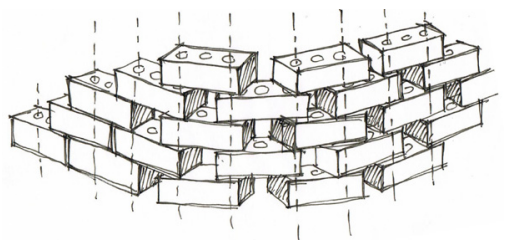

Fig 3.1.14 Sketch of curved brick with lines representing metal posts running through the standard holes to fasten

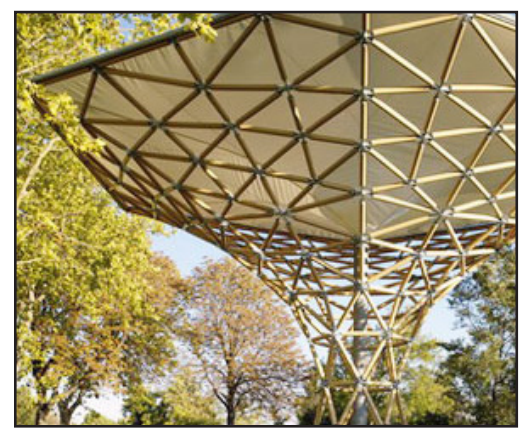

Fig 3.1.15 Shigeru Ban, Vasarely Pavilion, 2006
Center in Scotland in 2002. To speed assembly they used screws at lengths along the lapped strip, instead of at the end of every individual board (Design4deconstruction, 2011). They created a unique detail, used fewer metal fixings and allowed for easier removal of the materials. The lap joint is subtle, but expressive of the work that it is doing and the method of assembly. The lap joint could also be used to hold standardized panel materials in place as finishes.

The architect Shigeru Ban often employs bolted connections for his buildings and temporary pavilions. They connect coplanar materials and act as ornamentation since the metal pieces stand out from the standard bamboo, cardboard or wood that they hold in place. They often appear excessive in number and thus time-consuming to assemble and disassemble.

Renzo Piano used a bolted system to replace mortar, a permanent joiner, in a rain-screen wall design. For the IRCAM extension in Paris, steel bolts run the full height of an aluminum frame and hold stacked terracotta bricks, with nylon spacers between rows (Ermanno, 1990). The screen is visually surprising since it reads like a segmented brick wall, and is expressed as a light and impermanent mechanical system instead of a traditional compressive and heavy system.

Shigeru Ban also develops custom joinery to connect more standardized materials. In the temporary Vasarely Pavilion, a multi-nodal metal connector accepts between 3 and 7 structural cardboard tubes. Since each connector appears to be unique they were likely custom fabricated for the week-long pavilion, and are not likely reusable in other projects so it is beneficial that the connectors and tubing be of recyclable materials.

Shigeru Ban's Canal Museum Boathouse, in Pouilly-en-Auxois, France and completed in 2002, does not claim to be demountable or recycla- 



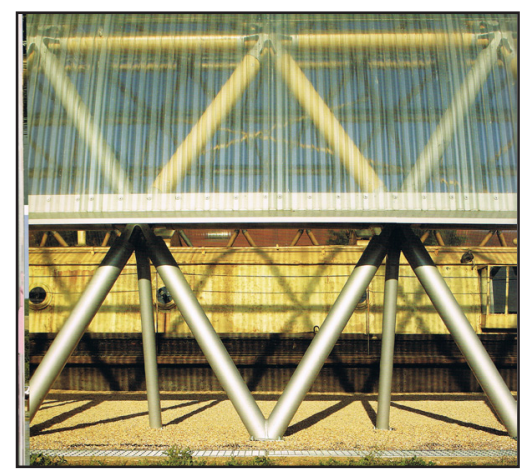

Fig 3.1.16 Shigeru Ban, Canal Boathouse Museum, 2002 ble, but it offers valuable concepts for an impermanent architecture that allows for disassembly and is expressed through joinery. This work is tectonically rich through material and constructive expression. Custom joinery allows structural tubes to be removed individually and replaced should the cardboard tubes be damaged or deteriorate. This connector is more repetitive because of the bay structure than that of the Vasarely Pavilion.

The choice of joinery depends on many factors. The expected functional life of the building must be taken into account. Temporary joinery could be tied or bolted, as it allows for reuse of materials or recycling. Notched, mortise and tenon, tongue and groove, and custom joints all depend upon a longer functional life because they demand more energy input into the creation of the joinery. Using recyclable materials for custom components and reducing the number of joints to conserve material and labour of assembly are good tactics. Almost all of the joint types listed can be embellished to be more expressive or downplayed to be more subtle. 



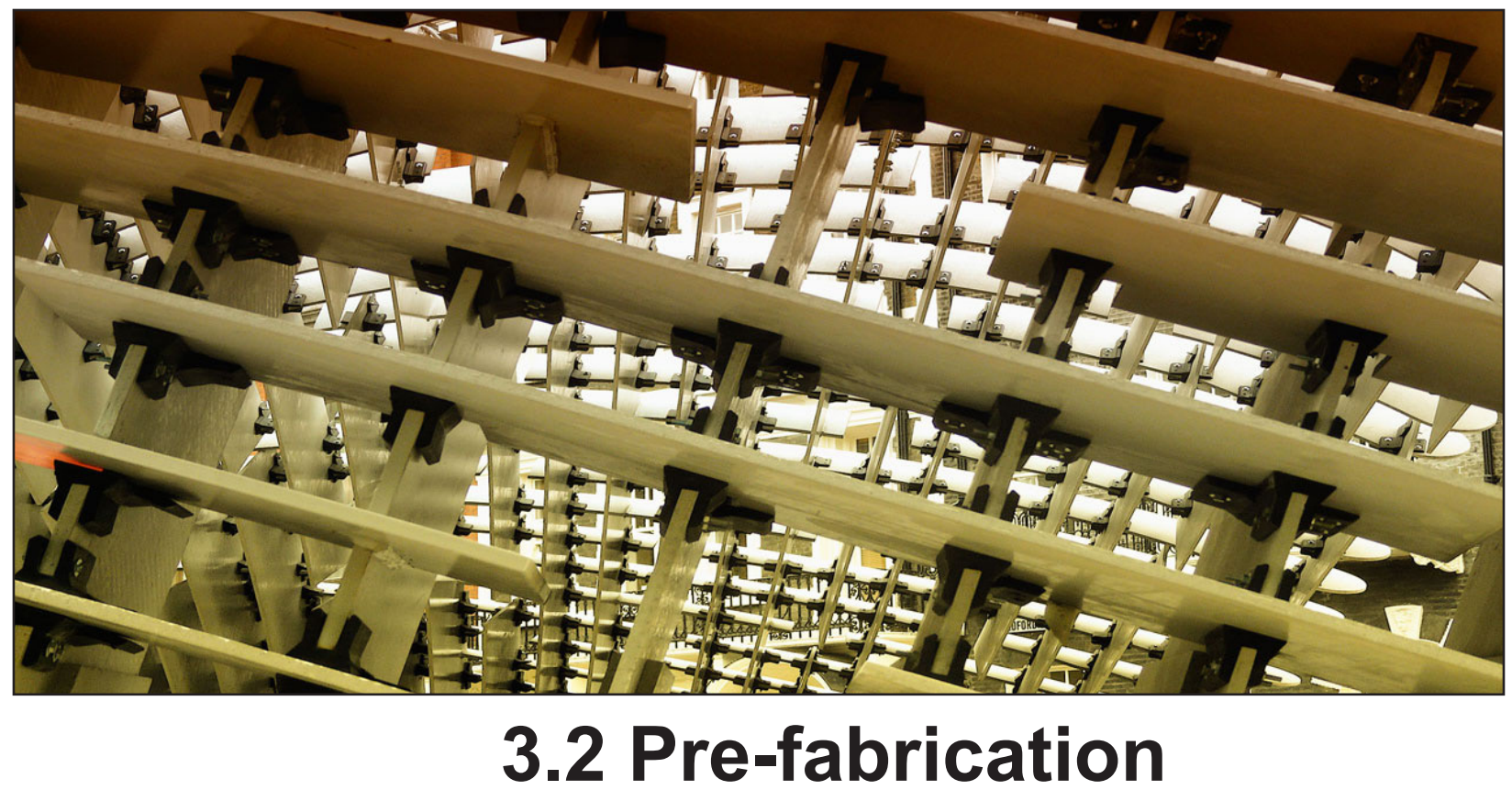

Fig 3.2.1 Dempsey and Huang, [c] space pavilion detail

Off-site fabrication creates a high degree of precision and fast assembly. It could also be adapted to speed and simplify disassembly. Digital fabrication can simplify the creation of complex joinery and allow for the formation of new standardized materials.

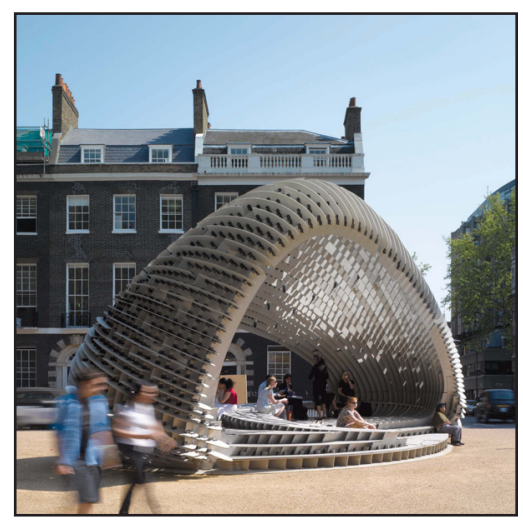

Fig 3.2.2 [c]space pavilion
For the 2008 pavilion, [c]space by Alan Dempsey and Alvin Huang, intersecting notch connections were cut in fiber-reinforced-concrete panels (Iwamoto, 2009). Notch connections require highly accurate cuts to achieve friction fit joints, which are easily achievable with digital machinery. 2000 joints were made from a digital model and CNC cutting (Iwamoto, 2009). The curved form would have been incredibly difficult to achieve without computer modeling, considering each intersecting notch lay at different angles. The pavilion may have relatively simple assembly and disassembly, but its form and materials are not ideal for extending life cycle. The customized curves of each panel of concrete do not make for easily reusable pieces. The composite material recipe does not allow for recycling of the concrete as an aggregate. The concrete panels would likely become landfill waste after the temporary use. The steel plate connectors are likely recyclable, or reusable if they are not customized. [c]space is a disappointing use of material, but a en- 

lightening display of the capabilities of digital fabrication for disassembly.

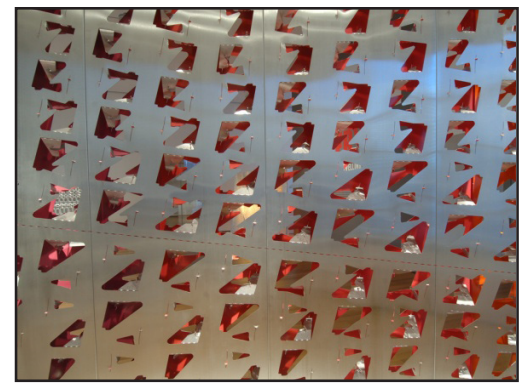

Fig 3.2.3 Marble Fairbanks Architects, Flatform installation, 2008

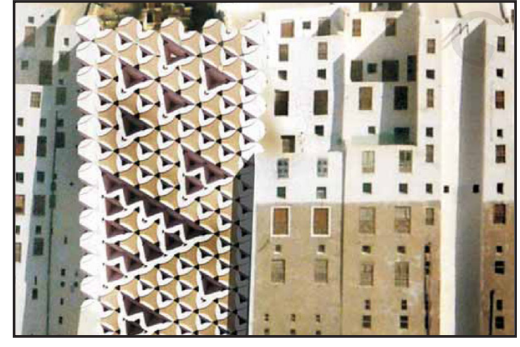

Fig 3.2.4 Bead Brick shown at a large scale in a high rise application

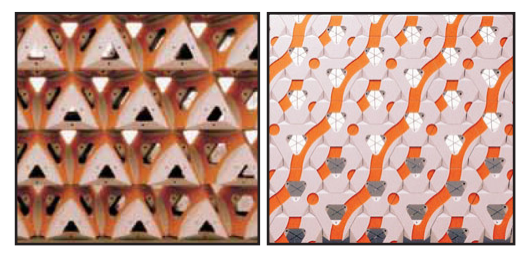

Fig 3.2.5 Bead Brick in different arrangements
The Flatform installation by Marble Fairbanks Architects demonstrates the new possibilities for expression of joinery possible with digital fabrication techniques. The laser-cut sheets are formed into the joining mechanism through folding (Marble Fairbanks, 2011). The connection is reminiscent of cross-lap furniture joints, but is infinitely easier to achieve with the precision of the tools. The joints maintain the sense of the panel, while at the same time breaking the whole form down into smaller parts. It is complex and simple, with a single joint language that demonstrates how the system is built. The decision to finish the interior surfaces in red emphasizes the assembly of the system.

"Flatform combines the constraints of material properties and pre-manufactured sizes with the flexibility of digital production processes to explore new logics of design and assembly. Architectural details are largely a product of the relationship of design to industry. If the modernist detail was based on negotiating tolerances (differences) between pre-manufactured, standardized building components through separate systems of fastening, today we are shifting to methods of production that are based on the management and organization of information, where details, tolerances, and assembly logics are numerically controlled and fully integrated during design. In this context, CNC (computer numerically controlled) systems bring the process of design closer to the production of buildings, merging them through a common language of information (Marble Fairbanks, 2011)."

The installation is shown as a hanging screen, while other applications could be finishes and cladding.

Forming with digital methods can allow for the creation of new standardized materials and components. Experimental stacking bricks by MIT student Rizal Muslimin aim to eliminate the need for mortar, creating dry and impermanent connections (Muslimin, 2010). The forms interlock in various arrangements to achieve different depths of wall with mortarless construction. They do not carry load like standard bricks, but are instead strung along steel cables. They create tensile lattice works that 

allow for varying levels of opacity depending on the organization. They would be applicable in more situations if they were load bearing, less delicate, and had the thermal mass of a traditional brick wall.

Pre-fabrication can help to create an architecture of assembly a through custom connectors, new standardized materials, and speedy and precisely cut joints. 



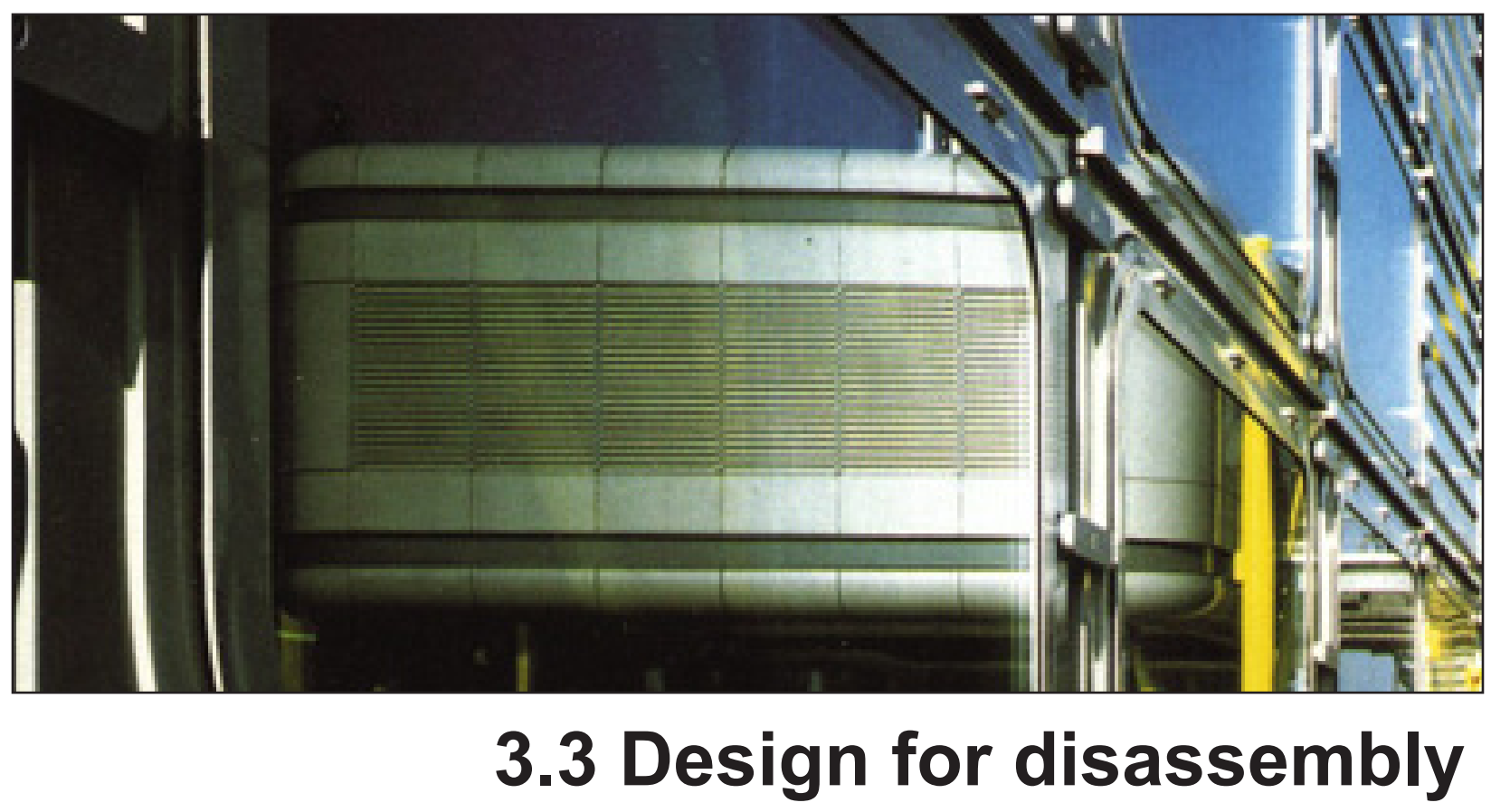

Fig 3.3.1 Nicholas Grimshaw, Igus Headquarters and Factory facade detail. Custom removeable and relocatable facade components allow for easy disassembly.

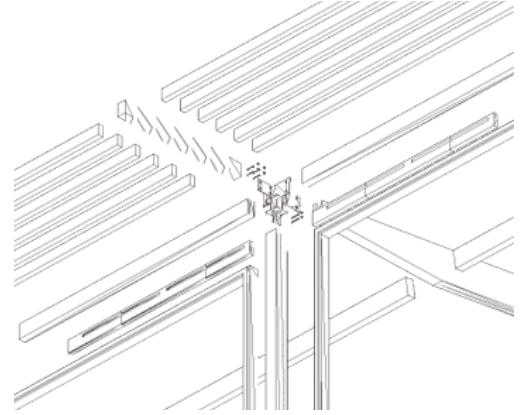

Fig 3.3.2 The Adaptable House axonometric detail of canopy

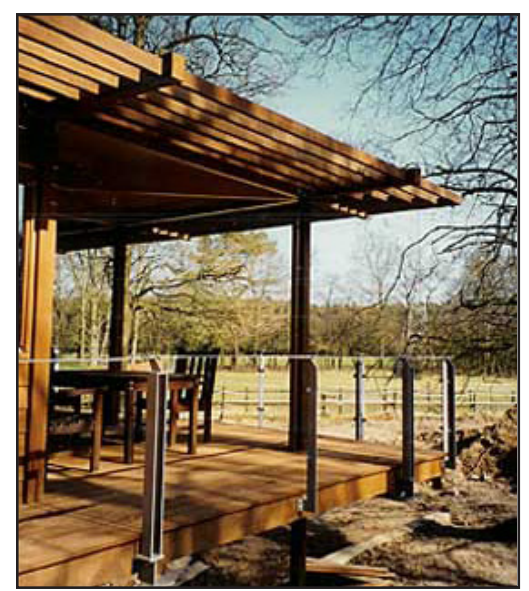

Fig 3.3.3 The Adaptable House deck
Design for disassembly was not conceived as a means of safekeeping materials for new buildings, so precedents have limitations when approached with the intended goal of reuse and recycling. Many disassembly projects try to disguise themselves as standard constructions. However, their connections and details tend to be more labor intensive than traditional methods, and thus more costly to construct. Precedents that claim to be 'designed for disassembly' or 'demountability,' are frequently not visually demonstrative of their impermanent intention and often fail to be thorough in their realization.

The Adaptable House, completed in 1999 by Elma Durmisevic and Buro Evelein is cited in the article "Designing for Disassembly (DfD)," written by Ken Yeang and Elma Durmisevic (2009), but does not offer a radical aesthetic change from traditional construction, and is limited in disassembly principles. The exposed timber structure, and wooden deck canopy form the extent of disassembly. These components employ the concept of layering using bolted, impermanent connections. The wooden canopy is detailed as a separate structure to that of the timber sheltered within the exterior walls. The canopy beams are bolted to a shared steel connector on the end of the internal roof beams. The detail permits the 

canopy to be easily replaced should it weather and fail over time without affecting the primary structure and also allows it to act as a cantilevered system from the interior roof beams. The interior finishes are not deconstructable. Traditional gypsum walls and tile bathroom floors do not offer an easy means of disassembly and reuse.

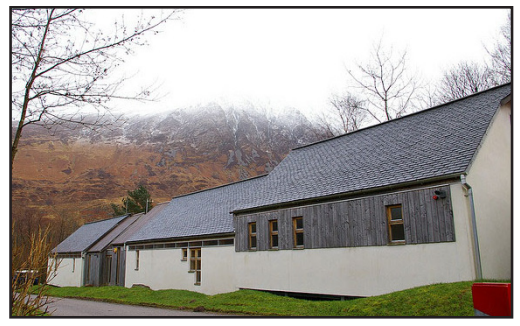

Fig 3.3.4 Glencoe Visitor Centre

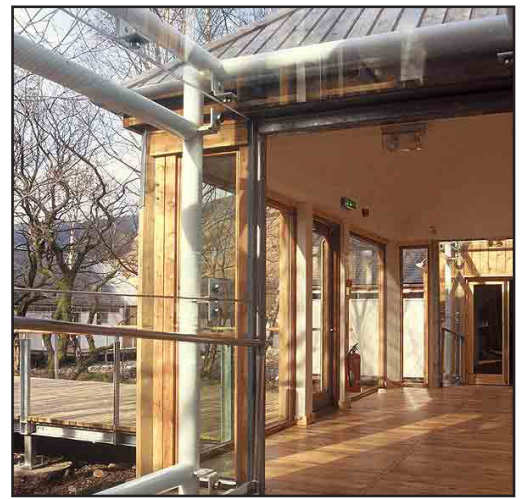

Fig 3.3.5 Glencoe Visitor Centre, glazed link
Gaia Architect's Glencoe Visitor Centre, completed in Scotland in 2002, raises similar issues, but manages to push disassembly detailing further. The architects aimed to reduce material use by designing a durable building with the ability to be modified over time (design4deconstruction, 2011). They claim to have built in independent layers, with the timber frame separated from interior partitions, to allow for future changes to the layout (design4deconstruction, 2011). Cladding and interior finishes are also layers separated from the structural frame. Services, such as electrical wiring and heating pipes, are located in voids between the frame and finishes in floor, walls and ceilings, which are made accessible through screwed-on skirtings and screwed-together floors (design4deconstruction, 2011). The design typically employs exposed bolts and screws as the method of joinery, avoiding adhesives and nails to allow for the layers to come apart. Material selection was very important to the architects, who tried to avoid coatings, finishes and composite materials to maximize recycling. The design compromises on plasterboard, a rendered exterior finish, traditional finishes in wet areas and nail connections in a few situations (design4deconstruction, 2011). The project is primarily traditional in appearance through material selections and form, although finishes appear slightly rough with exposed screws, and the series of buildings are raised off of the ground with a steel frame resting on pile foundations that minimize a permanent connection to the site. Where traditional construction is avoided the building becomes more interesting and expressive of its disassembly principles. Glazed links have large custom joints and exposed structure, demonstrating the layering of assemblies. 



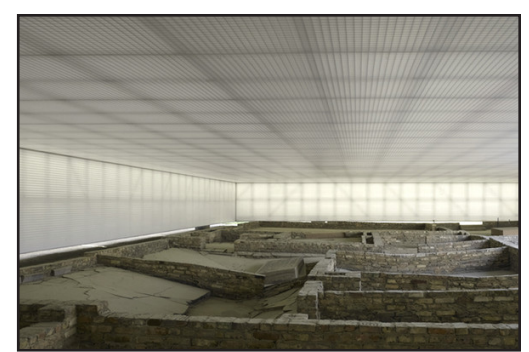

Fig 3.3.6 The Station Z Memorial interior

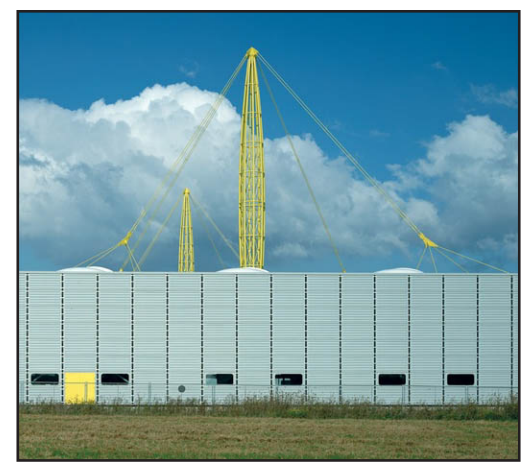

Fig 3.3.7 Nicholas Grimshaw, Igus Headquarters and Factory exterior, 2000

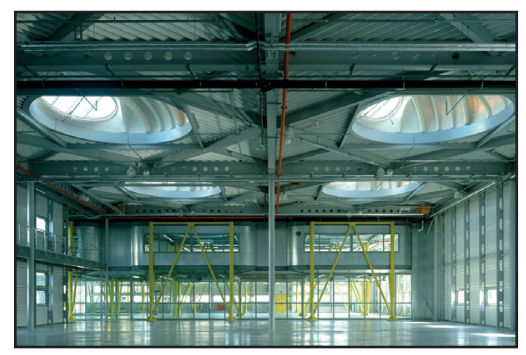

Fig 3.3.8 Igus Headquarters and Factory interior
The Station Z Memorial in Sachsenhausen, designed by HG Merz and Werner Sobek, shelters the remains of a Nazi gas chamber. The design divides the shelter into compression and tension components. Fabric is vacuum sealed in place on a steel frame made from standard rectangular sections (Sobek, 2011). Sobek claims that no connections are needed to hold the structure together as the relationship between frame and skin are sufficient. Werner Sobek stated that the enclosure is entirely demountable and recyclable (Sobek, 2010, p.36). It is not possible to test the veracity of Sobek's claim of disassembly however one can criticize that the architecture would be more powerful in its reusability claims if it expressed its intentions through evident reversible joinery to the user. A visitor to the site would likely more fully appreciate the cleverness of the design and the thorough vision of the material lifecycle if the intent of disassembly were apparent. They would also grasp the contrast between a hovering impermanent form overtop of the remains of a permanent assembly that is hard to disassemble or forget.

The Igus Headquarters and Factory in Cologne, Germany designed by Nicholas Grimshaw and completed in 2000, approaches the problem of disassembly from an manufacturing perspective (Kronenberg, 2000). The design employs a series of standardized components that permit replacement and flexibility. Office and administration pods can be moved in their entirety and rest on long steel legs with footpads (Kronenberg, 2000). The cladding is demountable by "simply loosening and swivelling an aluminium clamp" and is interchangeable with different options including aluminium, louvred, windows, or doors (Kronenberg, 2000, p.72) Joints are highly visible, almost to a fault on the interior, where the eye is overwhelmed by visual information.

'Nicholas Grimshaw and Partners' standard procedure is to spend more time in detail design than might be the case with many other architects...Because of this the lengthy detailed design process that the IGUS project involved was seen as fairly normal, despite the fact that it constitutes the most flexible static building ever built (Kronenberg, 2000, p.72)." 



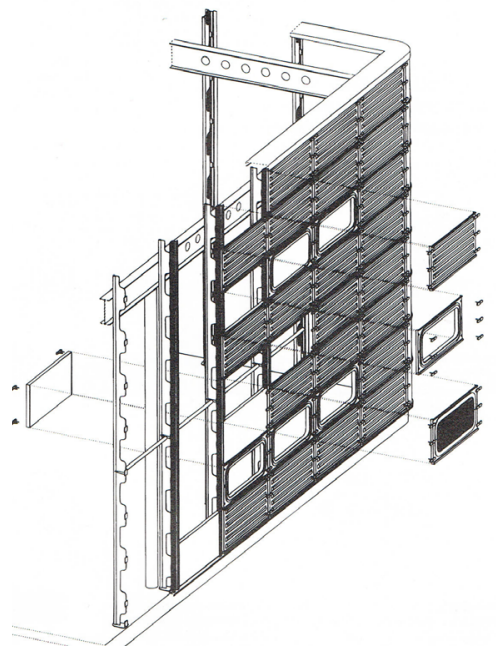

Fig 3.3.9 Igus Headquarters and Factory exterior cladding system
Pieces can be moved over and over without compromise to their function, which is an intelligent objective for demountable construction (Kronenberg, 2000). Piping and wiring is exposed and clipped to run along roof beams so that the factory floor is clear of services (Kronenberg, 2000). Flexibility was limited by meter locations and service connections, and the project appears to have poured concrete floors on grade, which are permanent and inflexible (Kronenberg, 2000). The IGUS Factory is a fairly successful example of disassembly construction and prefabrication that could be adapted for a variety of open span buildings. It employs custom components with long technical and functional life spans that ultimately can be fully recyclable.

When design for disassembly reverts to traditional means of construction or adapts traditional assemblies it appears less effective. More visible joinery and methods of assembly make apparent the impermanent intent of the work, but too much visible detail and joinery can be overwhelming visually. The effectiveness of disassembly architecture can be tested by measuring the quantity of permanent assemblies, while the added requirement of material life cycle could be quantified by looking at the percentage of recyclable and reusable content in relation to traditional building construction. A metric value would help to enforce the design for disassembly claims of efficiency that many of the aforementioned projects allege. 



\subsection{Layering assemblies}

The concept of layering independent systems is endorsed by proponents of design for disassembly. It allows for the removal of obsolescent layers without impacting others that have longer technical lives. Structure is typically the longest lasting layer, while cladding and interior finishes tend to wear quickly as they are exposed to weather and changes in desired aesthetic. Mechanical and electrical systems are often given separate accessible layers between the finish and structure to allow for updates and maintenance.

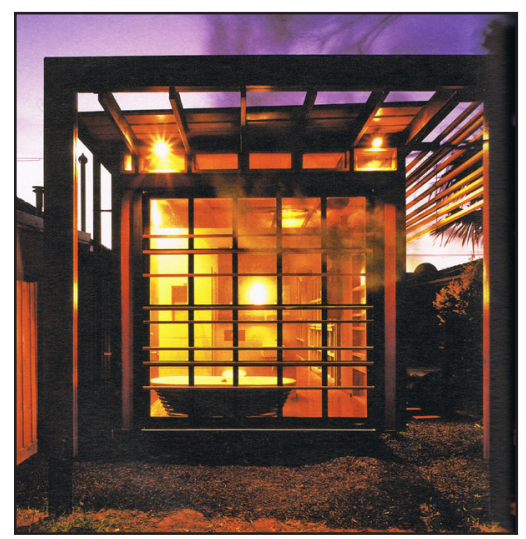

Fig 3.4.1 Essex House timber superframe
Structure acts as a separate super-frame layer in the Essex House in South Australia, created by Andrew Maynard Architects in 2006. Its structural timber members are separated by a physical void from the cladding and finishes, and connect by steel members to the body of the building. The structure forms a super frame encircling the volume of the enclosed spaces. The frame defines the space of the building, creating outdoor rooms and extending the concept of space beyond the shell. Joinery, such as steel bolts, is minimal and exposed, reveals are opened between connecting wood structural members to show the steel substructure running beneath the wood. The super-frame holds the interior spaces above the site, but requires secondary frame structure for the exterior walls, having little benefit. The structure layer traditionally lasts the longest and requires the least manipulation and updates in a building, so leaving it accessible and exposed to weather is not logical for disassembly (Durmisevic \& Brouwer, 2002).

The Steerwijk Community Centre in Holland, by Marx \& Steketee Architecten, employs a superstructure layer to allow flexibility for interior arrangements. The extensive roof and columns are independent from the cladding walls and interior partitions (design4deconstruction, 2011). The architects claim that the support columns can be moved, along with the exterior timber clad walls, and the interior partitions to modify the 



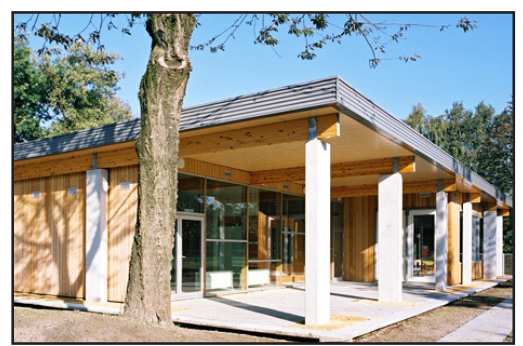

Fig 3.4.2 Steenwijk Community Cen-

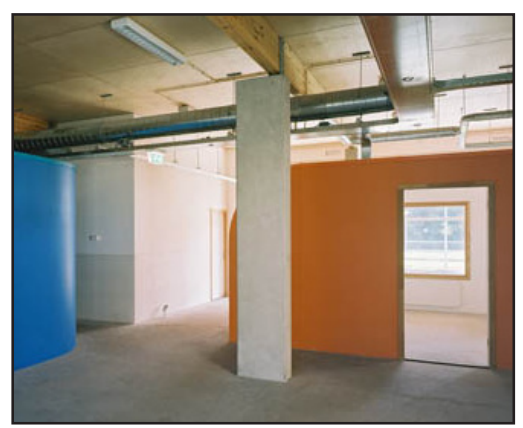

Fig 3.4.3 Steenwijk Community Centre interior layout according to user demands (design4deconstruction, 2011). Prefabricated components are connected with screws that are left exposed to allow them to come apart and be relocated (design4deconstruction, 2011). The project may be capable of coming apart into large prefabricated components, but it is unclear if the disassembly stops at that scale. Joinery is visible in the main roof, timber structure and column assemblies, but not within the wood paneled exterior walls or painted drywall interior partitions which appear to be traditional construction. Mechanical systems run in the space between the exposed beams and top of the interior partitions, but it is not apparent if they are assembled in a manner to come apart to respond to new floor layouts.

Within building assemblies, cladding and interior finishes tend to be short-lived layers. Exterior and interior finishes are exposed to the wear and tear of everyday use. Building skins often last half or a third as long as the life of the building that they are shielding (Weston, 2003). The exterior façade is the public image of a building, and its statement of social condition and beliefs (Meyers, p.36).

"...cladding can now be seen as a form of 'dressing', a fabric to be chosen at will and, potentially changed with relative ease... and buildings may soon be tailored with stylish but cheaper, shortlife 'suits', intended to be replaced with something more fashionable in a few years... Ephemeral 'decorative' exteriors could be complemented by permanent 'structural' interiors, offering the pleasures of working 'in the nature of materials' that high levels of insulation render problematic due to the cold bridges resulted from exposed structure (Weston, p.198)."

Finishes and facades cannot be expected to satisfy future generations, and short technical lifecycles means it is usually not required. Trend associated designs are at risk for early obsolescence. It is better to design for longevity to balance functional lifecycle with technical lifecycle, so the materials are best used. If finishes are likely to obsolesce due to technical reasons, they should be composed of replaceable and recyclable materials with disassembly methods. Cladding was a new layer atop an existing building in the Racine Art Museum in Wisconsin. 



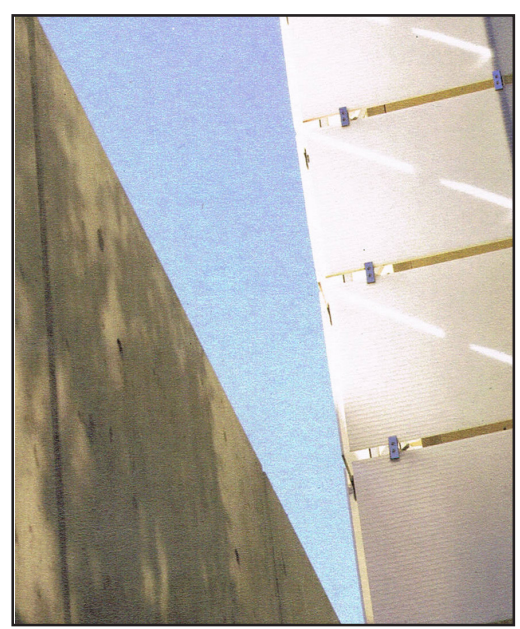

Fig 3.4.4 The Racine Art Museum new cladding corner detail

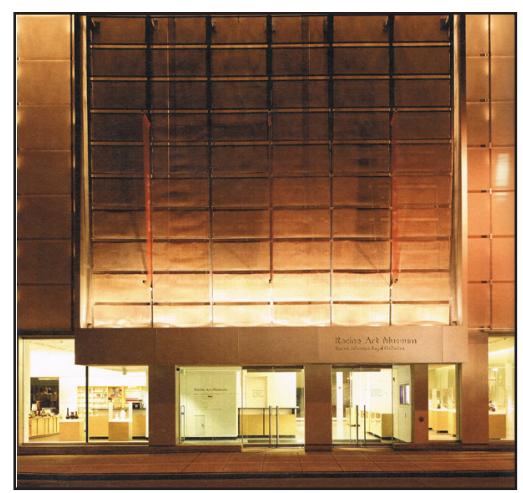

Fig 3.4.5 The Racine Art Museum new facade

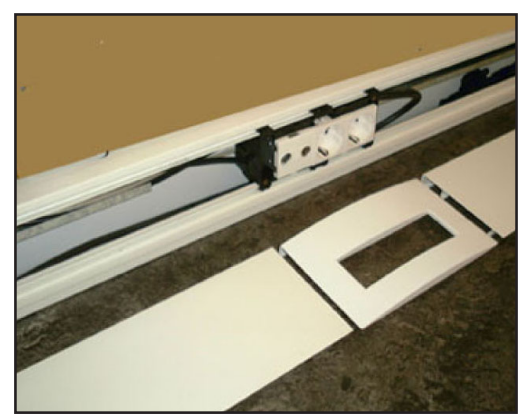

Fig 3.4.6 Open wall access panel with outlet cover and finish strip
In the 2003 renovation, by Brininstool + Lynch, acrylic panels were added over the existing envelope. They are held by metallic clips and offer a significant gap between adjacent panels. The joint at the corner of the volume is denied by panels that fail to meet. There is a sense of lightness and fragility to the new facade covering, that mirrors the sense of lightness the designers wanted to bring to the gallery spaces on the interior. The minimal system, with little material character, is continued on the interior with simple, clean finishes that allow the art to be the center of focus. The new system layered upon the old facade permitted the architects to create an intervention that made the mid nineteenth century building look "completely new," and shaded existing fenestrations to reduce energy costs, while creating ideal diffuse lighting conditions in the galleries (Bahamon and Sanjines, 2008, p.64). Exterior and interior finishes should be designed to employ disassembly principles due to their exposure.

Mechanical and electrical systems are often conceived as layers behind the finish and atop the structure. Architects and engineers have evolved various solutions for access and manipulation of mechanical and electrical systems in buildings. Several solutions incorporate the layered systems concept of disassembly. Drop ceilings and raised flooring systems create a plenum within which to run wiring and piping, and blow treated air above or below the structure. It acts as a secondary finish layer separated from the structure. Wall access panels are less common, but involve the creation of a reveal to access mechanical and electrical components between the finish and floor. Ducts and outlets are apparent along the length of the gap, and the reveal is finished with a panel flush with the wall finish (Durmisevic \& Linthorst, 2000). Holes do not have to be cut into wall finishes in order to create outlet and duct openings, and the panel creates a clean line, and easy accessibility to the systems for changes.

Layering makes sense for shorter functional and technical assemblies 

such as mechanical, electrical, cladding and finishes. Structural assemblies do not need to be left accessible as layers, but in the case of the Steerwijk Community Centre their exposure allowed for the flexibility of other assemblies. 



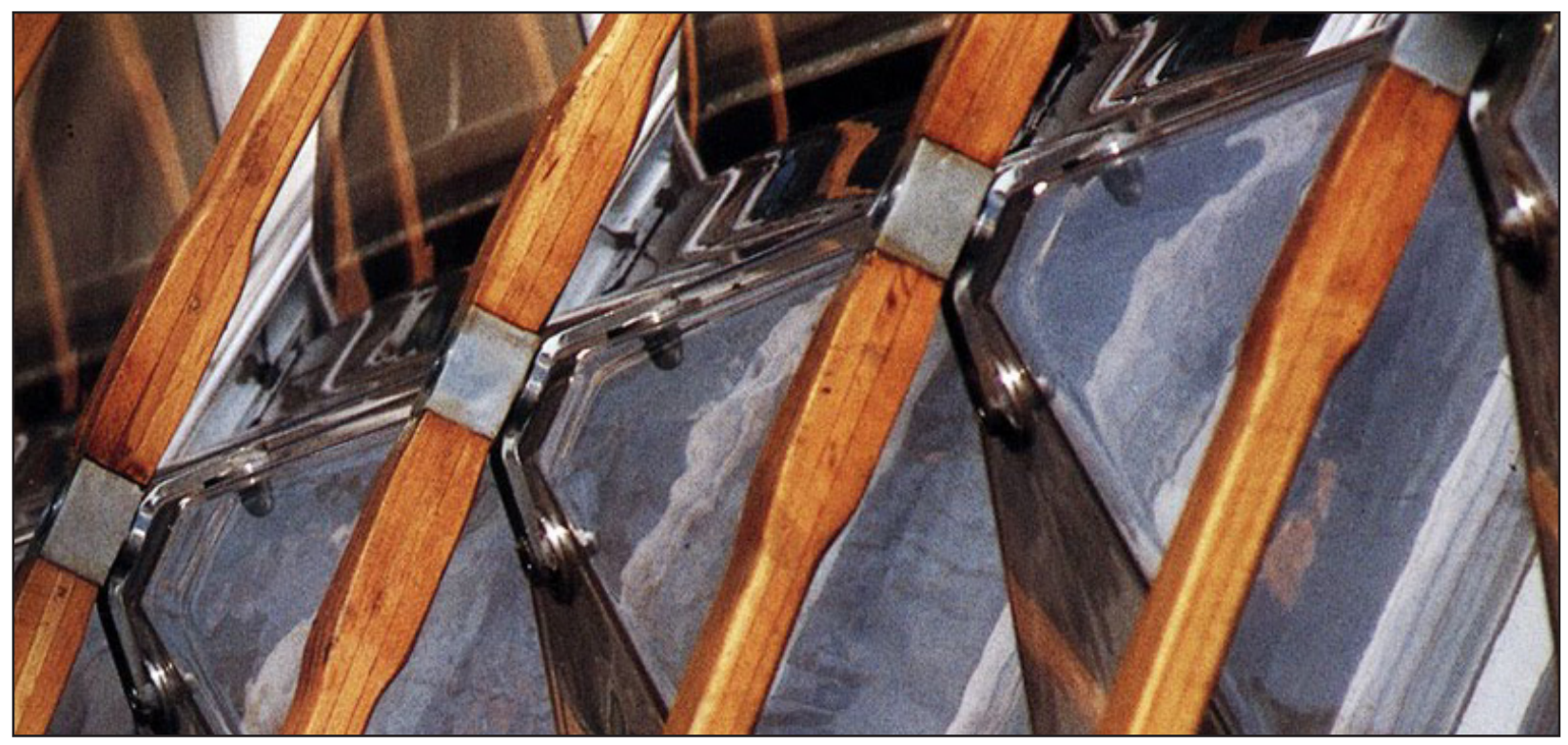

\subsection{Portable and temporary structures}

Fig 3.5.1 Renzo Piano, IBM Travel- Traditional portable structures, their contemporary iterations and temling Exhibition exterior detail, 19821984. Customized structural and cladding components are designed for disassembly and reassembly at new sites

porary pavilions offer lessons in architecture of joinery, impermanence and disassembly. Ideally they are portable when divided into their component parts, are essential and minimal for lightness, their joints are reversible, and they often avoid foundations or other permanent connections to sites.

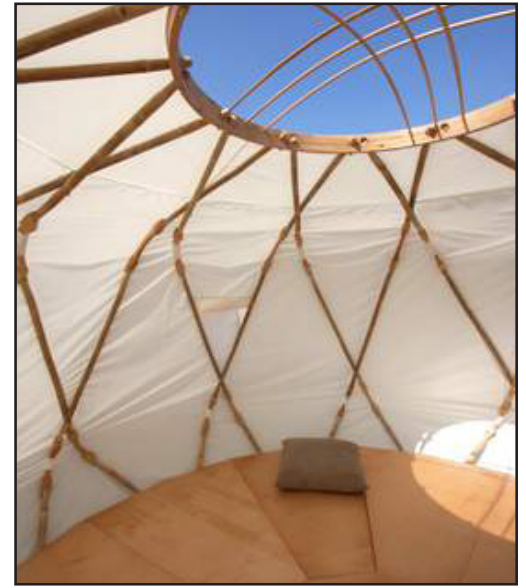

Fig 3.5.2 Ecoshack, The Nomad interior
The Nomad is a contemporary interpretation of the traditional portable yurt and is designed by Ecoshack (NOTCOT, 2008). The system is composed of a membrane acting in tension to hold the system together, bamboo posts that keep it from collapsing, and a platform to designate the space and form a solid base to anchor the other components. The connections are dry and easy to comprehend for assembly by hand. Bamboo posts slide into pre-cut holes in the base and a top ring, and are held in by the pressure of the membrane. Simple joints make the form easy to assemble and disassemble without mechanical equipment, but are thus open to manipulation by users. The wood elements lend a warmth and beauty that is reminiscent of the traditional nomadic 



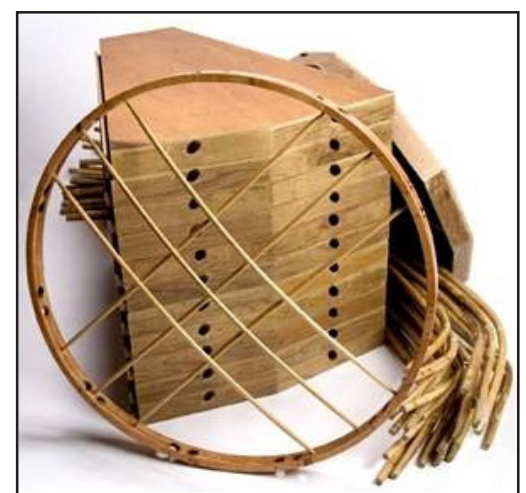

Fig 3.5.3 The Nomad kit of parts

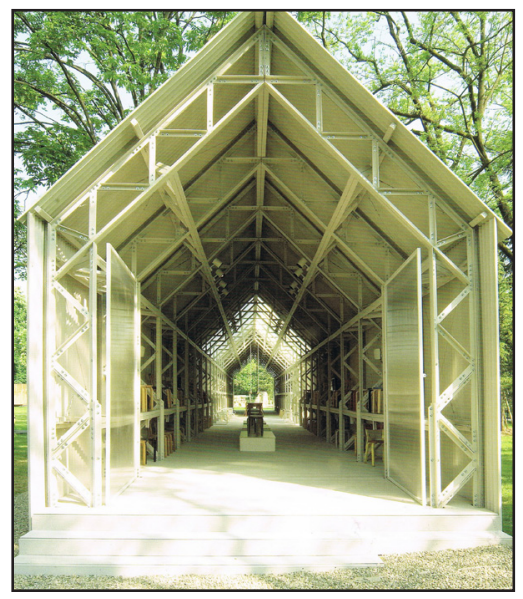

Fig 3.5.4 Shigeru Ban, The Artek Pavilion, 2007

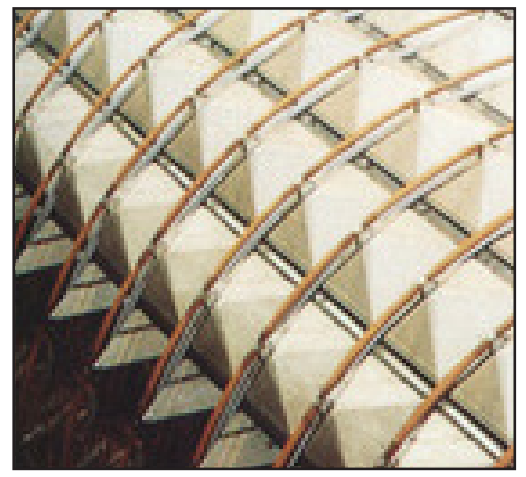

Fig 3.5.5 IBM Travelling Exhibition exterior

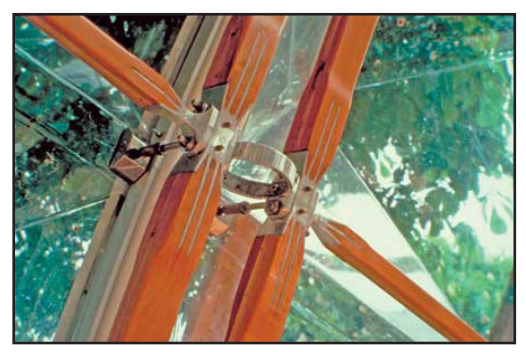

Fig 3.5.6 IBM Travelling Exhibition Pavilion structural detail structure. Component pieces are standardized, but highly specific, so if one is lost or damaged during transit it must be replaced by the manufacturer. Traditional nomadic structures were typically composed of local materials so that they could be easily replaced from within the environment. The assembly would be limited to flat, dry ground to avoid damaging the wood panel base and the membrane appears too delicate to last for a long period of time outdoors, so the yurt is likely meant to be a temporary and seasonal structure.

The Artek Pavilion, by architect Shigeru Ban, was built for 5 days of the 2007 Milan Furniture Fair and was deconstructed in the same amount of time. The pavilion structure was created from a prototype material of extruded plastic waste and wood fibres, in a repeated truss module, and is joined with exposed bolts (Miyake, 2010). The exterior skin is transparent in places to allow light to enter the long shed-like space (Miyake, 2010). The building rests upon a timber platform and appears to be free of permanent foundations. The repetitive structure acts as the architectural expression at the building scale, while the exposed bolted joinery acts as ornament on the small scale. The lack of insulated wall assembly and services allow for the simple layering of cladding and structure. The material choice is questionable since a composite of plastic and wood combines biodegradable and recyclable substances, so that they can only be disposed at the end of use.

The IBM Travelling Exhibition Pavilion designed by Renzo Piano Building Workshop, and functional from 1982 to 1984, is composed of prefabricated modular components. A steel floor truss hides a void for services with plywood floor panels, laminated timber arches affix into the floor assembly, and cast aluminum joints connect a polycarbonate skin to the structure (Kronenberg, 2000). The travelling building generally avoids foundations, except on grassy landscapes, because it rests on adjustable jacks that adapt to different sites (Kronenberg, 2000). The design exploited disassembly by having optional added layers for great- 

er insulation or sun-shading in different seasons (Kronenberg, 2000). The heavily customized polycarbonate, aluminum and timber components all have the potential to be recycled at the end of the temporary exhibition.

Portable and temporary structures are usually built with joinery expressive of their impermanence and avoid permanent connections. The impermanent bases, that avoid the use of foundations, would effective for buildings of minimal height and size. 



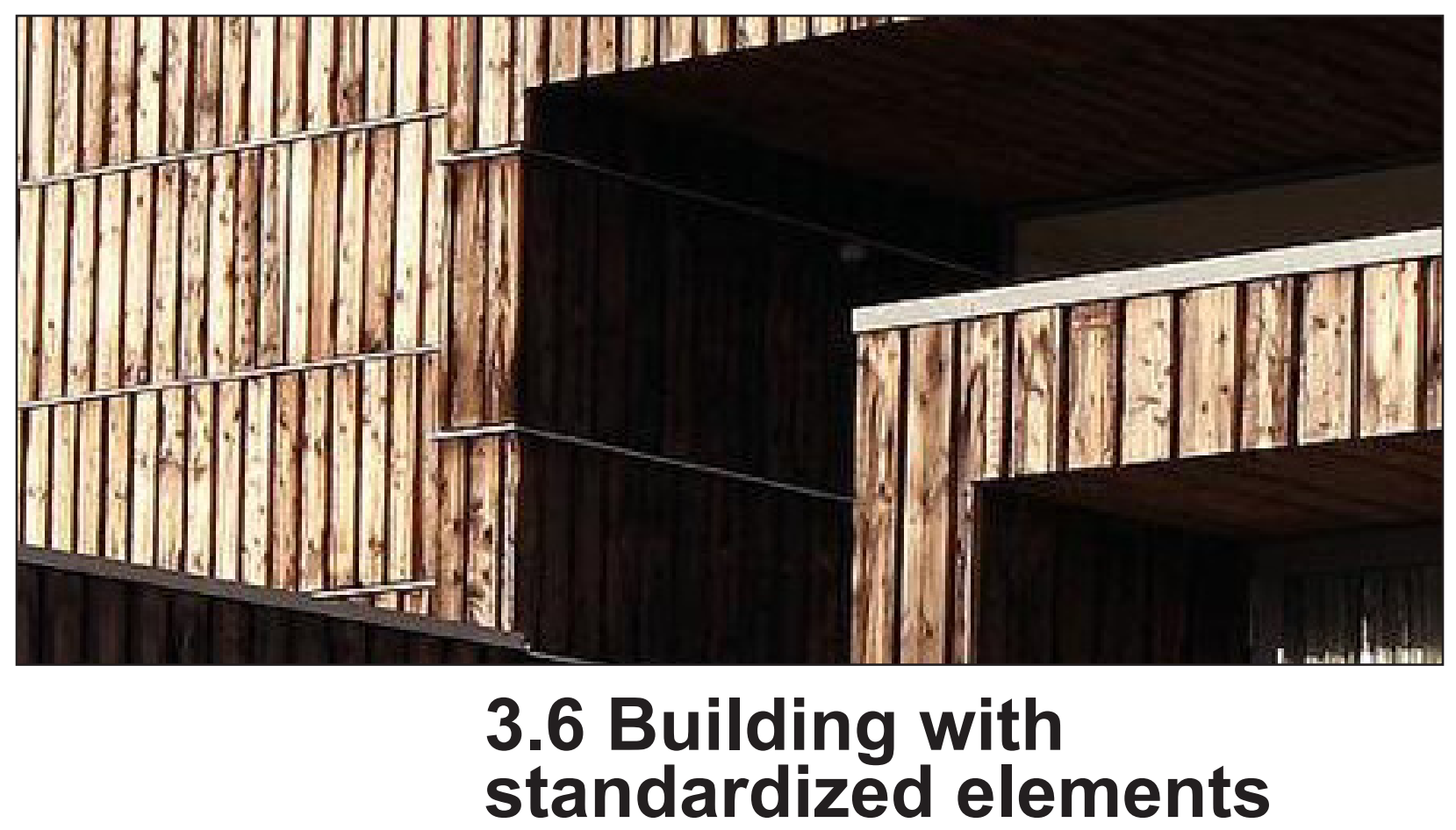

Fig 3.6.1 2012 Architects, Villa Welpeloo facade utilizing cable reel wood slats and reused aluminum flashing

Off-the-shelf standard sizes and components are more likely to be reused in new projects. If in a design a custom form is desired it should be composed of recyclable material instead of simply reusable, since non-recyclable materials can only be down-cycled or turned into waste when they are impractical for new projects. The use of repetitive standard components can also create a powerful material character.

2012 Architects used easily available and standardized reused material in Villa Welpeloo. They sourced wood from cable reels that would oth-

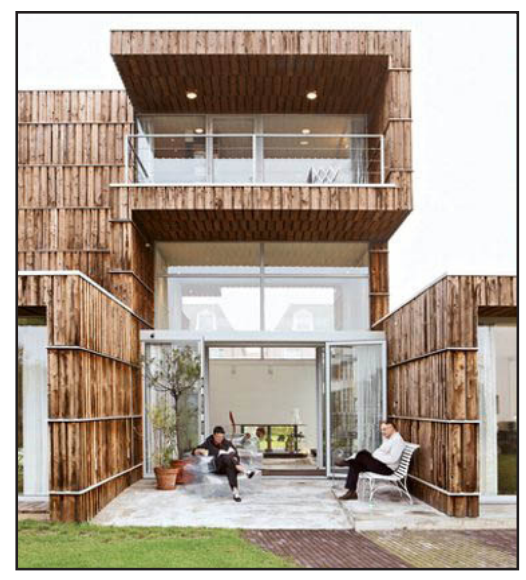

Fig 3.6.2 Villa Welpeloo exterior erwise have been discarded by the owners at a cost (Superuse, 2007). Significant energy would have had to be put into the stripping of material from the cable reels since they are assembled with permanent connections. This project illustrates an issue limiting material reuse that could be resolved through joinery to allow for disassembly. Reclaimed lumber that requires de-nailing costs an additional $\$ 0.15$ per linear foot regardless of the cross section, which adds a significant cost to small dimension lumber (Kernan, 2002). The center planks of the reel were still in good condition and utilized for the facade of the Villa, while rotten ones were used for temporary projects due to their compromised integrity. 



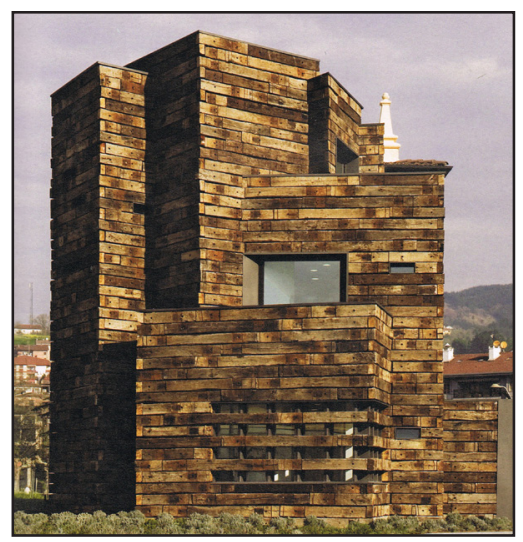

Fig 3.6.3 The Azkoitia Municipal Library clad in reclaimed railroad ties

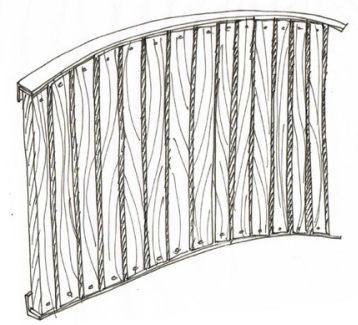

Fig 3.6.4 Achieving a curved form with standard lumber pieces and a custom curved metal angle

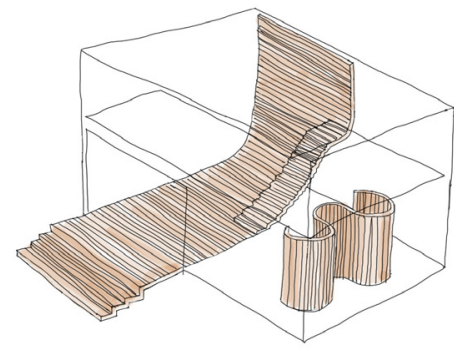

Fig 3.6.5 Building volume with standard wood flooring curving into wall surface, and freestanding walls

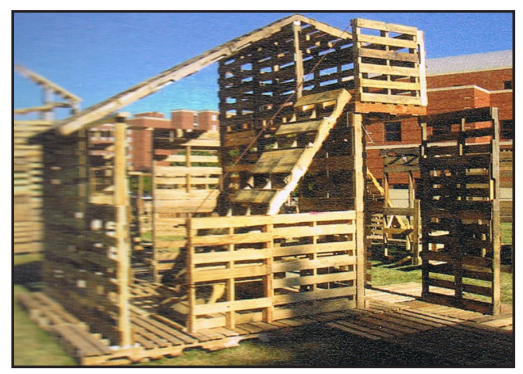

Fig 3.6.6 An unfinished Pallet Structure
The unified lengths of material allowed the designers to come up with a rigorous cladding system, and created a rich texture on the building exterior. Aluminum drip edges act as bright and clean reveals between each course of wood. Through their clean lines they highlight the weathered and rough quality of the cable reel wood.

The Azkoitia Municipal Library in Spain, by the architects at Estudio Berldarrain, also employs reused lumber lengths to create a robust material character (Bahamon \& Sanjines, 2010). Rough and weatherbeaten railroad ties are well balanced by the clean lines of fabricated glass and metal parapets, and the sharp edge of the entrance canopy. Corner joints are used to express the dimension and depth of the material. The railroad ties were screwed to strapping in a visibly permanent detail that does not express its ability to be removed. This project also employs reused material that was likely energy intensive to harvest from existing railroad infrastructure due to permanent connections - limiting the potential for reuse of this kind in other projects.

Pallet Structure by I-Beam Design, utilizing modular components held together with rope and nails, demonstrates the issues and opportunities of working with full planar material (Bahamon \& Sanjines, 2010). In the project, planes often do not meet at corners but extend beyond to form walkways and overhangs. The shadows formed by the slats are interesting, but lost on the pattern of striped floors and walls - their unique character could be enhanced through selective use. The system offers easy assembly and no permanent foundation. The forms are ultimately meant to be turned into relief shelters coated in durable materials like stucco. However, the use of stucco or other permanent finishing methods reduce the changeability and disassembly of the palettes - panelized roof coverings or impermanent membranes would be a superior choice for these impermanent buildings. An uncut panel in building is valuable for avoiding wasting material but is only ideal for right-angled perpendicular assemblies. Without cutting to fit, the planes extend be- 



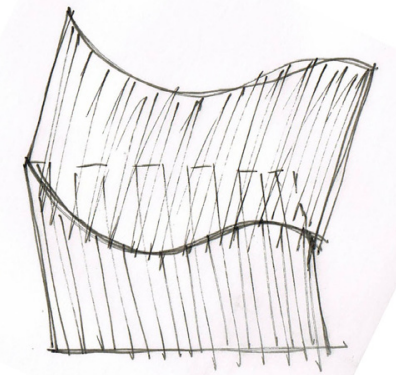

Fig 3.6.7 With the assembly of a planar material and a curve, there will be leftover material that would be wasted if cut

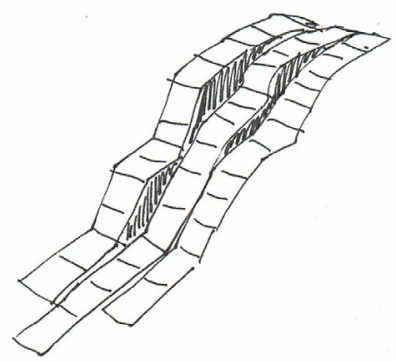

Fig 3.6.8 With the assembly of a planar material meeting other planear material at an angle, there will be leftover material that would be yond the edges or inscribe within a non-standard geometry.

Standard building materials and components are ideal for avoiding material waste because they are more likely to allow for reuse. However, they are best used in their original forms by avoiding cutting, and thus have a significant effect on component layout and dimensions in the project. Standardized material assemblies can create rich material buildings, but the use of uncut standardized materials offers serious limitations to formal experiments in architecture and flexibility of dimensions. 



\subsection{Case studies for disassembly}

Werner Sobek, R128 House, Stuttgart, Germany, 2000

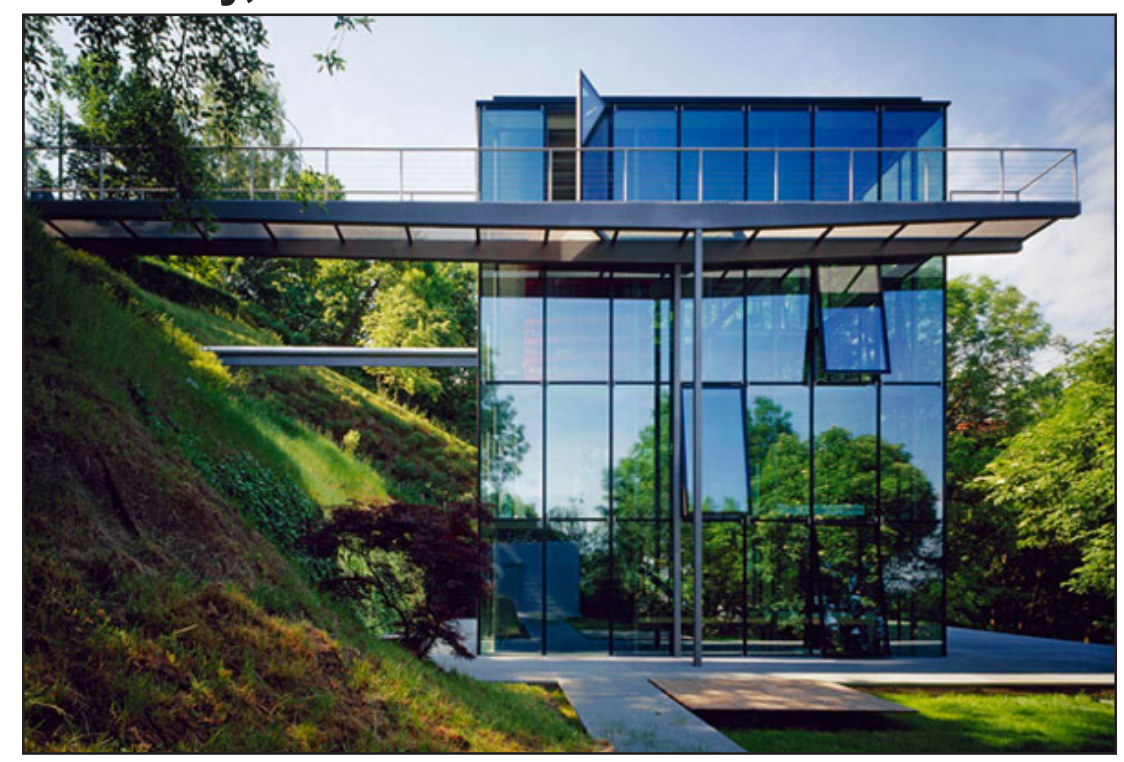

Architect and engineer Werner Sobek writes that design and construction methods need to adapt so that buildings become entirely recyclable to reduce resource use in construction (Sobek, 2010, p.35). His home, built in 2000 , reflects his beliefs. It is considered a fully recyclable building. He claims there are no organic materials in the primary structure and enclosure systems to ensure recyclability (Bell \& Rand, 2006). However, the floor panels are made of adhered wood and plastic, so would not be recyclable or likely reusable. The floor panels are prefabricated and rest on the I-beams below without fasteners. To simplify assembly and disassembly the building employs only mortice-and-tenon or bolted joints, and its components are prefabricated off-site (Sobek, 2010). To demonstrate the easy assemblage, the house took only 4 days to be erected (Stang \& Hawthorned, 2005). The four storey steel structure is bolted together and rests on the foundation of the previous "dilapidated 1923 house (Stang \& Hawthorne, 2005)." The glass facade and aluminum drop ceiling panels are modular, standardized and repeated based on the structural bay size. Troughs in the floor around the perimeter of
Fig 3.7.2 R128 House bolted steel structure 



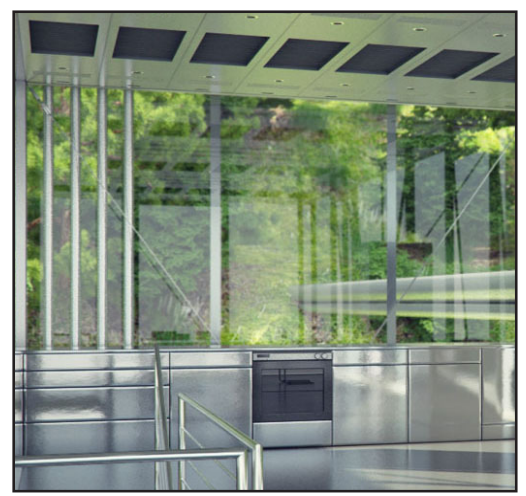

Fig 3.7.3 Pipes rise behind the kitchen cabinets the home hold the mechanical pipes, electrical and communication wiring, and are hidden by removable laminated metal covers (Stang \& Hawthorne, 2005, p.107). When pipes rise vertically between floors they are fully exposed in the space, and are expressed as seamless stainless steel forms. The design avoids internal walls, except for a small washroom core spanning two levels, which is clad in aluminum and frosted glass (Bell \& Rand, 2006). The lack of walls reduces material, allows furniture and openings in the floors to define rooms and creates a flexible and continuous open space (Stang \& Hawthorne, 2005). Connection details are often customized and prefabricated: "fixed triplex glass cladding panels are cradled in custom stainless steel "yokes" near each corner. This provides nodal connections to the glass without requiring penetrating bolts. An EPDM (ethylene propylene diene monomer) rubber membrane bounds each piece of glass (Bell \& Rand, 2006).”

The R128 house is customized, which offers little opportunity for reuse, but because the majority of components are recyclable there is little waste material. The project offers some evidence of its assembly: seams between prefabricated ceiling panels, exposed beams between floor panels, exposed mechanical pipes and steel fasteners. The project is primarily minimal and high-tech in expression, rather than expressive of joinery and assembly. It uses a lot of welded joinery instead of visible reversible joinery in its prefabricated components such as railings and staircases. The project could offer more evident expression of its intent to disassemble and recycle the building. 



\section{Kieran \& Timberlake, Loblolly House, Maryland, USA, 2007}

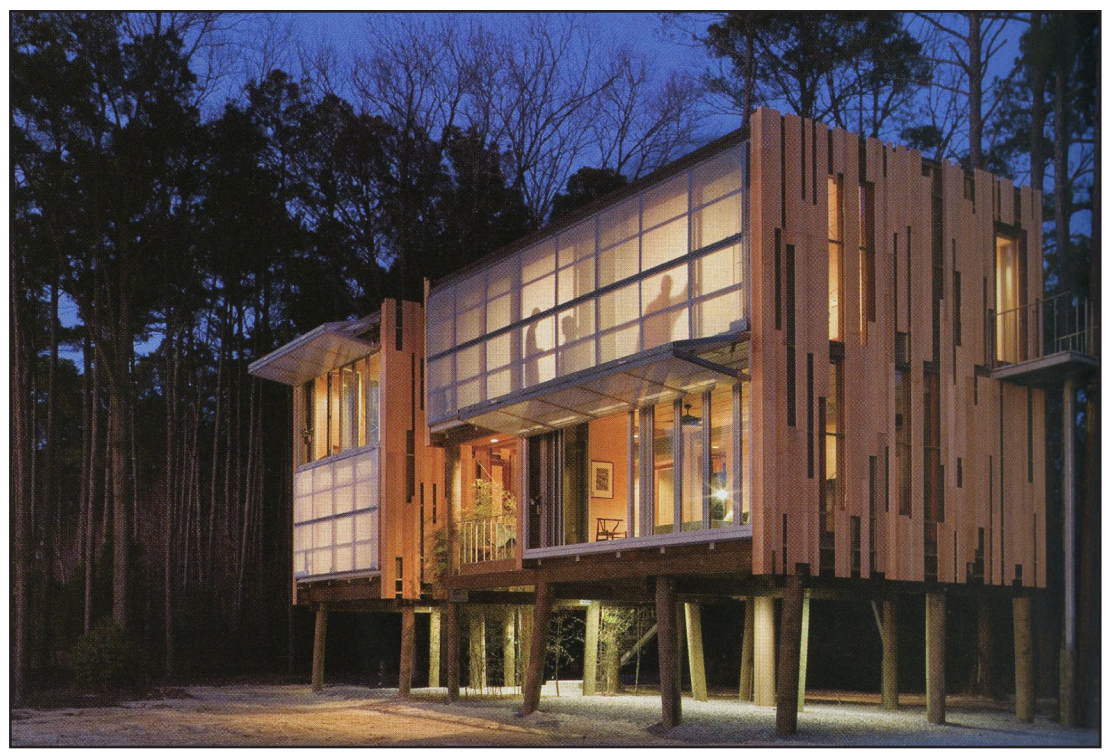

"Stephen Kieran...likens his family's new weekend house...to a duck blind.... And like a duck blind, the building...can be disassembled. Most of its pieces are then recyclable (Pearson, 2007, p.141)."

Fig 3.7.4 Loblolly House

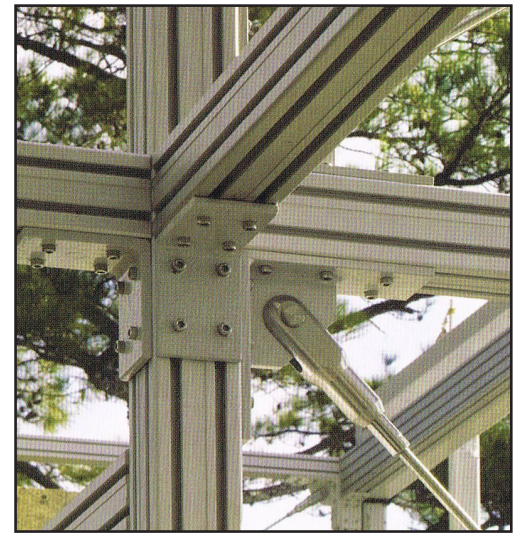

Fig 3.7.5 Aluminum frame with bolted connections
The building avoided creating a permanent connection to the site by creating a platform atop wooden piles sunk into sandy soil. Sandwich panels of wood studs, plywood or cement board were fabricated offsite and formed the walls, roof, and floor framing (Pearson, 2007). A frame, reminiscent of temporary scaffolding, formed the base structure that accepted the craned in panels. The scaffold was composed of two element types: extruded aluminum sections with standardized profiles and basic connectors. A standard t-shaped groove in the aluminum sections was made to allow for standard joinery, but also allowed for the creation of specialized joinery by the architects, and the introduction of sliding doors along the section (Kieran and Timberlake, 2008). The off-site fabrication allowed for very quick construction - it was built in 6 weeks on site once the piles and collar beams were installed. The architects tried to make minor assemblies from entirely off-the shelf elements and components, such as kitchen cabinets, and a metal spiral stair, which meant they were more capable of reuse (Pearson, 2007). The 



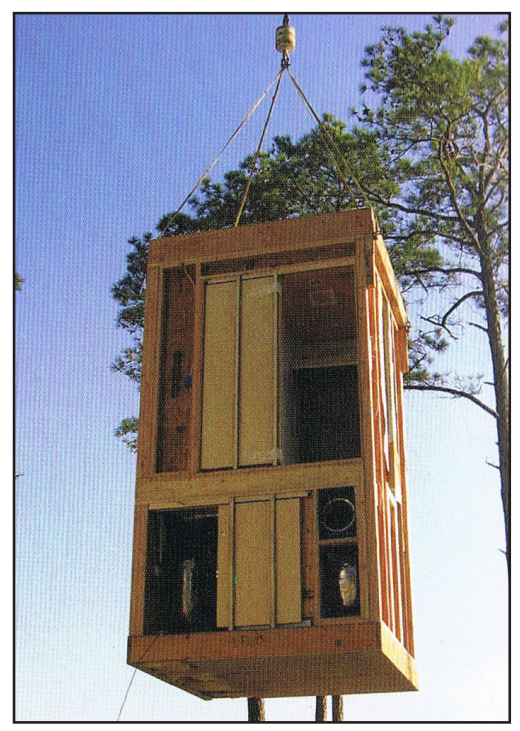

Fig 3.7.6 Washroom and mechanical prefabricated block standardized kitchen cabinets were not designed for disassembly once constructed. The designers avoided the layered systems approach by integrating radiant heating coils, structure, electrical conduits and ductwork into their pre-assembled floor panels. Plywood sandwiched structural joists and beams, mechanical, electrical, plumbing and insulation into one component (Kieran and Timberlake, 2008, p.84). This integration of systems meant that no layers could be amended and updated without having some impact on the others. Prefabricated wall, floor and roof sandwich assemblies appeared to be of traditional stud wall construction with permanent nail connections and inaccessible materials The cedar rain-screen, that attempted to unify the panelized assembly by wrapping around the living and bedroom volumes, was connected to its strapping with nails. It was built off-site and could have employed impermanent joinery techniques. The mechanical and electrical manifolds were built into the stud-wall bathroom blocks (Kieran and Timberlake, 2008). The fabricators avoided hot (and permanent) connections like soldering or fusing pipes, wires and ductworks - instead employing impermanent friction and clamp connections (Kieran and Timberlake, 2008, p.104)

Kieran and Timberlake's use of standard forms makes for easier reuse of components and dry connections make for easier disassembly. The building is only somewhat expressive of its assembly with some exposed structural scaffolding, cross bracing and fasteners. Interior finishes and exterior cladding are not visibly jointed and expressive of assembly and disassembly. The Loblolly House fails to achieve disassembly for material life cycle parameters when it favours speed assembly techniques, but it offers innovative ideas when it avoids permanent connections. 



\section{SMV Architects, Mountain Equipment Co-op Store, Burlington, Ontario, 2008}

Fig 3.7.7 Mountain Equipment Coop Store

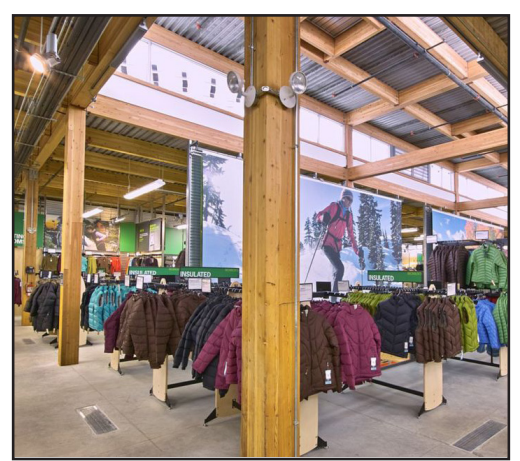

Fig 3.7.8 MEC Burlington interior

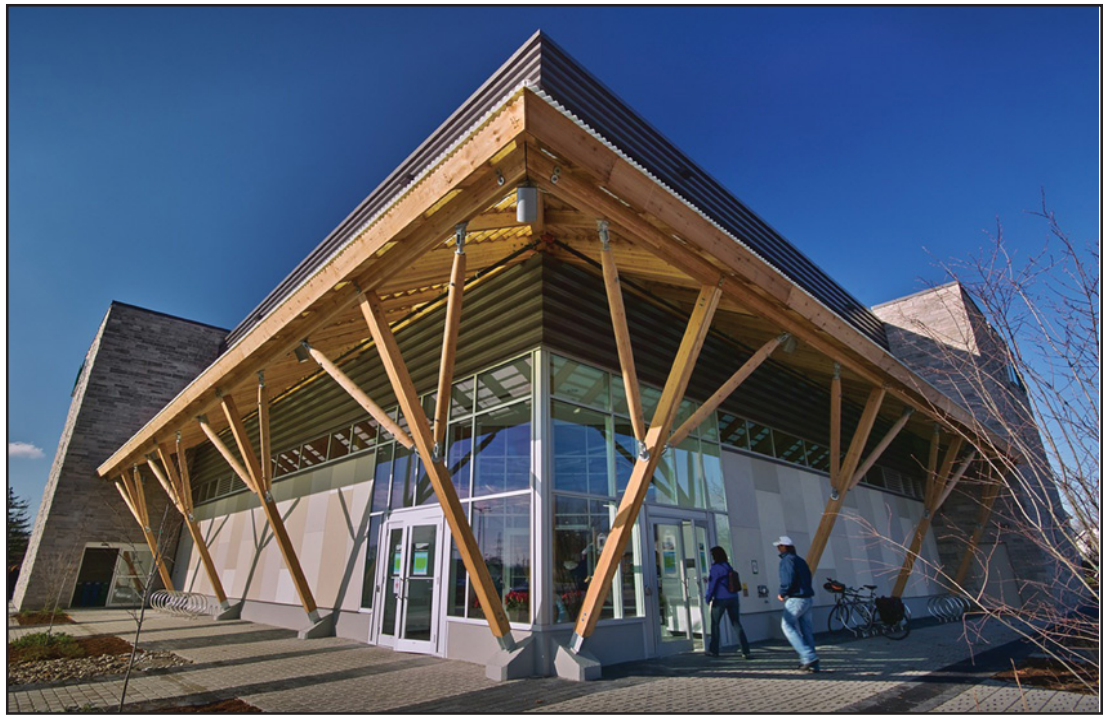

The architects claim to have designed the store for material recoverability after the life of the building is over. They chose to explore disassembly because of the short duration of stand-alone retail buildings, citing a lifespan of 25 years on average (Cowling, 2010). Dan Cowling, the partner in charge stated:

"Our efforts to apply sustainable design principles to an inherently unsustainable building typology can be seen as emblematic of the larger struggle to reinvent suburbia. Not all the problems can be solved at this moment in time, and our role as designers must in part be to help others implement more comprehensive solutions when the time is right (Cowling, 2010)."

The glulam structural frame, exterior metal panels, interior cement board panels and the base structurally-insulated panels are affixed with mechanical fasteners to speed removal and recovery (Cowling, 2010). To reduce material waste the building grid is laid out to accommodate standard widths of structurally insulated panels and cement fibre boards (Cowling, 2010). Wiring and piping is hung beneath the exposed structure in metal tracks, and lighting hangs from bolted connections in the metal decking above. Vents are built in to poured concrete floors, meaning that mechanical systems are inaccessible to updates. The efforts to design for disassembly are commendable, but limits of realization are apparent in permanent material and detail choices. Exterior rock 

cladding with mortar joints are difficult to disassemble and reuse. Poured concrete floors on metal deck are impossible to reuse and the composite assembly then limits recycling of the deck pan.

Using a bolted timber structure, avoiding interior finishes, and using standardized material sizes were effective means of addressing disassembly for material life cycle, but several cases of permanent connections limited the effectiveness of the project. 



\section{Design exploration}





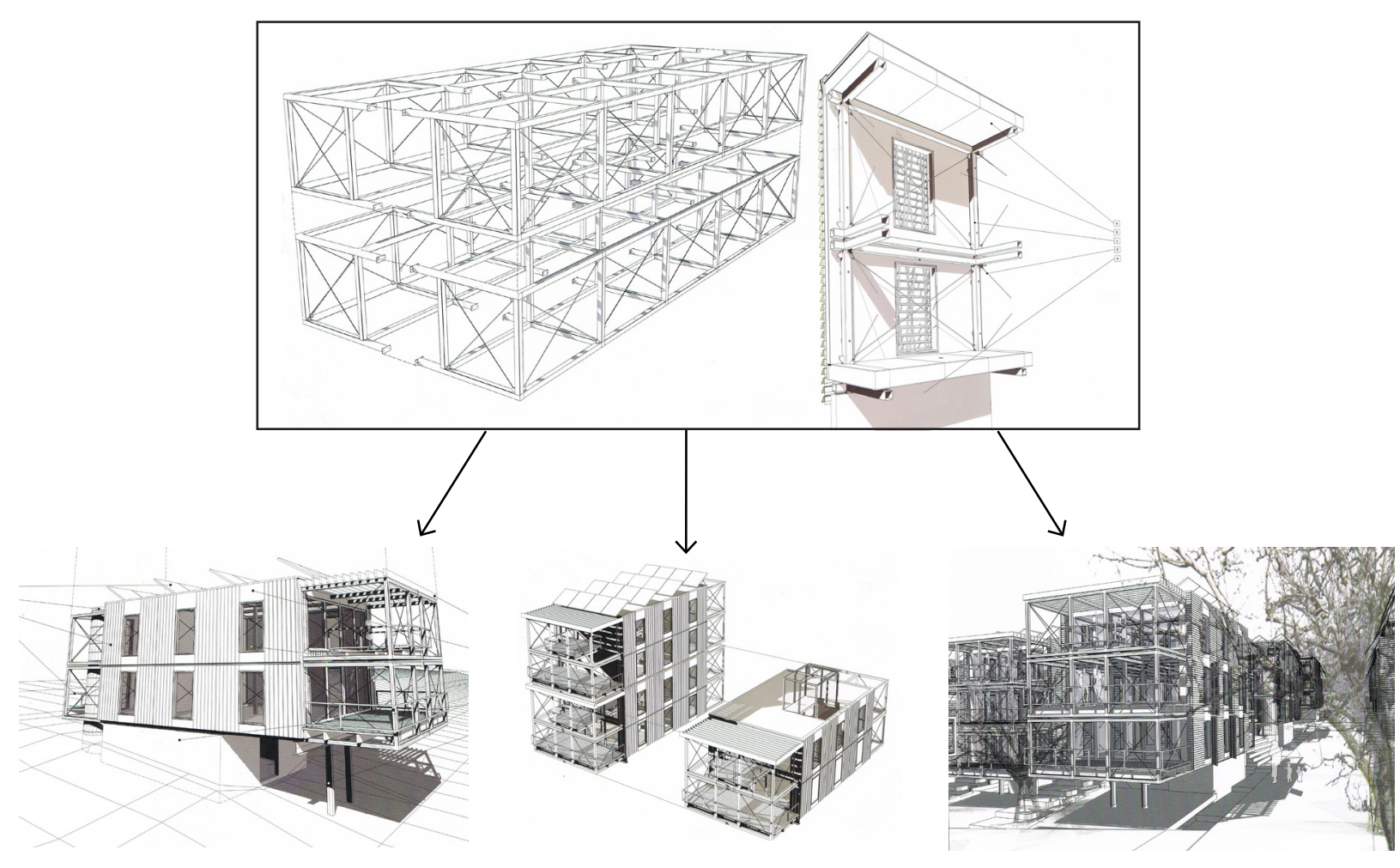

\subsection{System design proposal}

Fig 4.1 (Pages 67-68) worn plastic surface

Fig 4.1.1 Anderson \& Anderson, system design employed in various residential project scales
The project to explore the theories and practices of disassembly, and material life cycle will be a system of standardized building components that can be assembled and disassembled for reuse and recycling. Minimal programmatic distraction will allow for a focus on the intent of the thesis - the expression of disassembly in architecture, and the reduction of waste materials and components after the life of the building. The project will delve into detailed design of connections and material assembly, and will demonstrate the process of assembly, how it functions as a building, and how it can be taken down and the parts reused or recycled.

The building system will be developed for a generic commercial program and offer iterations of cladding, layout and finishes. Additionally, it would show how outdoor spaces, different cladding, shading, and energy collection systems could be added, and how the system could be adapted to form specific buildings in context. It will employ the layer- 

ing principle so parts can be updated without impacting more lasting assemblies. It will have accessible services, and show the avoidance of waste through material selection and standardized forms and dimensions. It will selectively employ customized components, and will look to prefabricated building processes to speed assembly and disassembly. The design would follow the principles of layering of assemblies, working with uncut standard forms, employing homogeneous materials instead of composites, using non-permanent connections, and using recyclable components when compelled to cut or customize. Since commercial buildings are likely to demand change before they have met the end of their technical lifecycle, it would be composed of reusable or recyclable materials. The built form would express the assemblage of pieces and joinery that allows materials to be separated. It would explore prefabrication of components and connectors to improve disassembly, and embellish visible mechanical joinery and the expression of assembly. It will demonstrate how cyclical material life and a disassembly system could produce superior material life cycle and a building system that allows for more efficient material use than traditional construction.

The building system is siteless, but through specific building iterations will demonstrate the ability to be employed at different sites and with distinct layouts. Unlike many architectural design approaches, a system design offers a more thorough study of assembly methods and materials. It is a technical approach to architectural design that incorporates elements of industrial design. The project maintains its status in the field of architecture, however, because each individual part of the system depends upon the whole for its significance. At the same time, the incorporation of an industrial design approach addresses facets of design that architecture typically minimizes, such as production and reusability. The added level of complexity is intended to create a functional building that adds economic, cultural, and social spaces to its community while performing in a greater material context. 



\subsection{Commercial agenda}

The commercial building is not the focus of my thesis, but to establish

a viable context, program, and scale of disassembly system the project

will require a predetermined stance on commercial developments.

"Commercial buildings have to adapt quickly, often radically, because of intense competitive pressure to perform, and they are subject to the rapid advances that occur in any industry. Most businesses either grow or fail. If they grow, they move; if they fail, they're gone. Turnover is a constant. Commercial buildings are forever metamorphic... (Brand, 1994, 7)"

\section{New design standards}

"[In the United States] the retail sector, with its involvement of many tenants and dependence on cars, has lagged behind other sectors in incorporating sustainable design... (Lee \& Moore, 2008, p.70)"

"In Europe, a region where high energy prices are taken for granted, designers, developers, and retailers have historically embraced energy savings as a cost-cutting strategy... the move away from the enclosed shopping mall and artificial climate control is a signature of European sustainable commercial design. Reduction of construction and demolition waste is also becoming a widely accepted goal on a crowded continent where hauling and disposal costs can reach the equivalent of thousands of dollars per truckload (Hoadley, 2008, 64)."

The BREEAM standards are a green design standard created in the United Kingdom in 1990 (Hoadley, 2008, 65). The first retail protocols were included in 2003, and they include construction waste parameters - such as quantifying the materials and energy utilized with new tenant renovations. The chain department store Marks \& Spencer - despite increasing its square footage by $20 \%$ between 2007 and 2012 - claimed that it would try for carbon neutrality and allow zero waste to be sent to landfills during the time frame (Hoadley, 2008).

Higher design standards will be demanded from developers creating commercial projects, and innovative practices have to emerge. A disassembly system of components would be an effective means to tackle 

material and energy use in construction, renovation and obsolescence.

\section{Suburban retail developments}

Fig 4.2.1 The concept of suburban retail

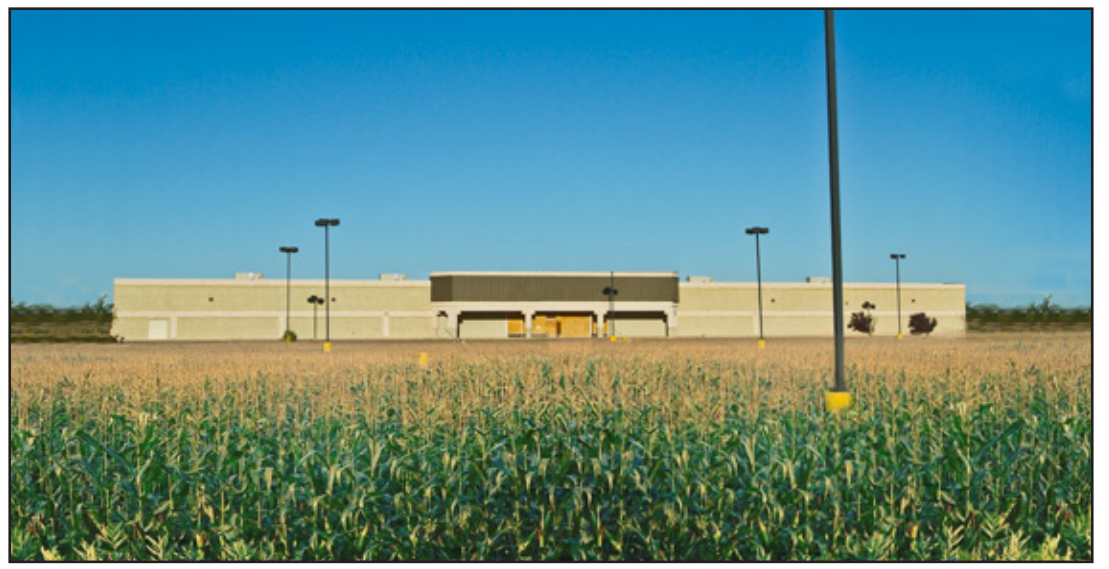

Advancing the design strategies for individual buildings cannot be independent from a greater planning strategy to reduce waste and encourage more sustainable planning.

David Platt, a Ryerson University Graduate claims in his thesis "Walkable Live/Work Neighourhoods in Big Box Greyfields," that "big box stores exhibit the worst tendency in our society to waste resources by building cheaper and less durable structures (Platt, 66)." Most stores are built with a technical lifespan of 15 years (Platt, 59). They utilize poor materials and assemblies. David Platt $(2009,61)$ interviewed a Toronto big box architect who claimed that "... it was not cost effective to reuse an older big box as they were too poorly built and... usually too big for most other uses." When the buildings obsolesce very little can be salvaged for reuse. A GTA demolition company that takes down half a dozen large grocery stores and a dozen malls and plazas every year claimed that they would recycle all possible materials, but "the lack of deconstruction design in [the] buildings prevented the recovery of useable components... (Platt, 65)“

The functional life of the big box store is generally shorter than 15 years for several reasons (Platt, 2009). Developers select sites anticipating an 

appreciation in value as population growth reaches the area. The store is then demolished and replaced with more profitable uses (Platt, 2009). Tenants also abandon the building when expansion requirements arise, and when the location is made redundant by "population shifts" or more convenient competing facilities (Killingsworth \& Farrow, 2007, 2). Abandoned big boxes are a particular issue in the United States. In 2007, Wal-Mart advertised for $21,000,000$ square feet of space for lease or sale (Killingsworth \& Farrow, 2007, 1). In "Adaptive reuse of large single-tenant retail facilities (Case study)," authors Killingsworth and Farrow (2007) claim that very little successful adaptation of this building type has been possible. Author of "Big Box Reuse," Julia Christensen (2008) claims that adaptation is difficult due to the excessive size, lack of pedestrian access, lack of natural light penetration, and permanent construction

The concept of suburban commercial plazas is itself an issue. Valuable agricultural land is lost when retailers support suburban sprawl. Ontario contains more than one half of Canada's most productive farmland, but the Greater Toronto Area has been consistently ceding that land to development. 150,000 acres of farmland were relinquished between 1976 and 1996, followed by 600,000 acres between 1996 and 2006 (Ontario Farmland Trust, 2012). Diminished local food production can lead to greater reliance on food with more extensive transport, and thus higher embodied energy. Suburban retail developments also depend upon customers with personal transit, instead of the more lauded energyreductive alternatives of cycling, walking and public transit:

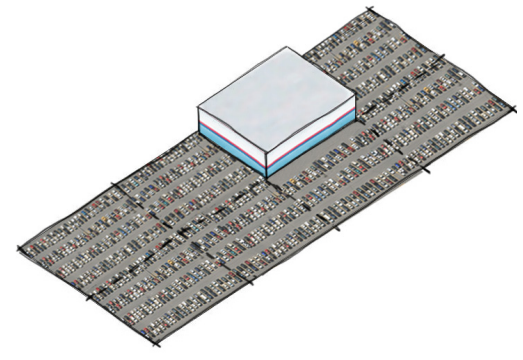

Fig 4.2.2 Suburban retail parking
"They have parking lots four to seven times the size of the store footprint with direct access to main arteries (Killingsworth \& Farrow, 2007)."

The business practices of some big box retailers are also worth scrutinizing. Although "Wal-Mart is leading the way to LEED in retail" for the design of their individual buildings conscious planners and citizens 

have become wise to energy-inefficient procedures (Kirck, 2006, 74).

"Wal-Mart's strategy has effectively closed many smaller Main Street retailers in surrounding towns, their strip malls and other big box competitors. They then close their first big box after a larger regional one is built. This forces consumers to drive even farther which has transferred distribution costs off Wal-Mart books to their customers. Another abandoned big box is also created in the process which is why Wal-Mart has so many of them (Platt, 2009, 24)."

The reduction of waste and efficient use of energy and materials must extend to planning and development strategies. Inaccessible and excessively large commercial buildings can no longer be tolerated.

\section{Commercial project intentions}

Commercial developments cannot be placed beyond the reach of pedestrians and transit. Planners are developing downtown department stores, retail main streets and walkable neighbourhood centres. "Compact urban development" reduces miles of vehicular use by 20 to $40 \%$ (Paull, 2008, 3). Infill and brownfield developments are energy-saving approaches. A 2001 study found that an acre of brownfield redeveloped was equal to approximately 4.5 acres of greenfield developed (Paull, $2008,9)$. Urban infill projects utilize the knowledge that there are savings in the order of $25 \%$ on infrastructure maintenance and construction for urban versus suburban projects (Paull, 2008, 3).

For the purpose of this design exploration, the size of commercial buildings would be dictated by the urban site dimensions and zoning, while secondary internal divisions would adapt to permit various tenant types, whether small retailers or large grocery stores. The disassembly system will employ the efficiency of modular components. There will be a minimum floor plate for small retail and sites, and the opportunity for added modules on larger sites, to increase floor area and height.

The commercial container can be used by a variety of tenants rather 

Fig 4.2.3 Concept for commercial infill in vacant urban land or atop existing outdoor parking lots (includes opposite page)

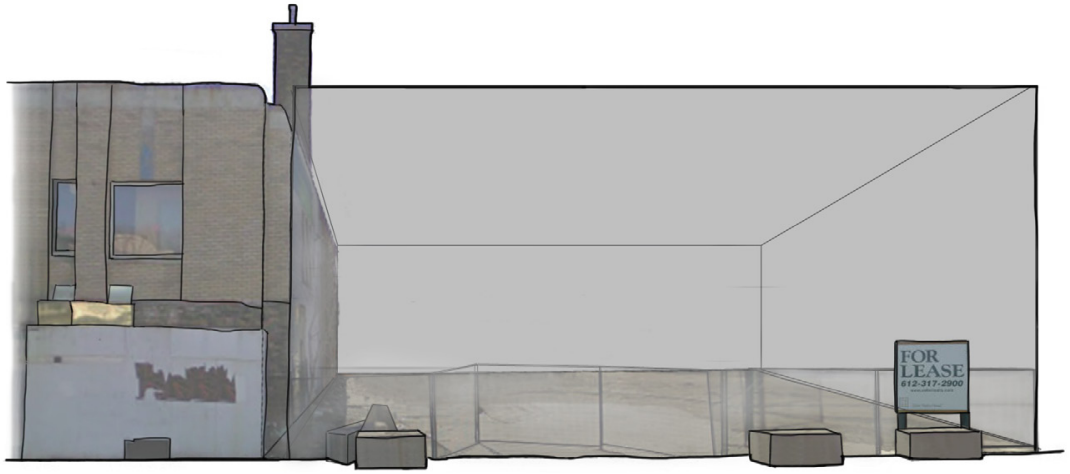

than be overly specific and risk obsolescence. Independent tenants can personalize with merchandise and furnishings. Generic commercial buildings may not be high-design, but nor do they have to be poor quality boxes. 19th and 20th century warehouses are adopted as housing for commercial, residential and office applications because of their high quality, flexible, and durable designs.

"They are broad, raw space-clear-spanned or widely columned, with good natural illumination and ventilation and high ceilings of 12 to 18 feet. The floors, built strong enough for storage or to hold heavy machinery, can handle any new use. Their heavy timbers and exposed brick appeal to the modern eye... [they] are honest, generic, sound, and common (Brand, 1994, 108)."

Franchises and chains propagating template buildings and developers of multiple commercial sites could implement a system with superior design and materials allowing for adaption and reuse in new locations, instead of disposal.

A disassembly building system would allow a new business model where commercial buildings could occupy temporarily vacant lots or low-density urban parking lots while leasing to retailers for previously untapped revenue. Durable design would allow for temporary but potentially long-lasting construction, so the retailer could stay for as long as necessary, until a new use is slated for the site. The building would then be taken apart into components, returned to the factory for repair and reconfiguration and then moved to the next vacant urban site for reassembly. The commercial program could be used to satisfy resident needs and desires, while disassembly principles would allow for flex- 



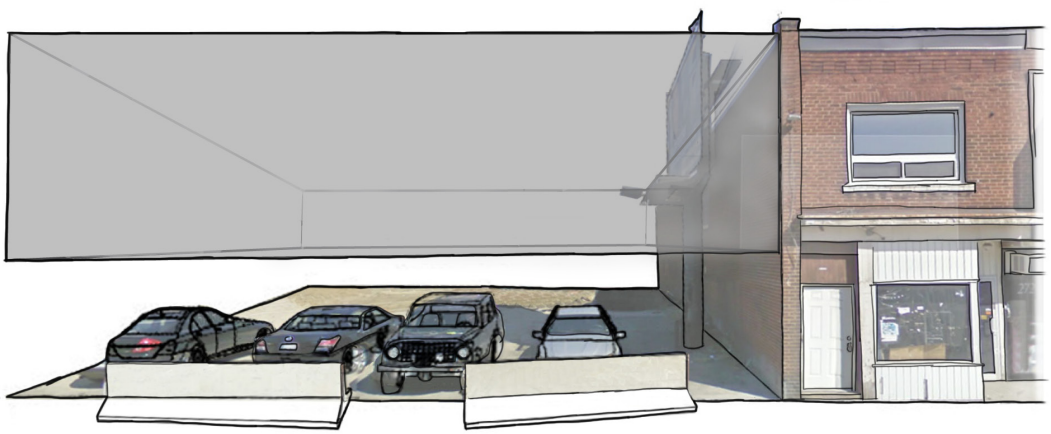

ible commercial inhabitation while making use of vacant lots and declaring new urban space. 



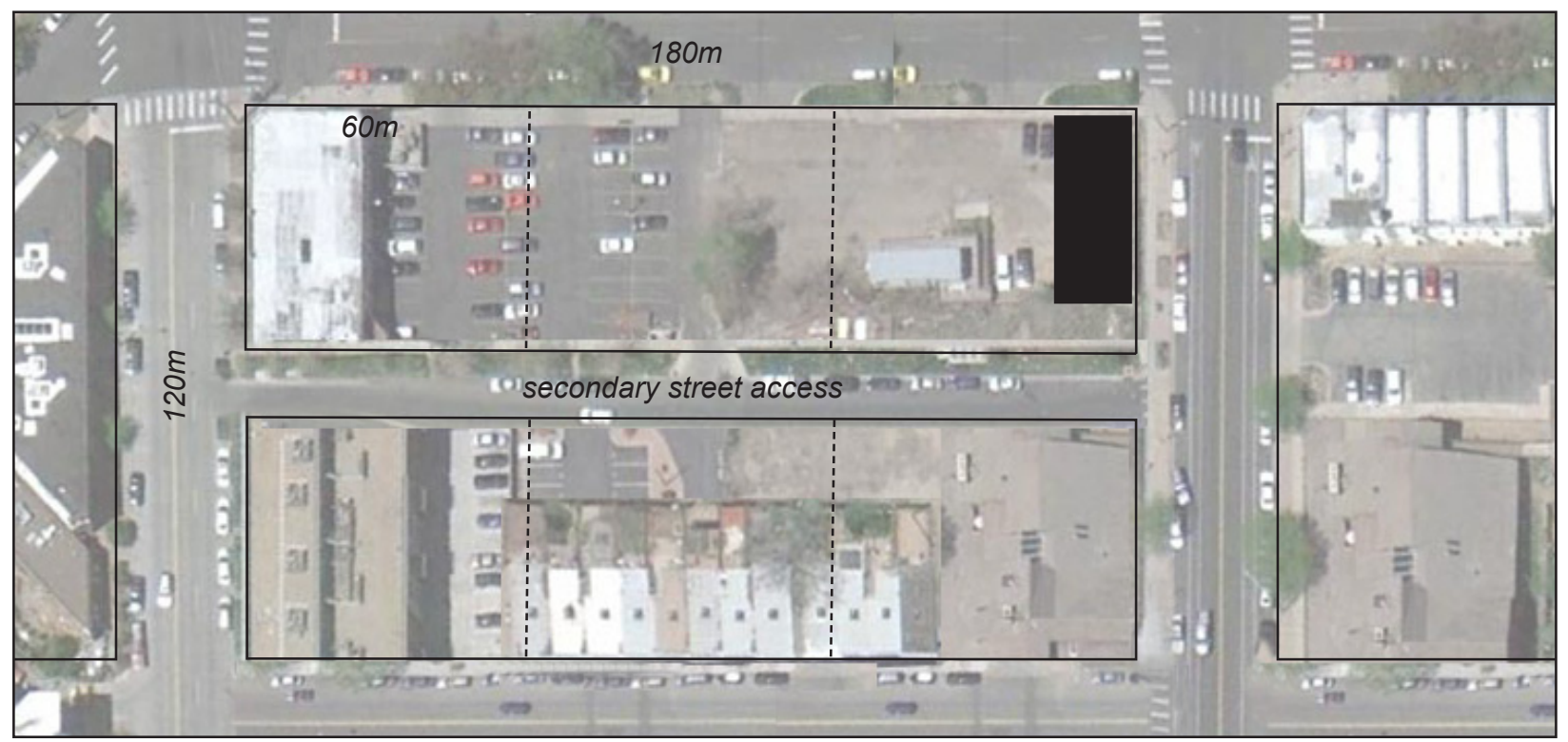

\subsection{System design}

Fig 4.3.1 Toronto urban block size with optimum urban lot in black

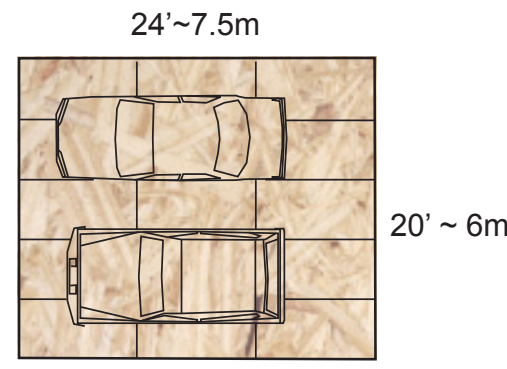

Fig 4.3.2 Bay dimensions with building panels, overlayed with car parking
The scale of the building system is driven by the efficient use of 4' $x 8^{\prime}$ building panels, and made to fit within standard block and lot sizes for urban land in Toronto (Siksna, 1996). In Arnis Siksna's (1996) paper "The effects of block size and form in North American and Australian city centres," optimum urban lots are said to be 15 to 20 metres wide and 30 to 40 metres long. They are appropriate for small scale building forms and can be amalgamated to create square lots to build medium size buildings. This lot size is appropriate for Toronto's existing grid system divisions since it follows the allotment for secondary street access within major blocks. Toronto has many narrow commercial buildings on main streets that appear to range between 5 and 10 metres wide. The system module bay comes to $20^{\prime} \times 24^{\prime}$ so that it fits within a 7.5 meter wide narrow lot and can add up to an ideal $15 \mathrm{~m}$ width of two bays. It also functions as a structural bay for parking lot stalls should the system be implemented to infill the air space above an existing urban outdoor parking lot.

The individual layers of the system are described in detail over the following pages. 



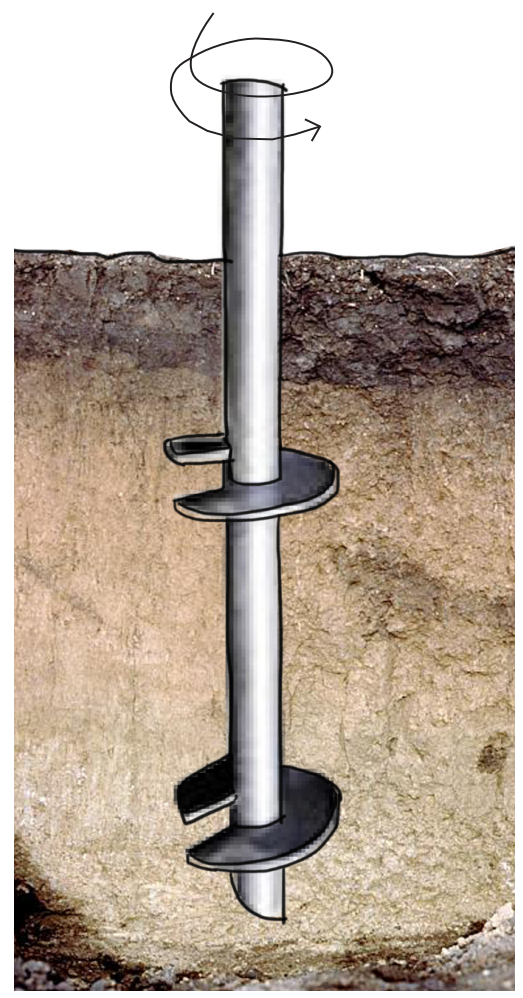

Fig 4.3.3 Screw pile as a mechanical and reversible foundation

\section{Site}

Connections to the site are difficult to create impermanently, but there are several options for the base of a potentially impermanent commercial building. Pre-cast concrete blocks are used often as the platform for small modular projects (Triumph Modular, 2012). They have the appearance of impermanence and require repositioning over time as the earth shifts. The precedent section 3.5 Portable and temporary structures showed the use of platforms sitting directly on the site for several impermanent projects. Frames on the earth can decay from moisture penetration in certain materials, so are not ideal for use in a project that could potentially last and otherwise intends to continue reusing materials. Both blocks and platforms would demand a somewhat level site since they do not penetrate the earth surface, but they usually have the benefit of little site preparation. Screw piles offer significant advantages to the aforesaid options. The standardized steel forms function like screws penetrating the soil. They are rapidly installed compared to traditional foundations that demand time for concrete to cure - one installer claims that you can drill them in the morning and begin to build in the afternoon (techno Metal Post, 2012). Screw piles cause minimal disturbance to the soil, so they can be used on sites where there is risk of contamination. The quick installation is also beneficial where they can again be removed like screws at obsolescence and taken to a new site for reuse. They are lightweight compared to prefabricated concrete blocks and offer more flexibility in terms of acceptable site conditions. The increased stability over platform or blocks means there is potential for a long lasting built form. 



\section{Structure}

The building structure is a typically long lasting layer that should be formed of either recyclable or durable materials, because it will have a long functional life to mirror a long technical life. Since it is a layer requiring little manipulation and updates over time, it can employ custom and expressive joinery. On the lower floor level a combination timber and steel structure would have a rich material character, and be durable and reusable in standard forms. The roof level employs lightweight steel

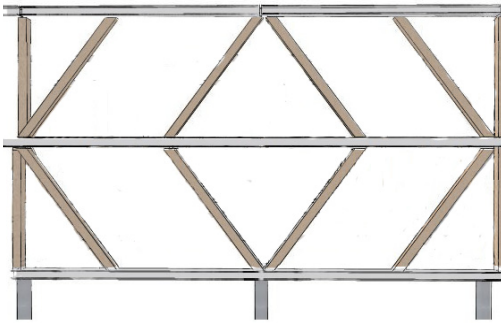

Fig 4.3.4 Timber cross-bracing at the building perimeter

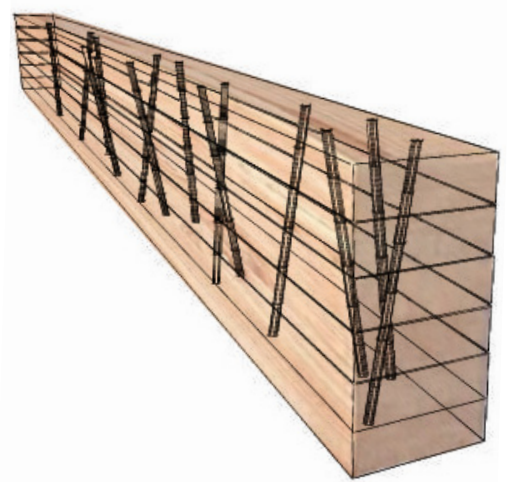

Fig 4.3.5 Timber beam held together with nonaligned dowels joists and columns since it carries less load. The post and beam systems utilize less material than load bearing walls, can be left exposed, and are transportable by individual member and assembly. Angled posts and columns become both load bearing and lateral-load bearing members. Canted posts would act as the perimeter supports, while the internal posts would be un-canted to allow for flexible layouts and movement in the floor plan.

Timber can offer significant spans and can be left exposed. To avoid adhesives and maintain the organic wood composition, "laminated" timber can be created from penetrating stacked dimensional lumber with wooden dowels at alternating angles. This technique of creating timber allows the wood to ultimately be recycled, energy recycled or decompose naturally. In "The Ecology of Building Materials," reuse and recycling can extend the functional life of pine from 75 to 350 years (Berge, 2009).

Steel is an essential structural material for its lightweight strength, standardized dimensions, and recyclability. It can be composed of entirely recycled content - in 2010, the Steel Recycling Institute (2011) in the United States claimed that the recycling rate for structural steel was $98 \%$. It is a natural choice for impermanent and custom structures since it can be returned to the factory for recycling when its life is complete instead of the landfill, thus eliminating the need to harvest more iron ore 

from the earth. Durable steel connections would stand out visually from the timber structure, and withstand repeated assembly and disassembly to allow for adaptation and for the reuse of timber and steel. The steel could be left exposed and given a fire rating of 3 hours with a coating of intumescent paint (Krytiuk Specialty Contracting Inc., 2012). The paint is durable and easily repaired, and would allow for continued reuse and disassembly, since it does not affect access to steel members and connectors.
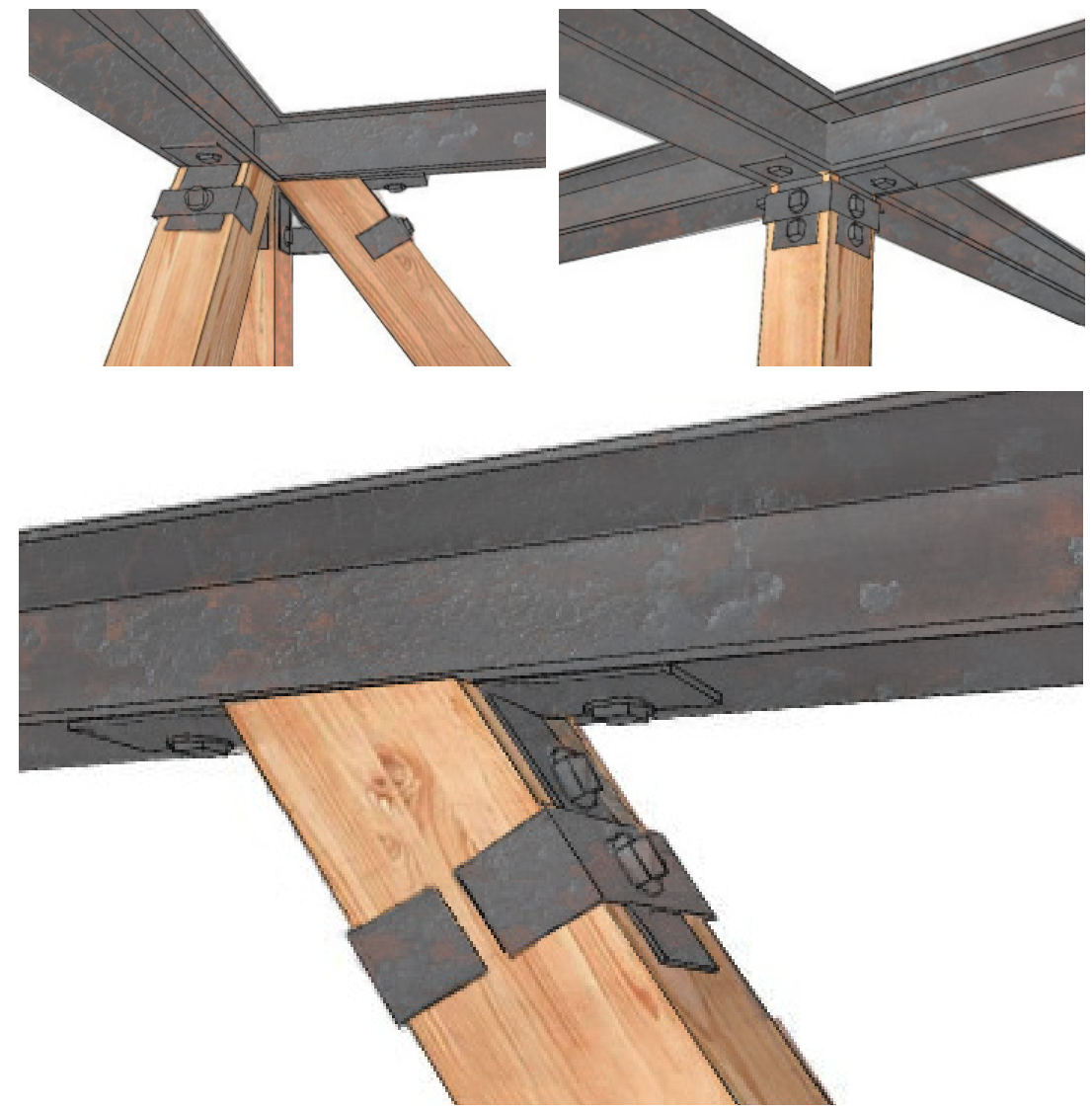

Fig 4.3.6 Exposed metal joinery

The visible joinery throughout the project could become that of folded steel ribbons, bolted to connect standardized uncut materials - and be implemented in furnishings and finishes to create a common language. Simple and often oversized joints would minimize the number of fasteners and connectors to increase the speed of disassembly. The durability of steel would ensure a continued ability to reuse the custom forms, but also recycle them when the system obsolesces or is damaged. 



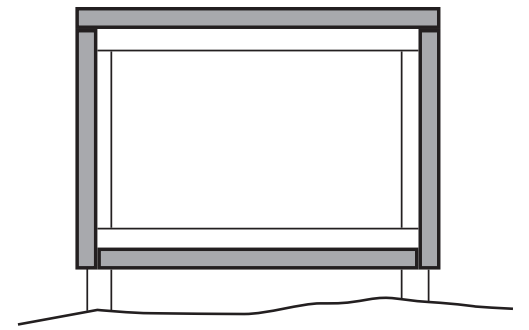

Fig 4.3.7 Skin location on the outside of the structure

\section{Skin}

The system will take advantage of the benefits associated with a panelized building enclosure, including roof, walls and under-floor panels. Structurally insulated panels (SIPs) are typically laminated layers of OSB or plywood adhered to a rigid insulating layer, but have been built with material variations. Their quick assembly on site can immediately provide a finish surface on the interior, the air barrier and high levels of insulation for the building (Anderson \& Anderson, 2007). They are ideal for low-pitch or flat roof buildings because they do not have trapped air spaces that need ventilation (Anderson \& Anderson, 2007). Standardization and prefabrication make them an inexpensive option. They can be preassembled into lengths up to 24 feet at 4 or 8 feet wide with standard panel dimensions (Anderson \& Anderson, 2007). When SIPs are not used for their structural properties as walls and roofs, they require only light connectors to align them.

Standard SIP construction is not, however, appropriate for disassembly. In addition to using adhesives to form the panel, they are also typically used to assemble panels into an entire wall, floor or roof system (University of Virginia, 2012). Assembling with adhesives removes the option of disassembly and reuse of the materials. It is unlikely undamaged materials will be salvaged from breaking the strong chemical bonds, so mechanical connections are preferable for reuse (University of Virginia, 2012). Additionally, the common elements of SIP construction, EPS and OSB, are not readily recycled due to their chemical compositions (University of Virginia, 2012). Recyclable and non-toxic alternatives would be substituted. All panels in the system would be based upon standard $4 \times 8$ foot dimensions and mechanically fastened together off-site into larger arrangements based upon the building dimensions. Material layer compositions and fastenings will differ based on the panel location in the building, whether roof, wall or subfloor. The panel assemblies are designed to be reused in their entirety or broken down into their individual 

elements for reuse or recycling.

The roof panel is composed of an exterior layer of durable corrugated metal roofing backed by building paper and several layers of compressed agricultural fiberboard - which act as both sheathing and insulation for a total of R20. The agricultural fiberboard is a fully recyclable and biodegradable material. The waste fibers from harvesting wheat grains are compressed at high temperatures until they release their own natural binding resin, and are then formed into standard-sized panels (NAHB Research Center, 2001). The panels can be made up to 4 inches thick, after which the natural resin is not enough to hold the fibers together and additional adhesives are required. Manufacturers have improvised by creating thicker panels by layering several boards atop one another (U.S Department of Energy, 2011). In the roof SIP, adjacent panels overlap and slot together like puzzle pieces, thus avoiding thermal bridging and water penetration. Panels are fastened together mechanically with bolts, and are assisted structurally by secondary supports of roof and floor joists. The roof is sloped gently to allow precipitants to drain and be collected.

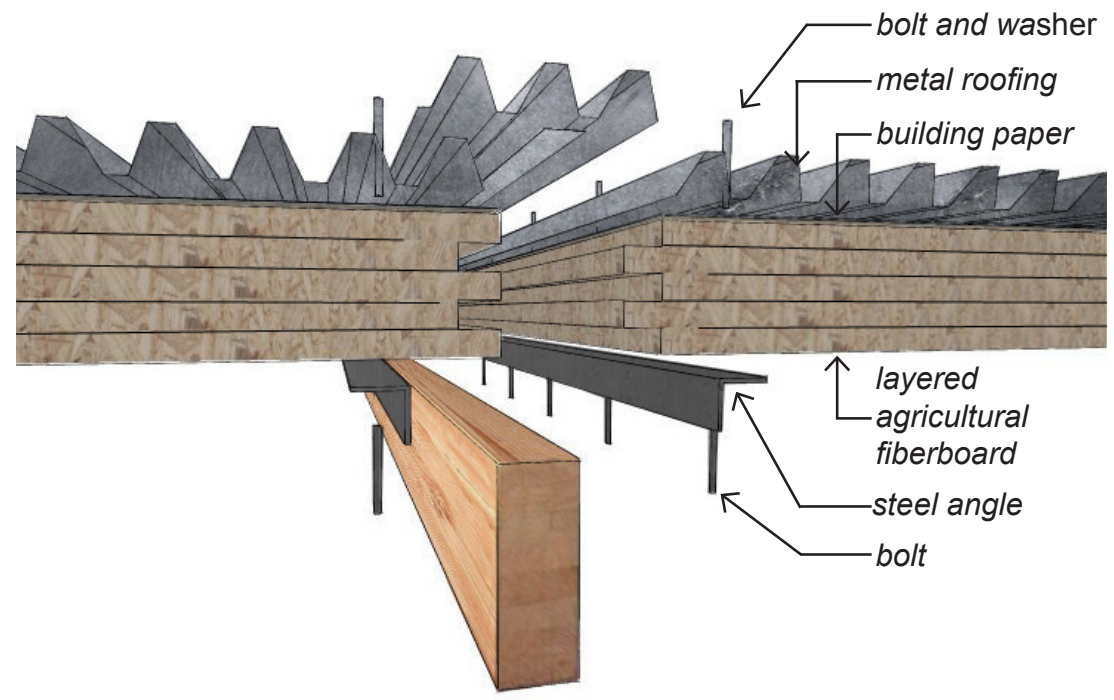

Fig 4.3.8 Roof panel prefabricated assembly
Wall panels are similarly constructed to roof panels. Layers of agricultural fiberboard intersect in a tongue and groove fashion for thermal continuity. Lengths of several panels are bolted together off-site to cre- 

ate 20 or 24 foot long sections, depending on the bay orientation, and fixed with exterior building paper and exterior finish to reduce on-site labour. On site, folded metal connections would hold the panels to structural beams. The sections would be connected together and the seams tightened with folded metal strips bolted in place. The exterior seams between adjacent panel modules would be taped atop the building paper to prevent air and moisture penetration, and a final folded metal reveal would fill the space where finishes were held back to allow the joint to be taped at installation. Exterior finishes can vary but are limited to the panel dimensions. Selections can be more impermanent because of the higher occurrence of damage and decay with repeated exposure to the elements. Wood rainscreen is shown in the image below for its durability and ultimate recycling, because it would likely fail technically before it fails functionally.

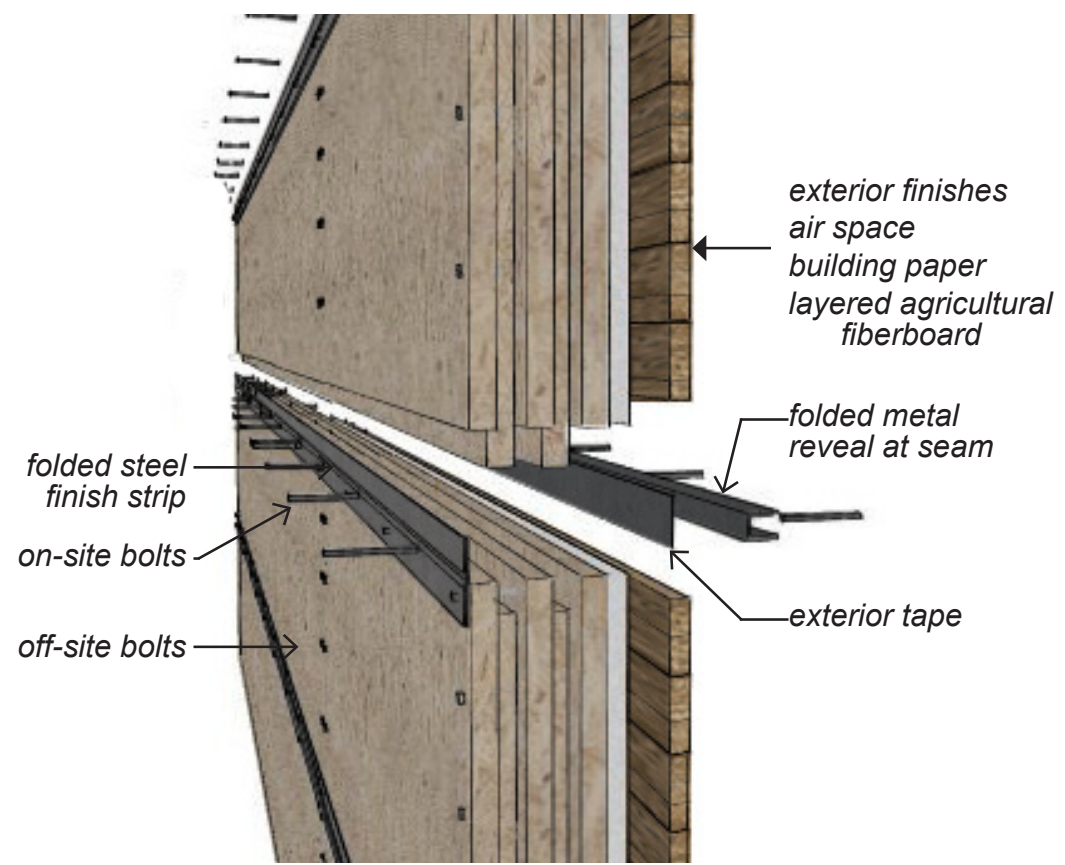

Fig 4.3.9 SIP wall section

The glazing component of the building system will be a custom, unitized curtain wall system. It will be assembled in factory and shipped to site as large units, for more reliable seals and assembly, less labour on-site, and quicker installation (National Institute of Building Sciences, 2012). Unitized curtain walls tend to have more robust dimensions than stickbuilt, which ensures they are capable of travel between sites for reuse. 

The vertical mullions would anchor to beams at the floor edge, and gaskets seal between adjacent units. The market for curtain wall mullion reuse is currently greater with aluminum than steel. Service life is expected to be 10-15 years, in which case they can be removed and replaced, in order to be re-anodized and sealed in the factory (National Institute of Building Sciences, 2012). Glazing panels would be standardized to match the dimensions of wall panels, so that solid and glazing could be interchangeable depending upon the desire for natural light and view. Glazing panels would have customized metal frames to slot into SIP tongue and groove connections.

Underfloor panels are composed of the same mechanically-fastened and layered agricultural fiberboard assembly. They would be maneuvered into the channel of steel i-beam supports by crane. Once timber joists are in place above, the panels would be bolted to them with the use of steel connectors. The panels would be protected from moisture and damage on the exposed underside with building paper and exterior finish material in the same manner as the wall panels.

Fig 4.3.10 Floor panel connection

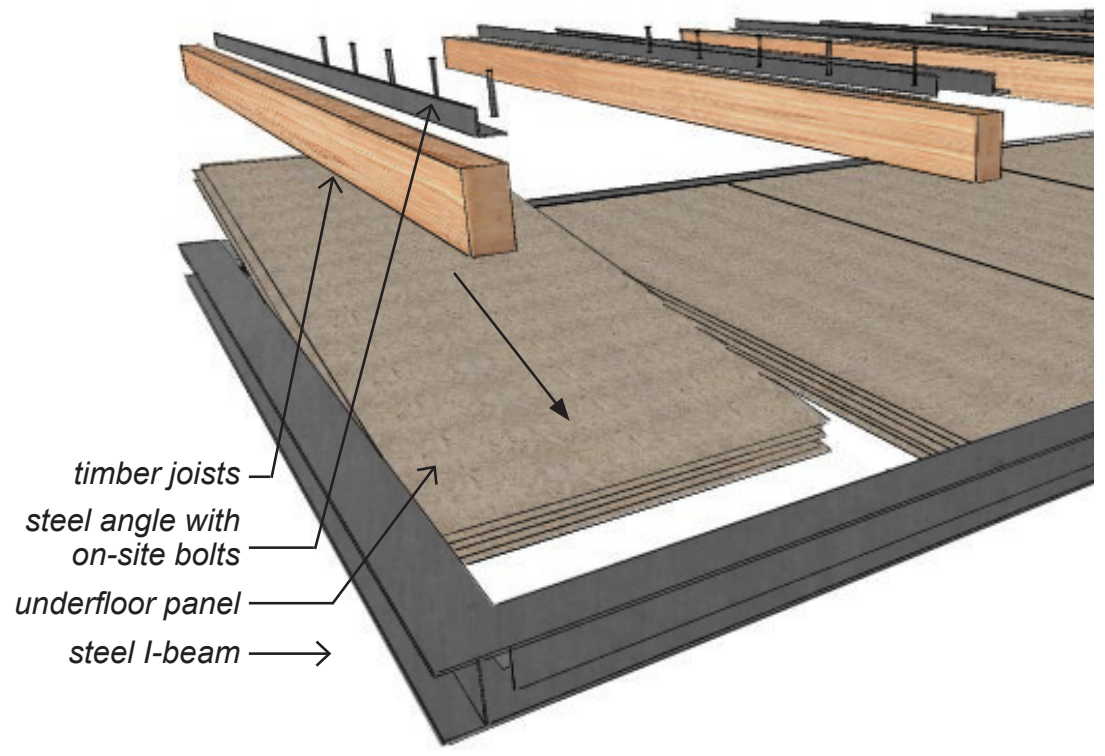
perspective 



\section{Services}

Volumetric prefab components would serve as vertical circulation and access to site services. A washroom core extends insulated space below to grade to connect to water, hydro and waste, and becomes washroom pods within the building. A vertical circulation core reminiscent of a temporary elevator wrapped by a staircase would be assembled from a few pieces on site and encompass an entire structural bay. It does not require a machine room, hoistway, or overhead load but simply uses its own weight resting on the ground as ballast (GEDA USA, 2012). Steel frames with bolted panel finishes create simple prefab volumes.
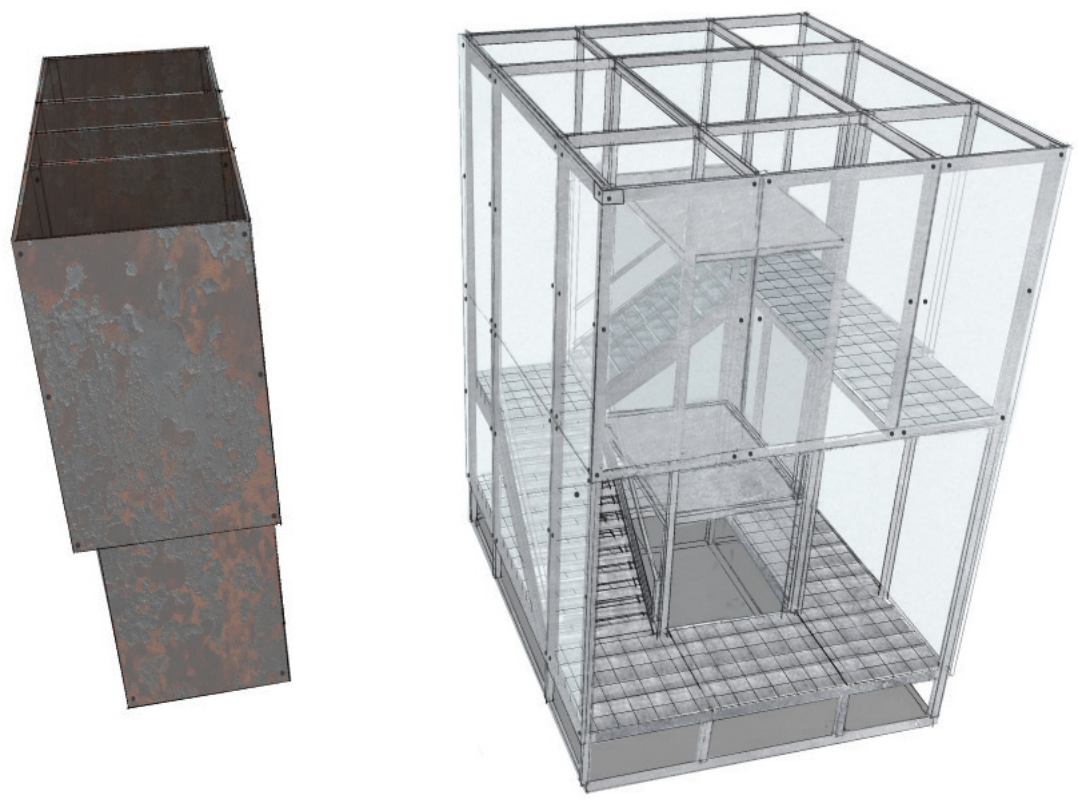

Fig 4.3.11 The service-washroom core and circulation core

On each level services run alongside the length of the structure at both floor and ceiling level. Services, such as electrical, plumbing and HVAC would be located in a raised floor system and run in between the joists to provide floor level electrical outlets and diffusers at interchangeable locations. Exposed lighting tracks would run alongside beams at ceiling level for easy accessibility. 

Fig 4.3.12 Service plenum layout perspective

Fig 4.3.13 An exterior planter and shelving with folded metal connections bolted to standard timber lengths

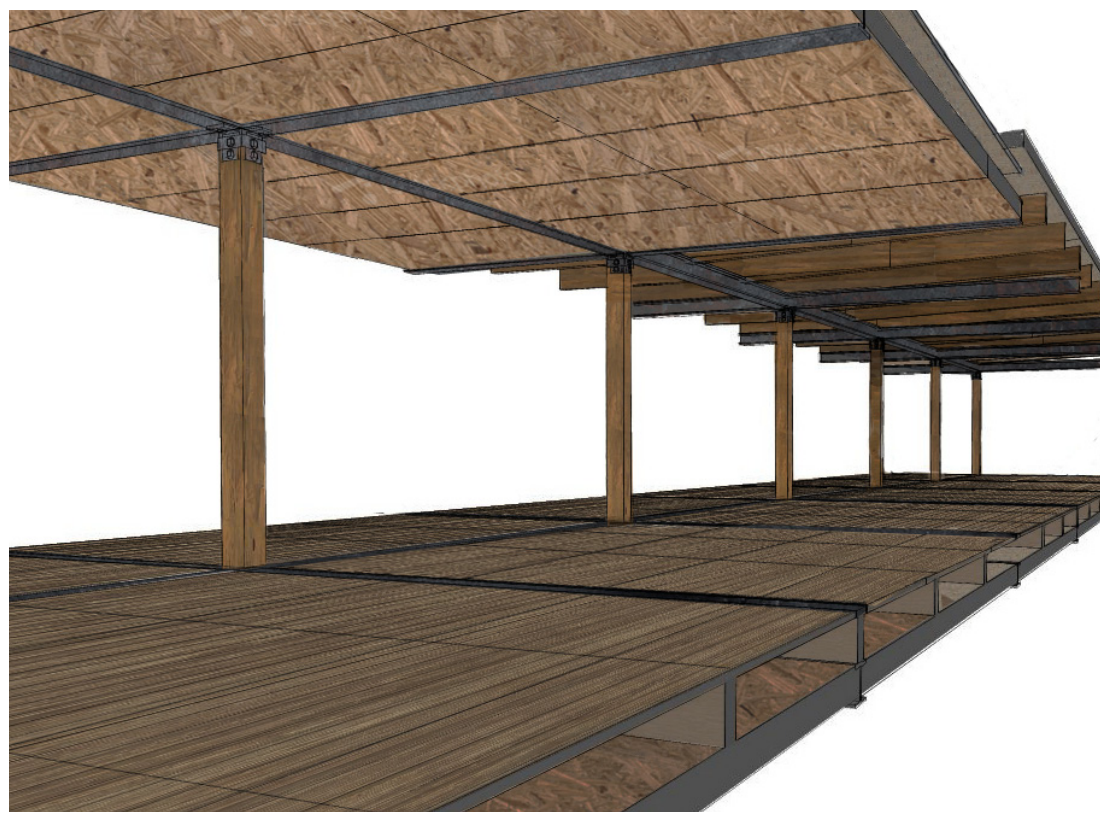

\section{Furnishings}

Standardized furnishings would incorporate disassembly to be easily transported to new sites or replaced if one type of commercial were unsuccessful. They would be constructed of reusable or recyclable components so that at obsolescence they are not discarded. Shown are an exterior planter and shelving examples with folded metal connections bolted to standard timber lengths.

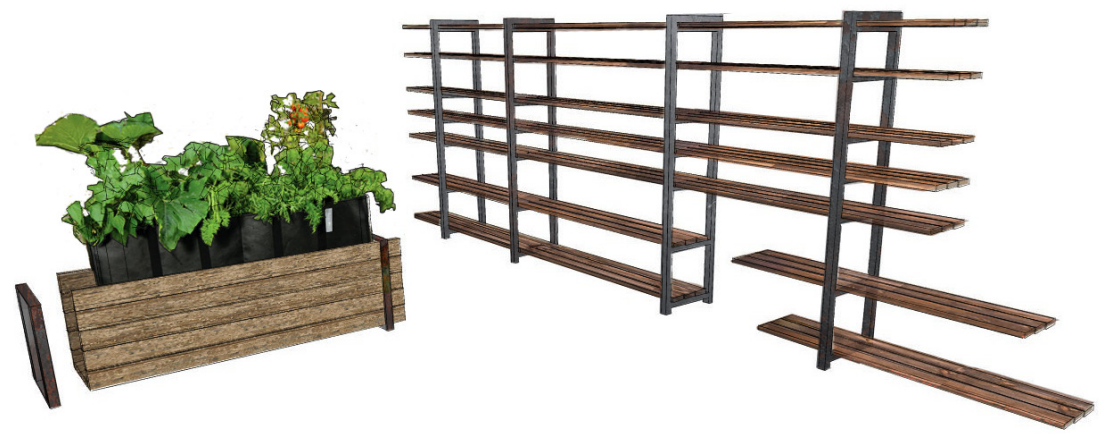

This category also includes canopies, exterior stairs and ramps that work at a smaller scale to customize the site iteration. Where site situation allows, standardized and self-contained planters and solar panels could take advantage of open, sunny spaces to create energy and grow plants for sale or use. 


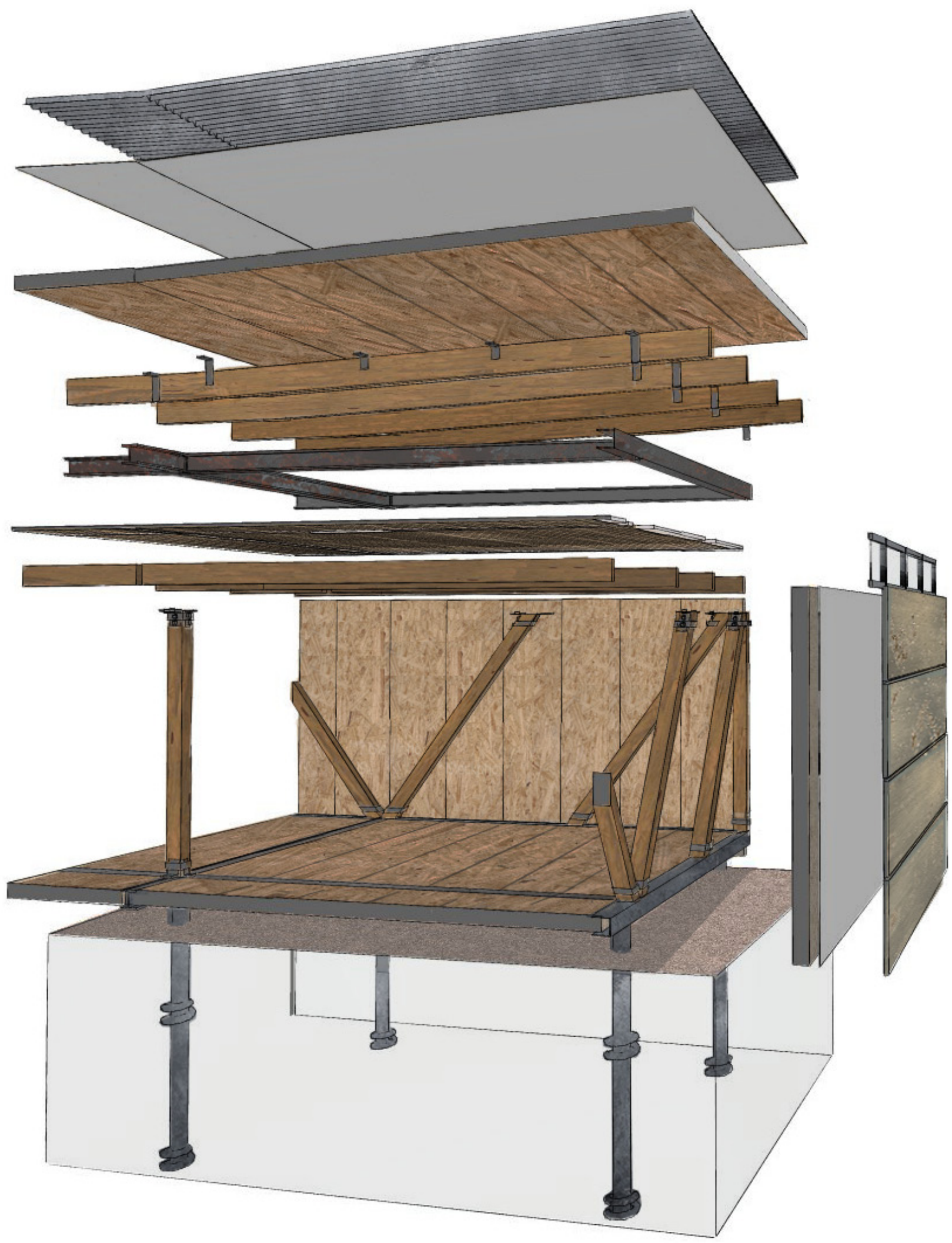




\section{Systemized disassembly}

When the building iteration obsolesces all parts can be reused in a new building layout - but when a specific component obsoleses it can be resolved into its industrial or natural nutrients for recycling. The materials are divided into biological and industrial categories. Components are selected for durability in the hope that they be reused after the building obsolesces. However, if damaged or worn, biological and industrial components can both be recycled into their respective nutrient cycles.

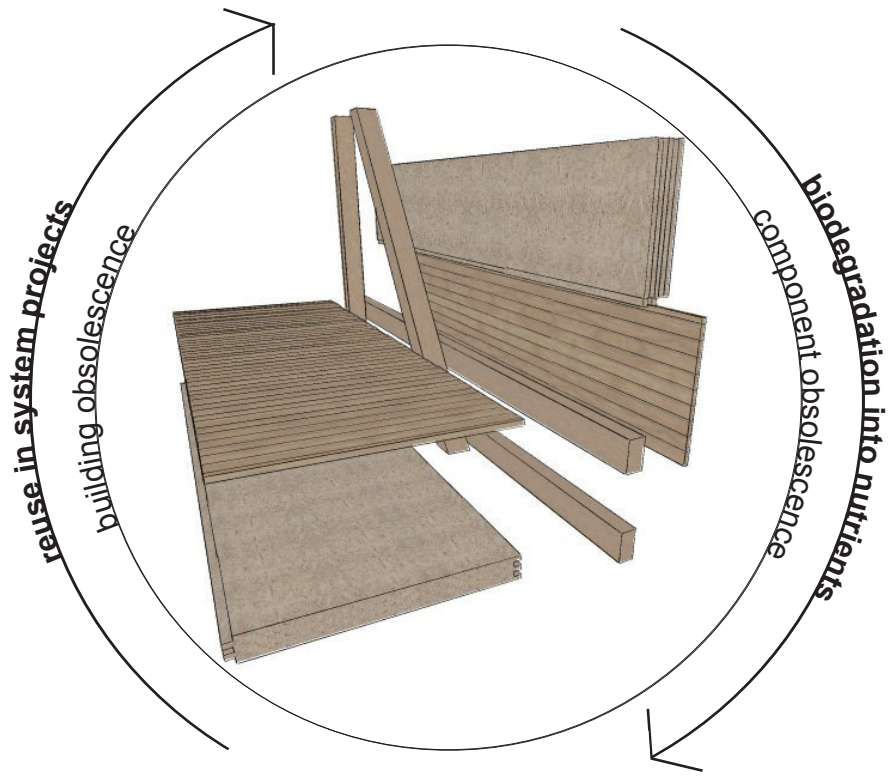

Fig 4.3.14 (Opposite) An example of a bay assembly using the system Fig 4.3.15 The process cycles at building or component obsolescence

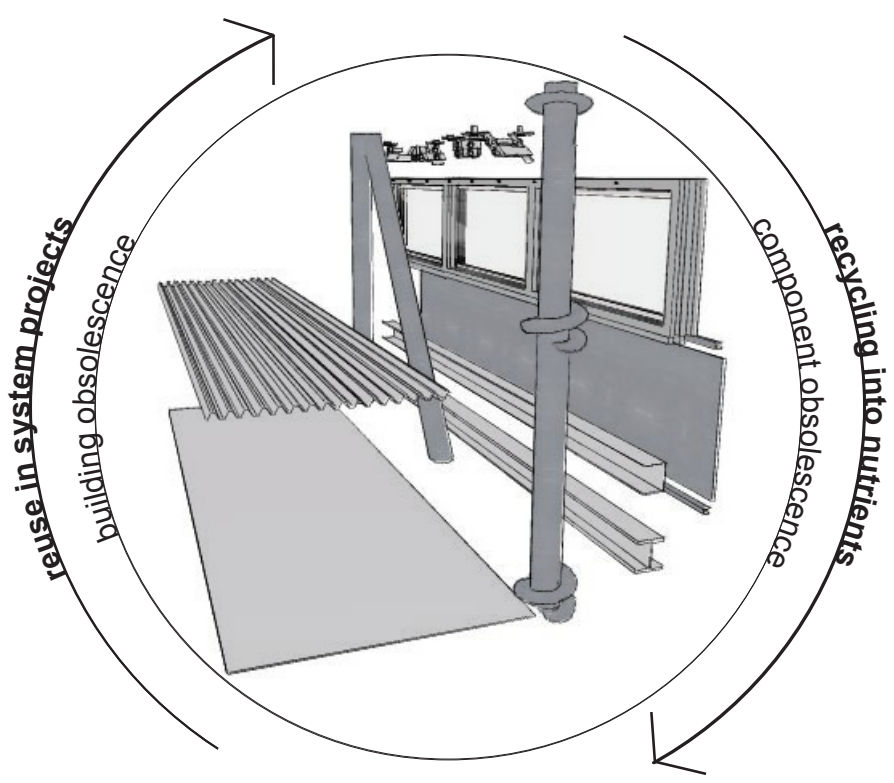



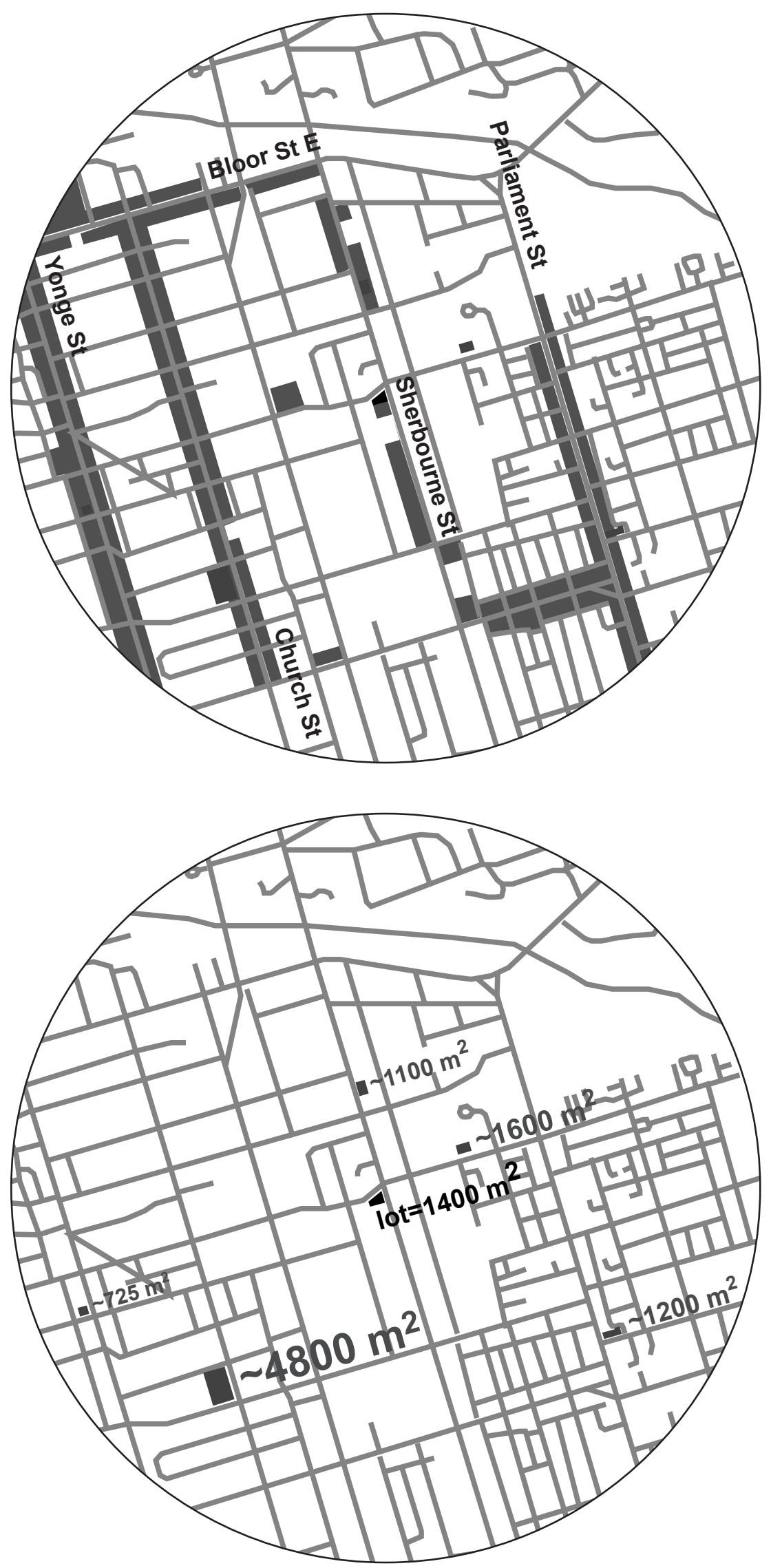

166 


\subsection{Site specific design}

Since the system can be used for various commercial building iterations and sites, with different combinations of components, specific examples are necessary to demonstrate the level of specificity that can be achieved in context.

\section{Wellesley St E and Sherbourne St site}

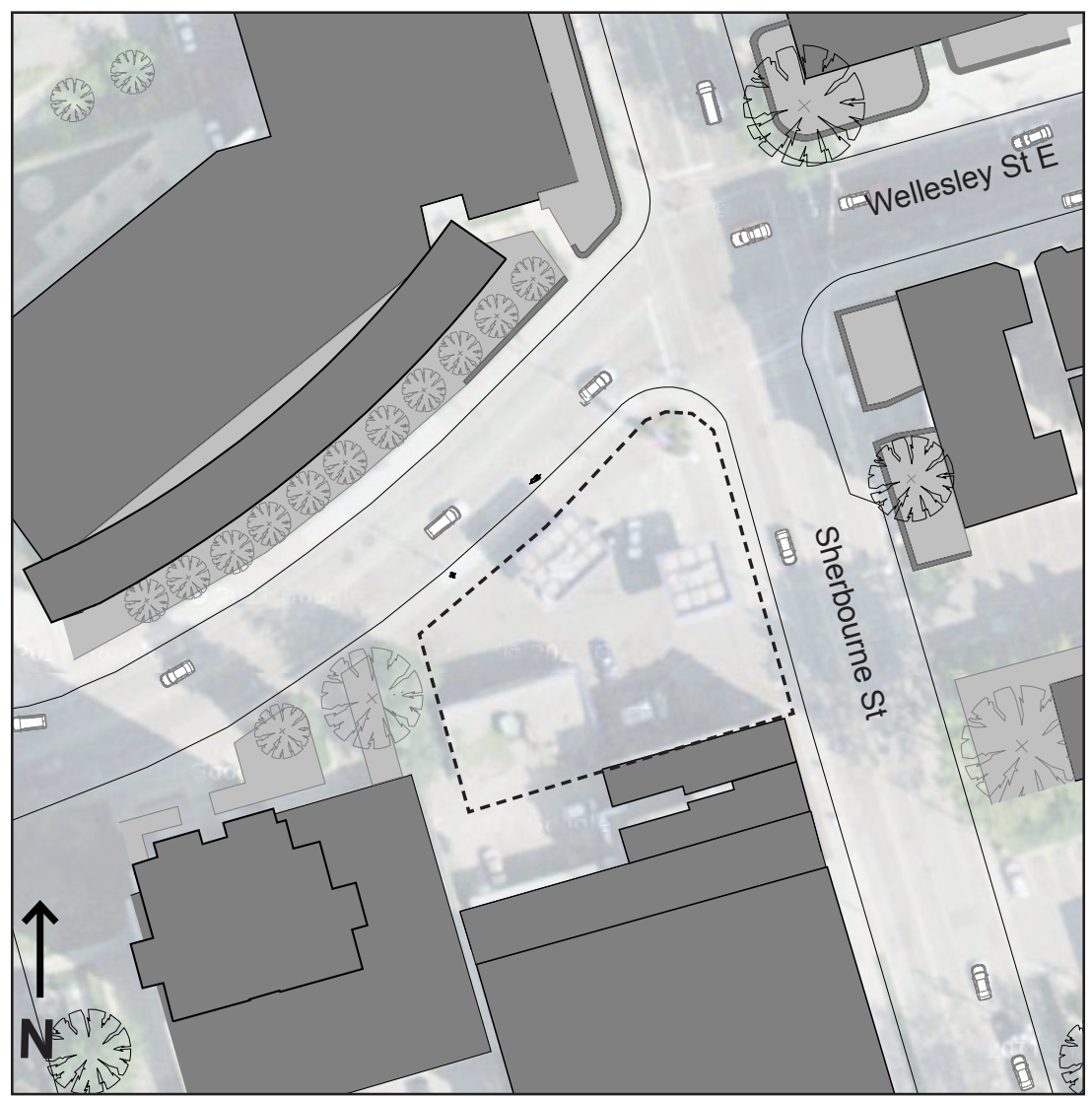

Fig 4.4.1 Aerial view of the former gas station site, which is now cleared of existing buildings

Fig 4.4.2 (Opposite top) General commercial land-use within a $1-\mathrm{km}$ radius (8 minute walk) of the abandoned lot in downtown Toronto

Fig 4.4.3 (Opposite bottom) Square footage of large chain grocery stores within a $1-\mathrm{km}$ radius $(8 \mathrm{~min}-$ ute walk) of the abandoned lot in downtown Toronto
A former gas station and donut shop lot at Wellesley Street East and Sherbourne Street in Toronto offers the opportunity to test the disassembly system. It has stood vacant since 2010 on a triangular parcel of land on a corner across from a new library, a medical building and brick apartment building (Toronto blog, 2011). Abandoned gas stations are frequently left vacant due to soil contamination, and often at prominent commercial locations. Cleanup is expensive so developers and buyers often avoid them (Konieczna, 2005). 

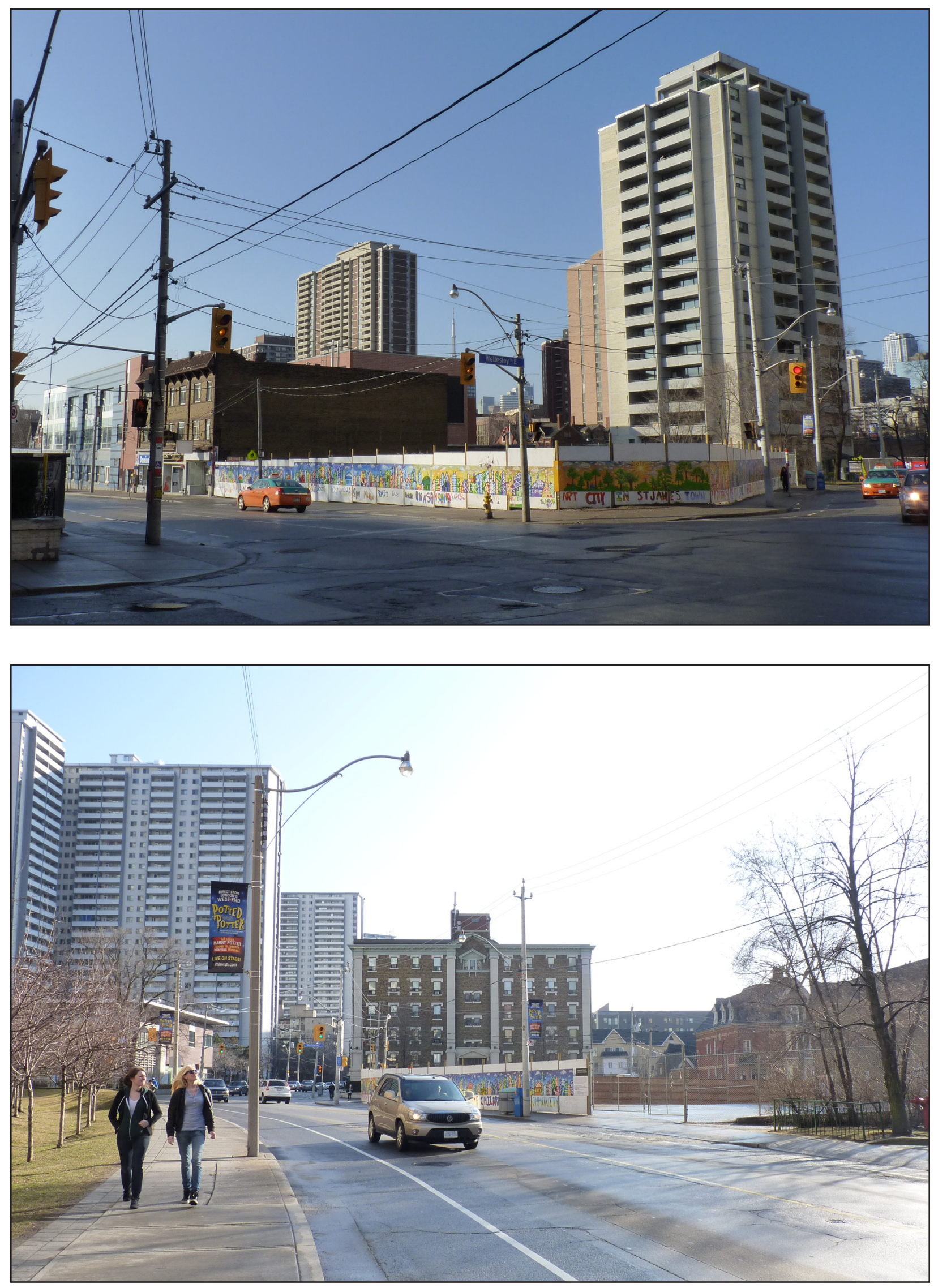
Fig 4.4.4 (Opposite top) Site photo taken from the North-east corner of Wellesley St E and Sherbourne St in February 2012

Fig 4.4.5 (Opposite bottom) Site photo taken from the West side of Sherbourne St on Wellesley St E in February 2012
The disassembly site connection permits building on contaminated land. Where contexts permitted, the soil remediation process could be completed on site while the building performed, with a form raised above the earth to allow bioremediation through plantings beneath. Soil remediation by plantings (phytoremediation) could be attempted on portions of the site left open, or if the building were raised to allow access to natural light and precipitation particular to the type of contamination and thus types of plantings.

A proposal for a new condominium tower on the site has been circulated, but neighbouring residents are adamant that no more residential towers be built in the area. The site is in proximity to the highest density residential zone in Toronto, the high-rise neighbourhood of St. James town. The condominium proposal encloses the entire site footprint while residents have demanded that public space be created at grade.

The corner location is prominent and advantageous, and should be reinforced by the massing of the new building. Planters and greenery are characteristic of the adjacent corners, where every building is set back from the street in some fashion. The integration of open space is important to the site design. The public library at the North-East corner has integrated seating into raised planters that pedestrians use while awaiting transit. There is a bus stop on Wellesley Street East at the North end of the site.

Area residents are served by commercial strips nearby at Parliament St, Church St and Yonge St. The site sits along a broken commercial strip and is appropriately sized to house several smaller bays of commercial tenants, or one large retailer. Covering the footprint of the lot would provide enough square footage for a large department style retailer to function. The building created is two storeys at 1250 square meters and leaves a significant portion of the site open for public space. 

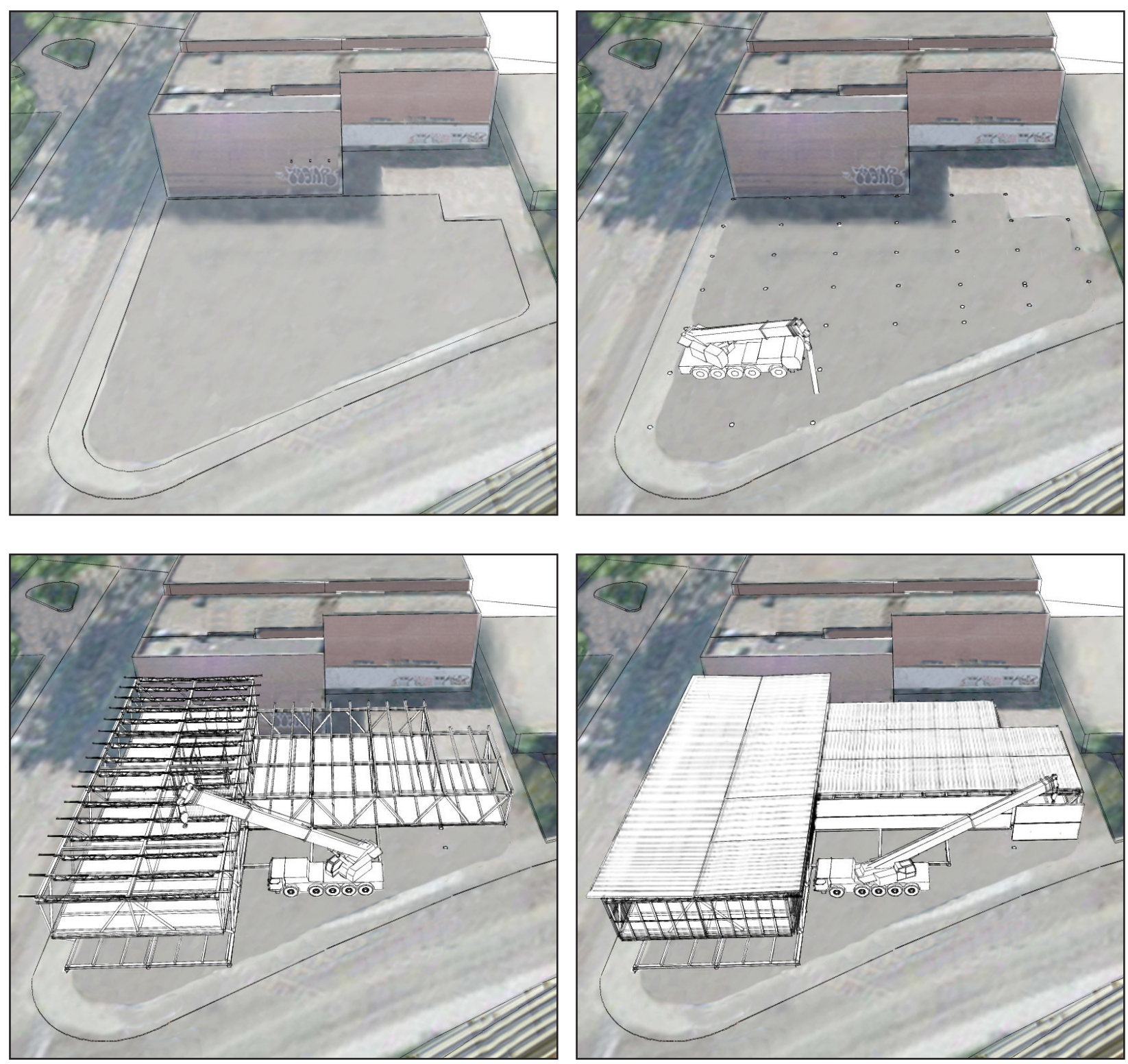

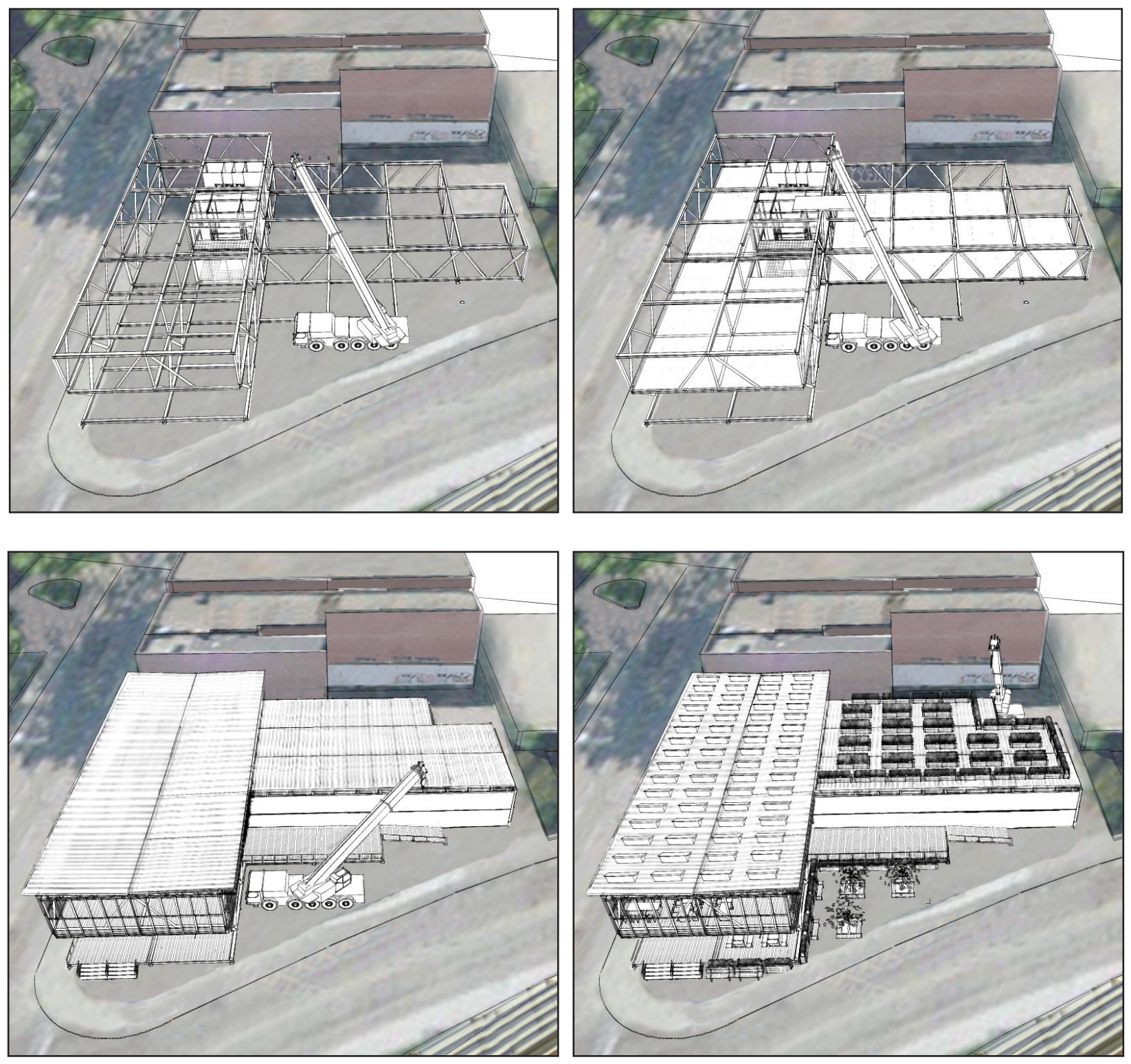

Fig 4.4.6 (Pages 170-171) Aerial view of assembly process 

To assemble the building, prefabricated members are maneuvered and affixed on site with the use of a truck-mounted crane since it avoids a permanent foundation. The crane can reach from 15 to 25 meters and lift 0.8 to 80 tons depending on the size of truck (Hubei Fotma Machinery Co., 2010). First the screw pile foundations are drilled. Then the stick-built structure is bolted together and the cores are located. Next, underfloor panels are slid into place bearing upon the beams. Joists are bolted in, and window, wall, and roof panels are affixed with respective finishes. Services are installed, followed by finishes and partitions on the interior, while on the exterior decks, ramps, and stairs are located and bolted in place, then finished. Final touches involve the placement of planters and other site specific assemblies. In this building iteration, the site is un-shaded by adjacent buildings, so it is shown with independent weighted solar panel kits that sit atop the highest roof.

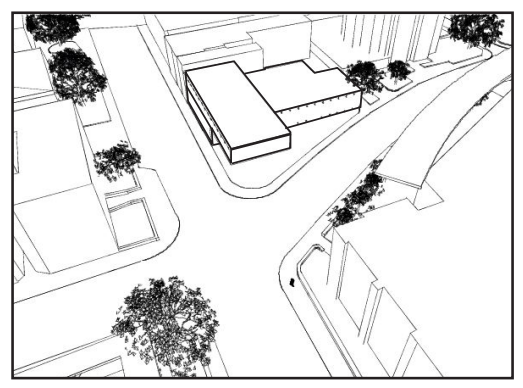

Fig 4.4.7 Simple block massing of the building on site
To reinforce the corner a raised volume slides along Sherbourne St and conveys the existing length of retail buildings next door to the intersection. There is access from both streets for pedestrian approach - a ramp up from Wellesley St East and stairs at the Sherbourne St corner. Glazing wraps the ground level corner on Sherbourne St to entice customers, and the service and circulation cores are visible through to the street as independent features in the open space.

The building entrance is off a covered deck beneath the overhanging volume. It was critical to create public space to satisfy resident demands, so there is ample room for outdoor gathering spaces, both sheltered, and uncovered. Seating and tables could be used by shoppers and the community as a public porch for gathering and socializing. A bus stop on Wellesley Street East at the North end of the site benefits from grade level outdoor seating. On the interior, the bays demonstrate the use of functional aisles if laid out with merchandise in a standard manner. Freestanding furnishings allow for flexible occupation. If one retail type fails then furnishings can be removed and replaced with another 

layout. The optional layout is intended to keep the retail type vague, but demonstrate inhabitation of the building.

The upper volume would be partly glazed to offer views up Sherbourne Street at the North end, and would be screened overtop the glass on the East and West of a potential dining space. Most of the south end of the volume would have solid walls around kitchen and service spaces, but transom windows between the joists would allow natural light into the spaces. The transom windows are ideal for shopping areas as well, where solid walls can be backed by merchandise. On the roof adjacent to the dining area there is opportunity for plantings to supply a restaurant with fresh ingredients, or roof terrace dining. Significant exposed structure and the lifted canopy volume are reminiscent of the canopies on the library and medical buildings nearby. 


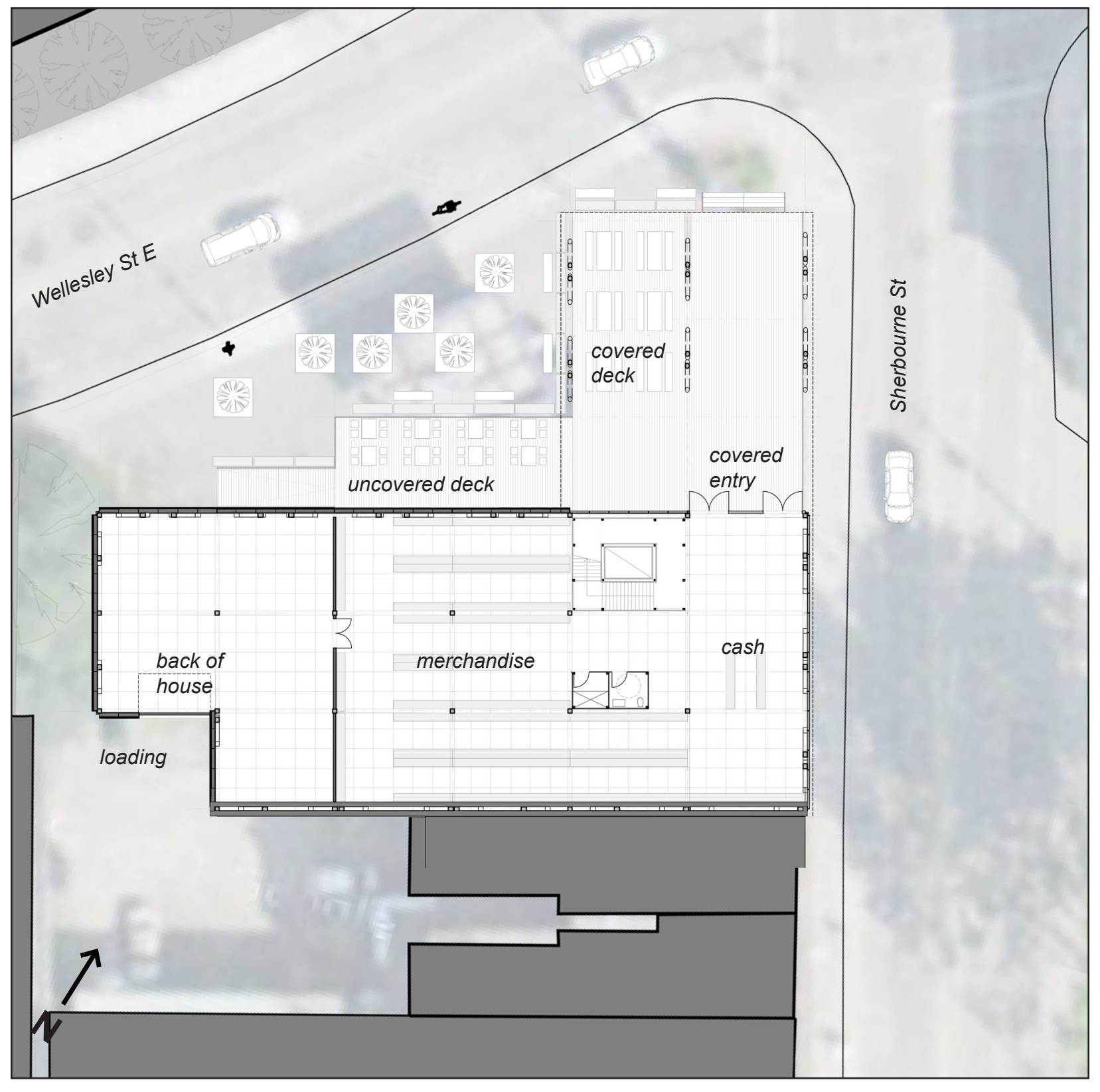




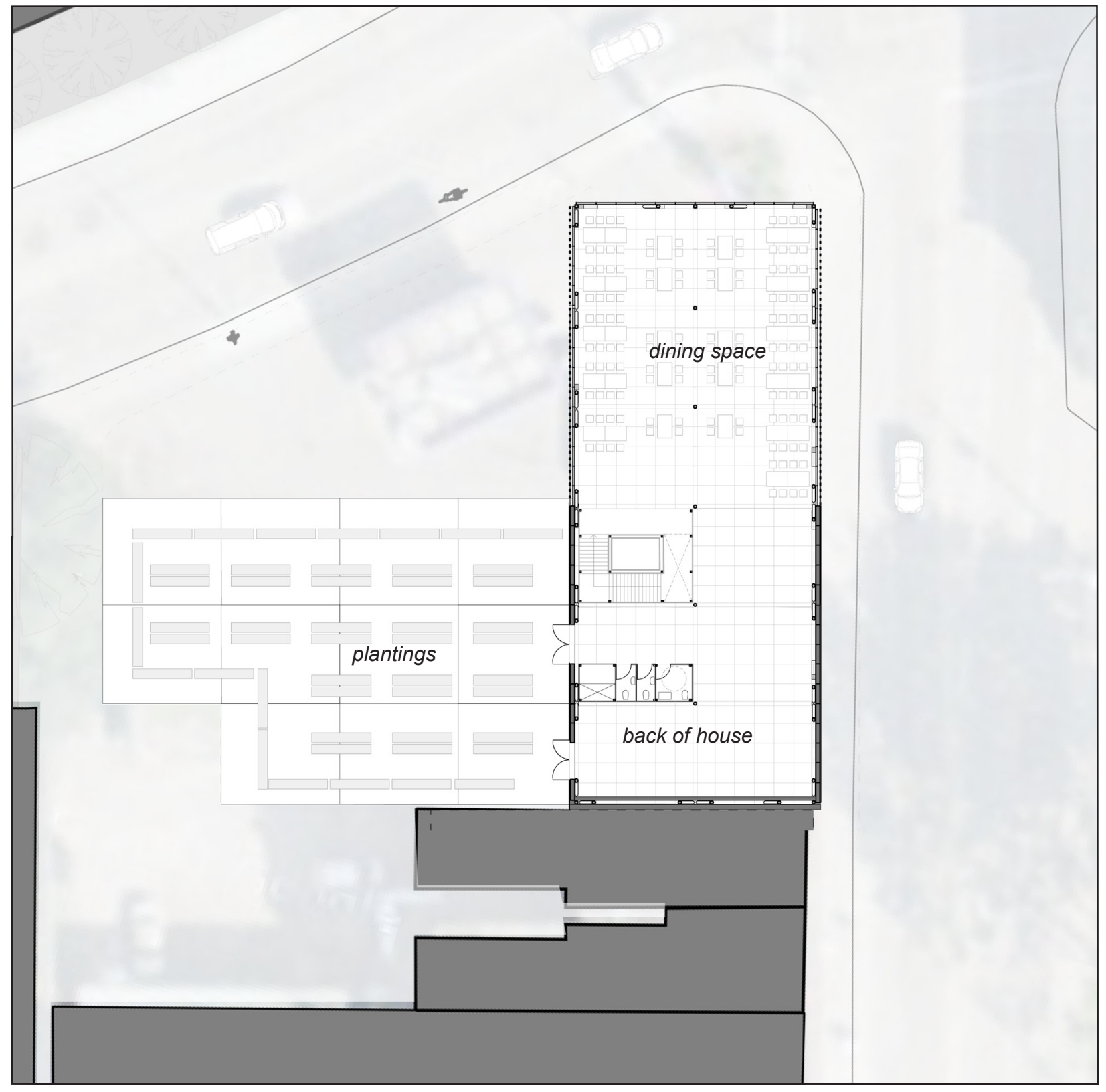

Fig 4.4.8 (Opposite) Ground floor plan

Fig 4.4.9 (This page) Upper floor plan 

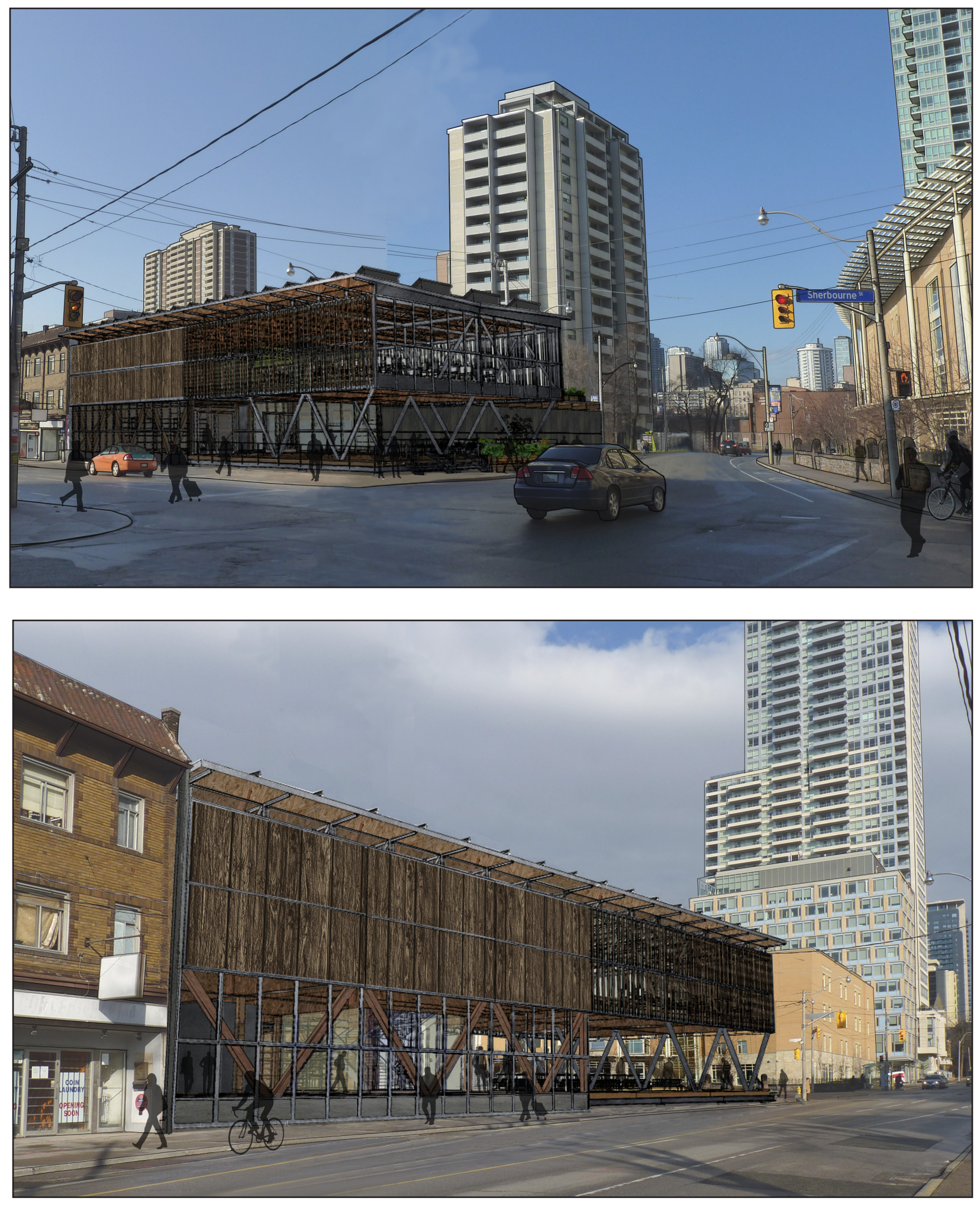


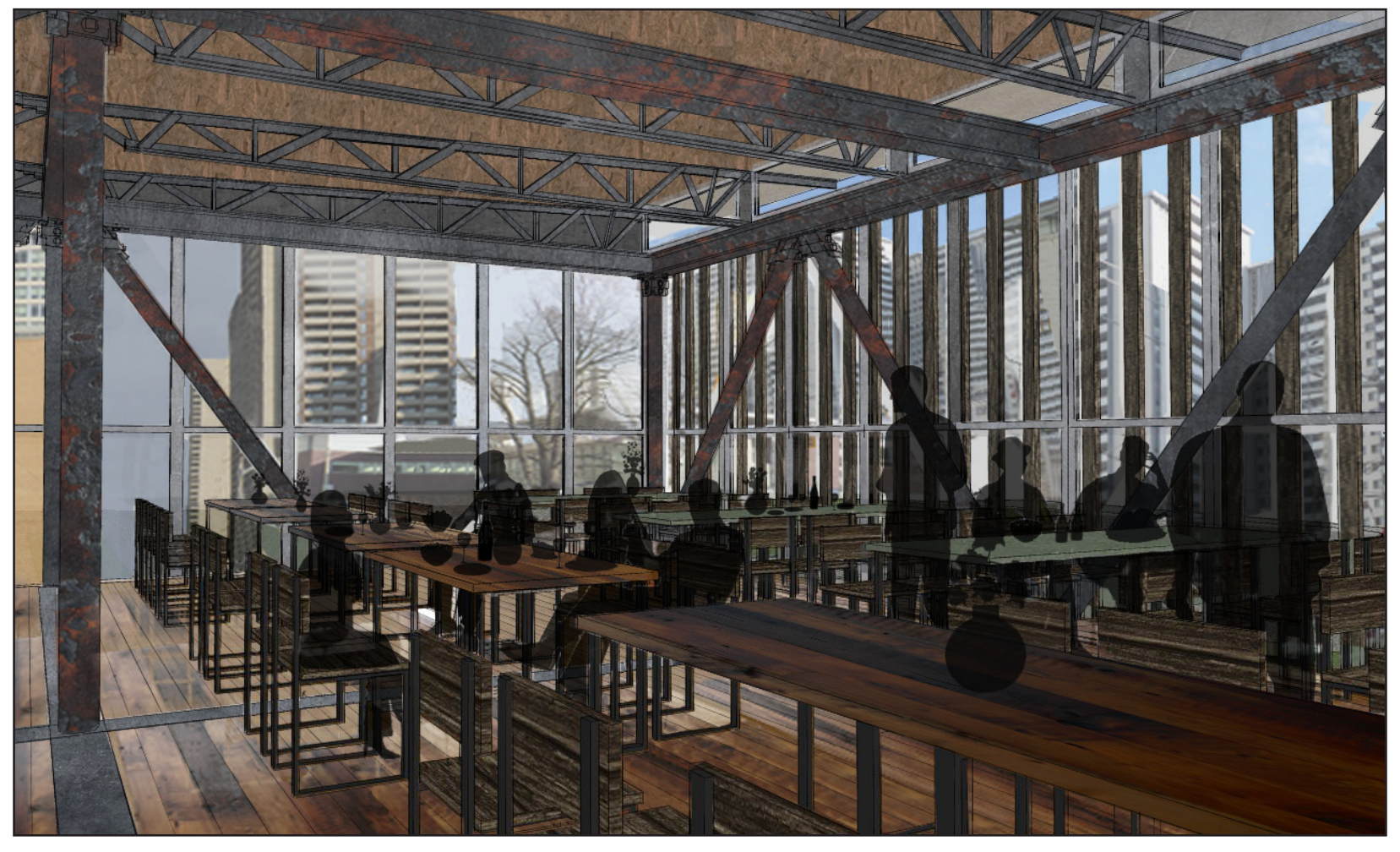

Fig 4.4.10 (Opposite top)Wellesley Street East and Sherbourne corner

Fig 4.4.11 (Opposite bottom) Sherbourne Street looking North towards Wellesley Street East

Fig 4.4.12 (This page) Upper floor interior view towards the Sherbourne-Wellesley intersection 

The process of disassembly is the reverse of assembly, starting with the removal of items that are not integral to the building, such as planters, solar panels, and furnishings. Then come exterior built forms, interior finishes, electrical and mechanical. The panelized wall, window and roof assemblies are detached, followed by joists, then under floor panels. The post and beam structure is unbolted piece by piece, the cores removed, and finally the screw pile foundations are reversed and loaded up for repair or to be taken to a new site.

Fig 4.4.13 The disassembly process at Wellesley St E and Sherbourne St
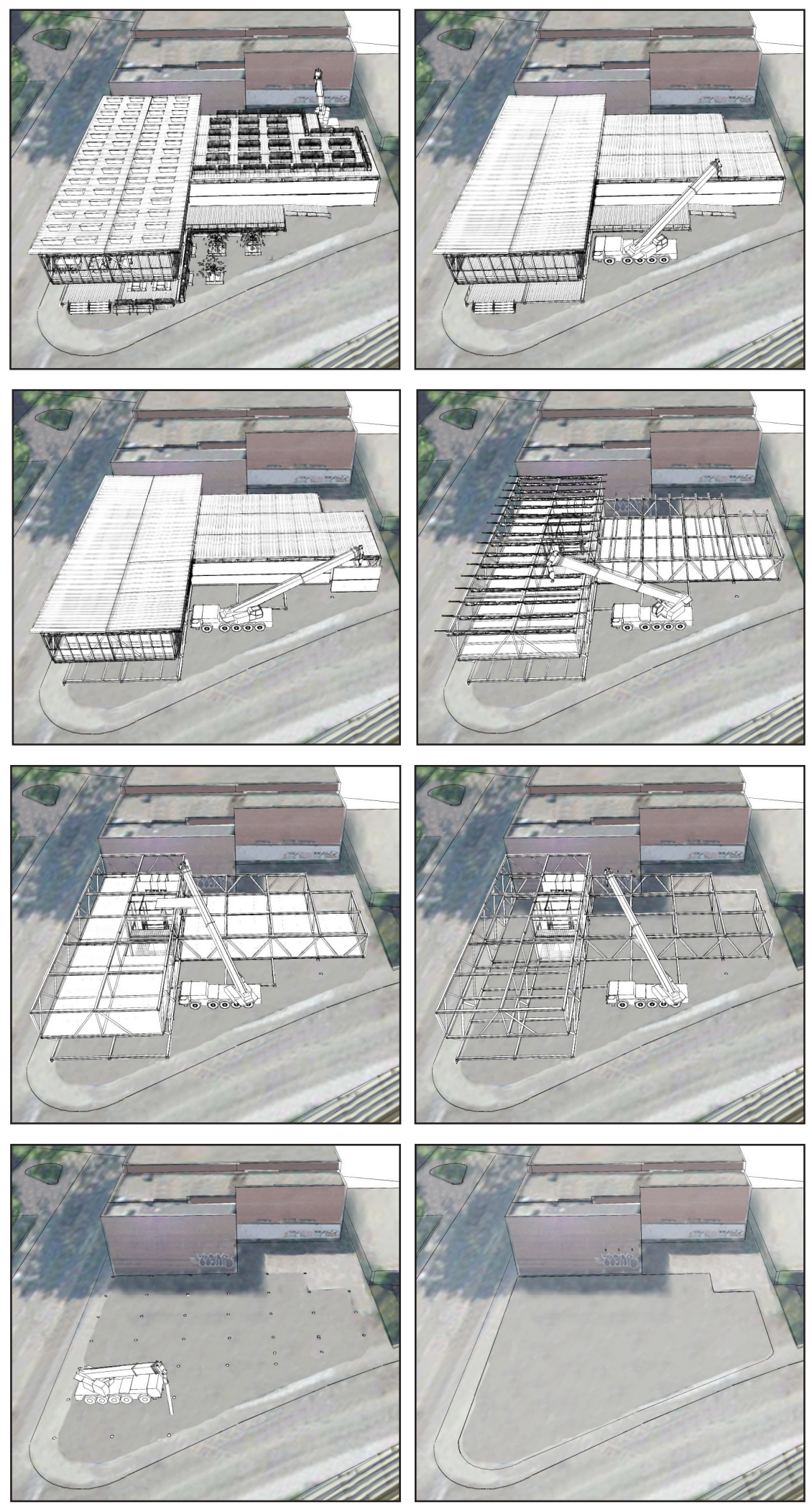



\section{Danforth Ave and Playter Blvd}

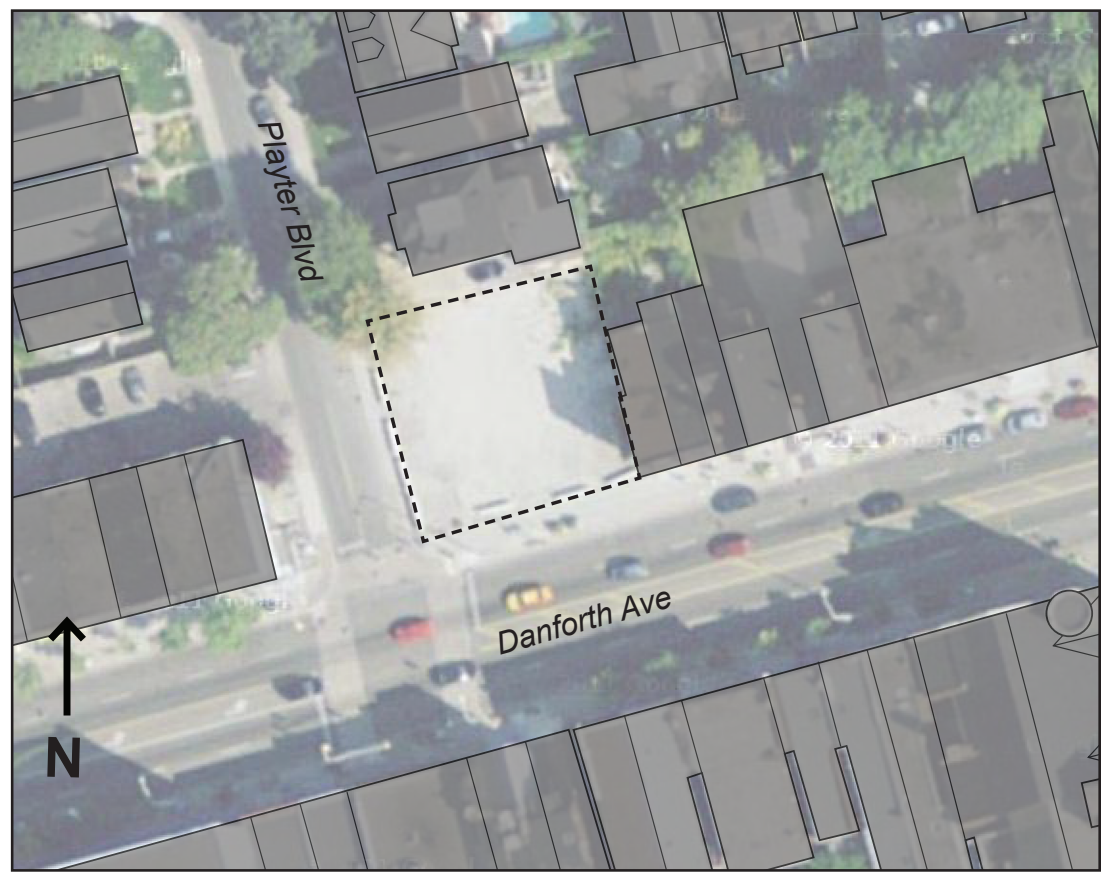

Fig 4.4.14 Aerial plan of the vacant lot on Danforth Ave
In order to demonstrate the ability of the system to adapt to different situations another building example is developed. A vacant corner lot on Danforth Ave has been used occasionally as an unofficial parking lot, but currently stands empty. The lot acts as a significant void in the active commercial strip between Broadview and Chester subway stations, and a prime location for retail outlets, with a healthy pedestrian population. The site is flanked by two and three storey brick buildings with commercial on the ground floor and residential above. Large single-family homes with treed lots make up the neighbourhood to the North.

The assembly process is the same as the last iteration with variations in arrangement, finishes and furnishings specific to the site and context. The building mass is set back from adjacent commercial buildings along Danforth Ave in order to bring pedestrians up a few steps to the building floor level, which creates an exterior walkway. The building is also significantly set back from its lot line on the west side to form a large outdoor patio - which the Danforth lacks despite its rich restaurant options. The patio falls in line with front lawn setbacks of the large homes to the 

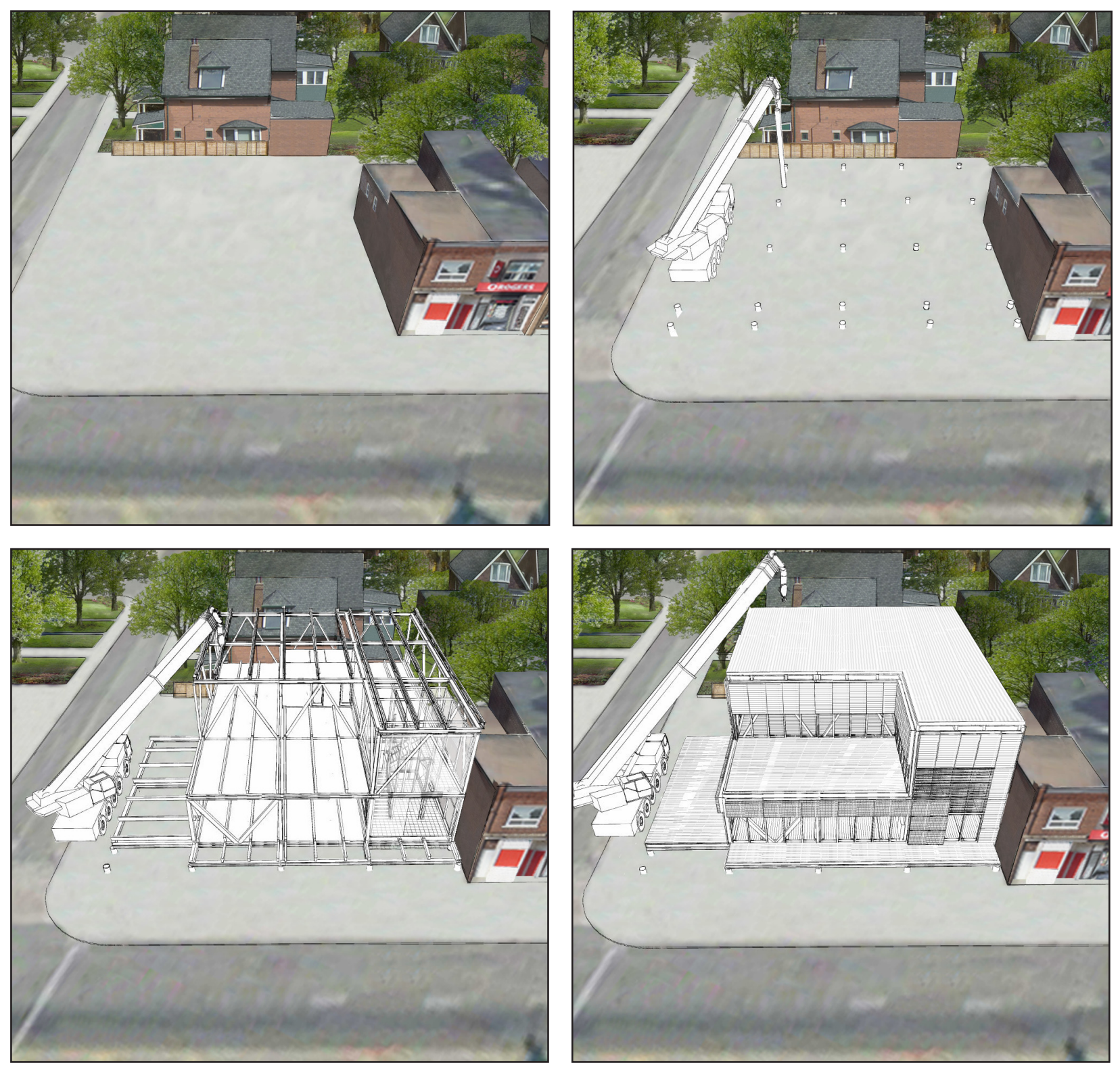

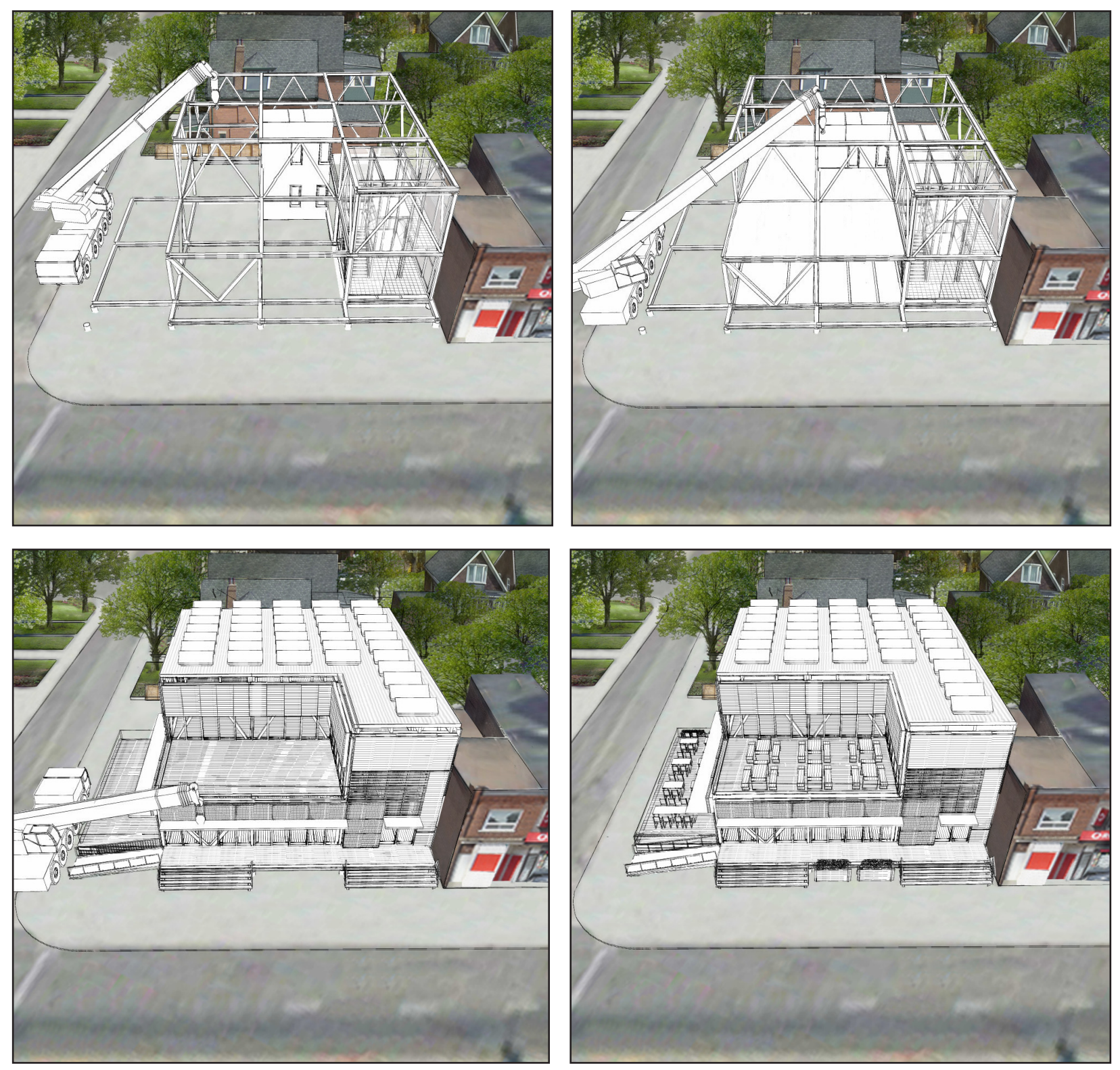

Fig 4.4.15 (Pages 1184-185) Aerial view of sassembly process at Danforth Ave and Playter Blvd 

Fig 4.4.16 (Opposite top) Ground floor plan

Fig 4.4.17 (Opposite bottom) Upper floor plan
North. The building mass is broken down on the upper level to create a terrace on the south-west corner, and to minimize the building scale seen in elevation from the street. A massive facade along Danforth ave would not have been appropriate for the intimate size of the surrounding building context. Modular steel canopies are employed to protect entryways. The roof structure employs shorter joists, and the roof assembly is less one 4' x 8' panel to avoid the overhangs of the last iteration that were not aesthetically fitting in the context.

It is expected that the building iteration would house several smaller tenants, such as a restaurant on the ground floor, and a bar or gallery space on the upper floor that could make use of the west-facing terraces. Loading is achieved off of Playter Blvd, and the circulation core is accessed directly off of the street entrance to ascend to the upper level. The washroom-service core bridges the division between front and back of house on both floors. Stair and washroom cores are designed to be accessible from either bay direction so that they can function in various building layouts.

The building offers less exposed structure, and appears more solid and subdued in its possession of the corner lot - more in tune with the heavier structures along the Danforth - but still retains its language of assembly and impermanence through panelization, exposed joinery and visible structure. It is shown with wood cladding and screen on the upper volume and terracotta rainscreen panels on the lower form as a lightweight version of the heavy bricks in adjacent homes and stores. Up close, visible details, joints, and worn materials give a sense of the assembly process and the potential for disassembly and reuse. 


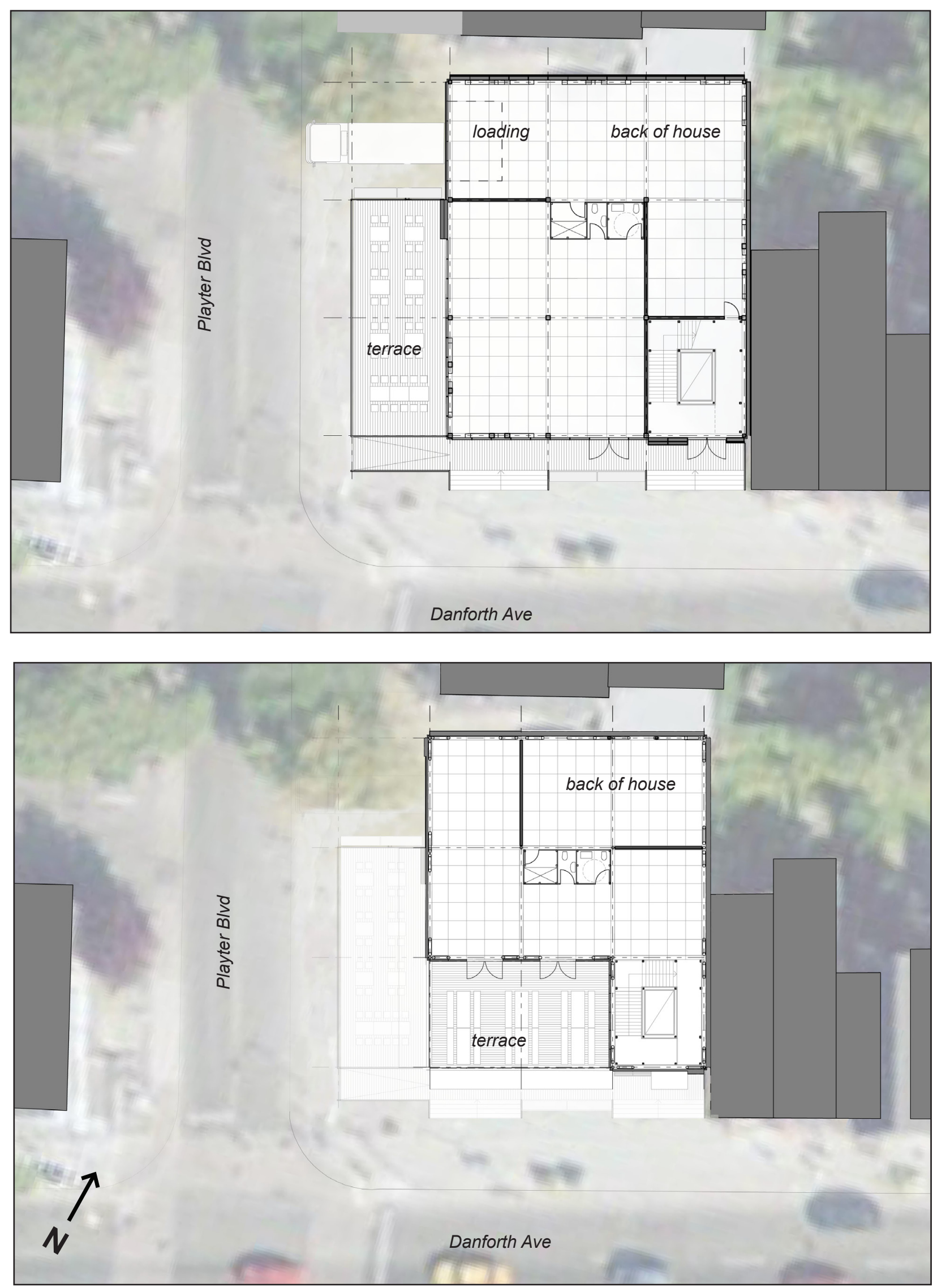

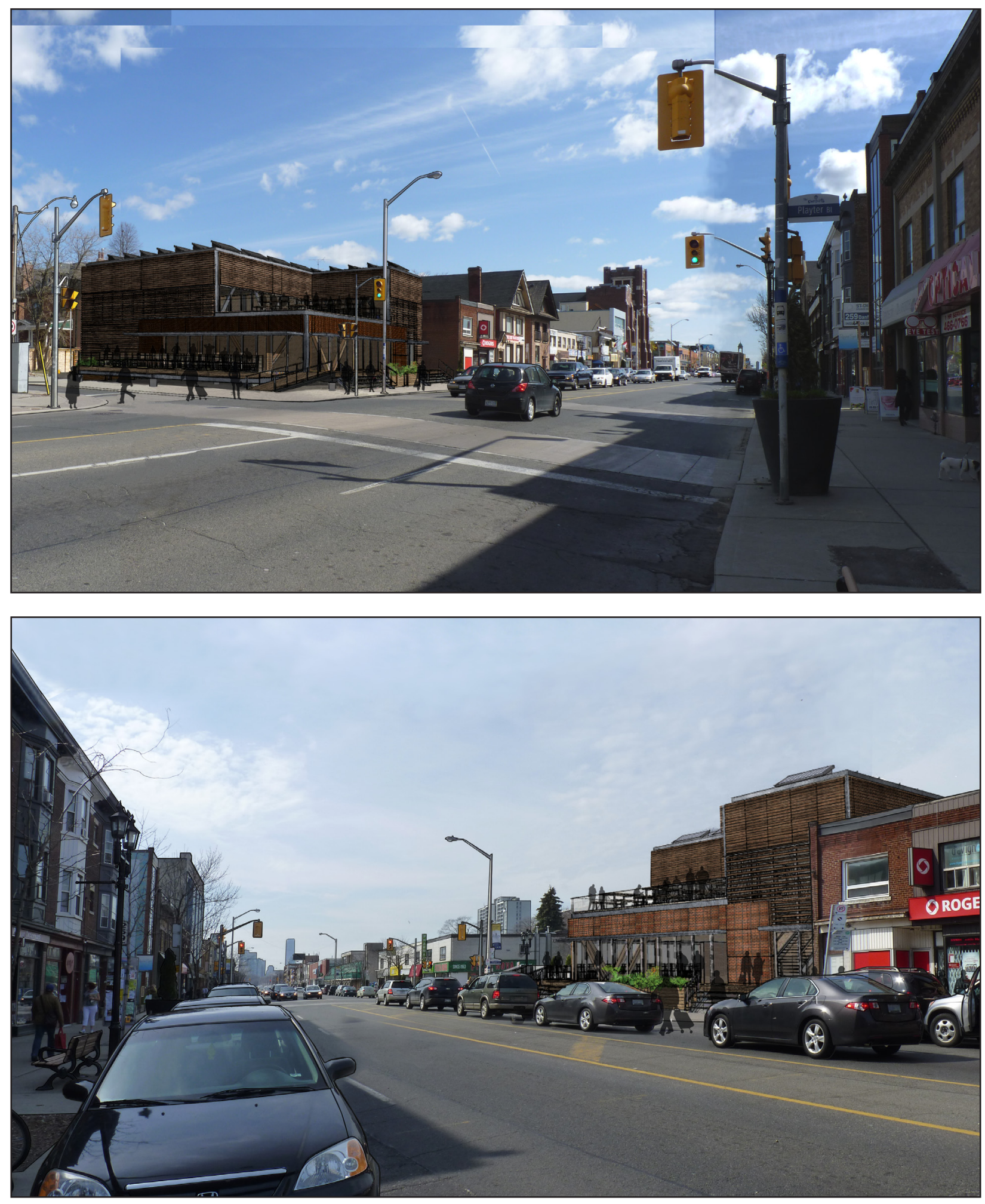


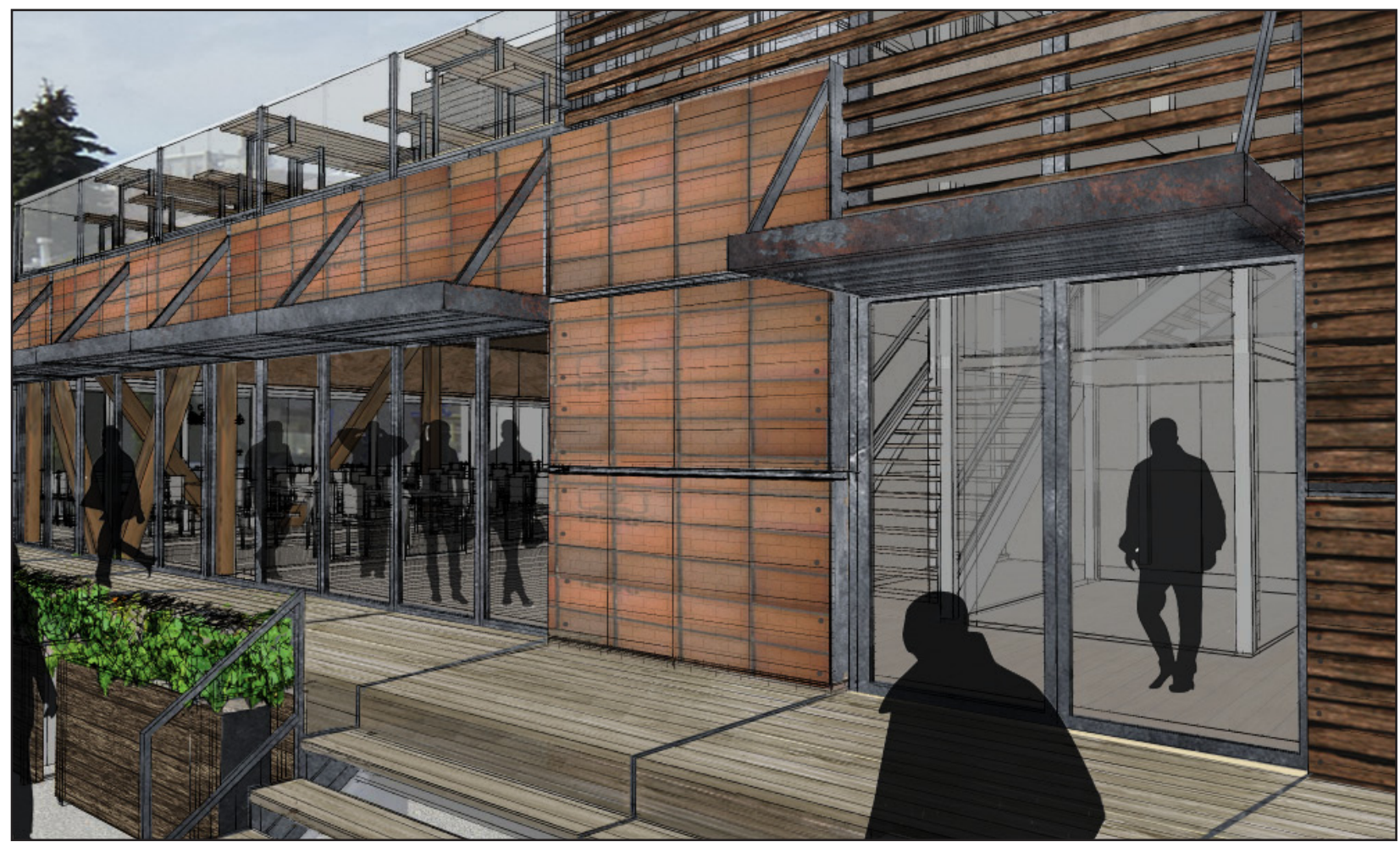

Fig 4.4.18 (Opposite top) View eastward along Danforth Ave

Fig 4.4.19 (Opposite bottom) View westward along Danforth Ave

Fig 4.4.20 (This page) Exterior entrance view from Danforth Ave 


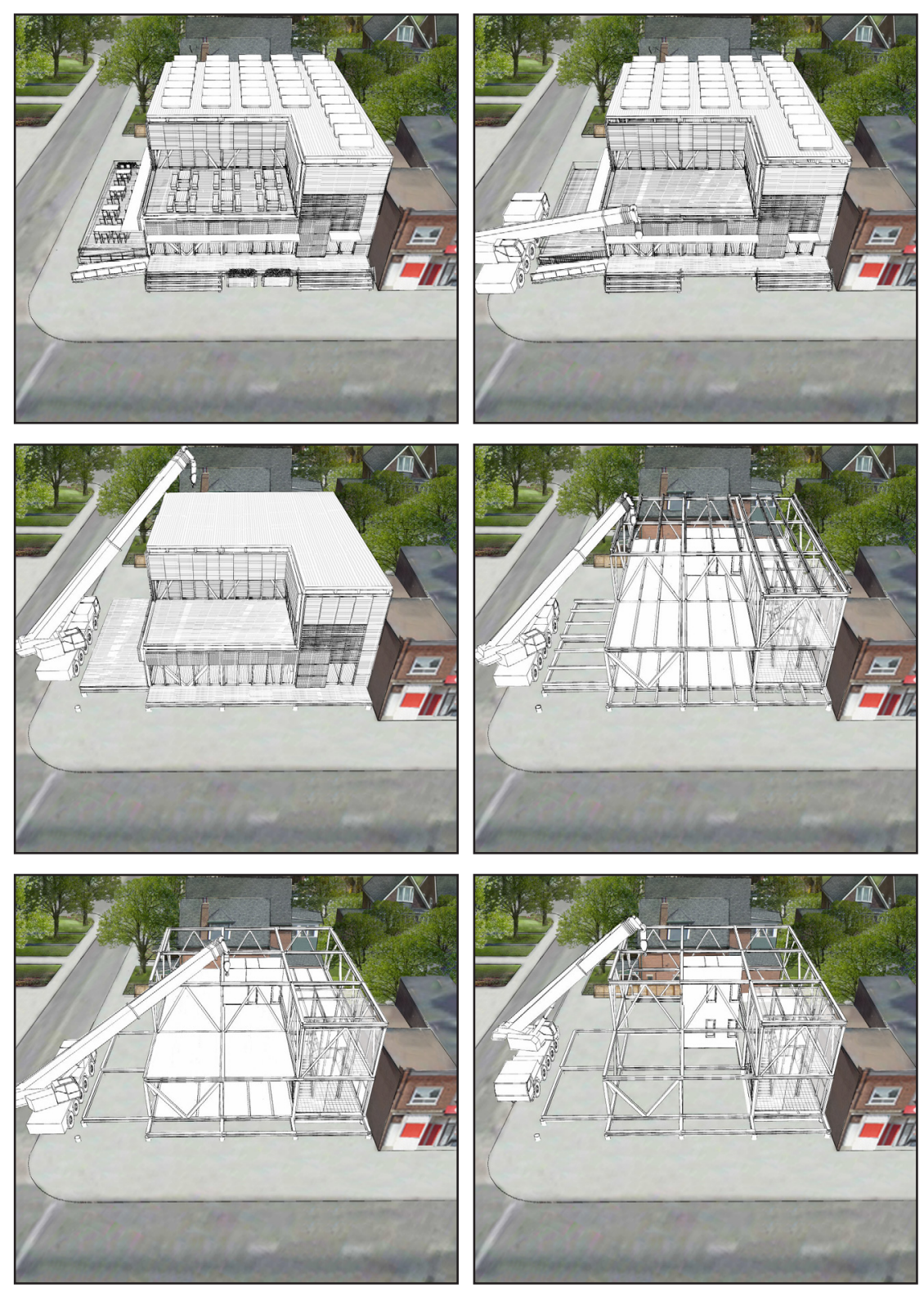

Fig 4.4.21 Aerial view of the disassembly process
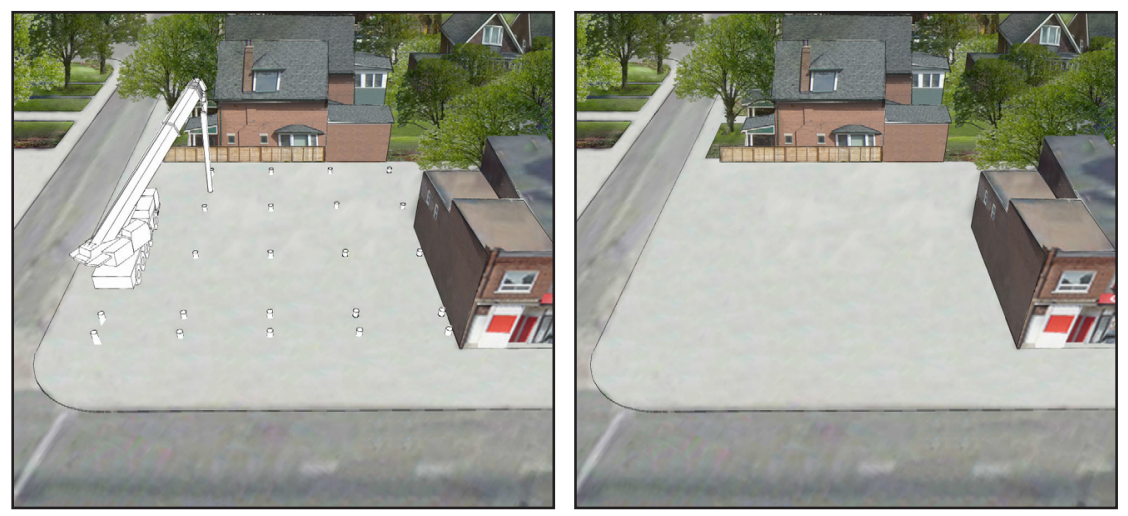



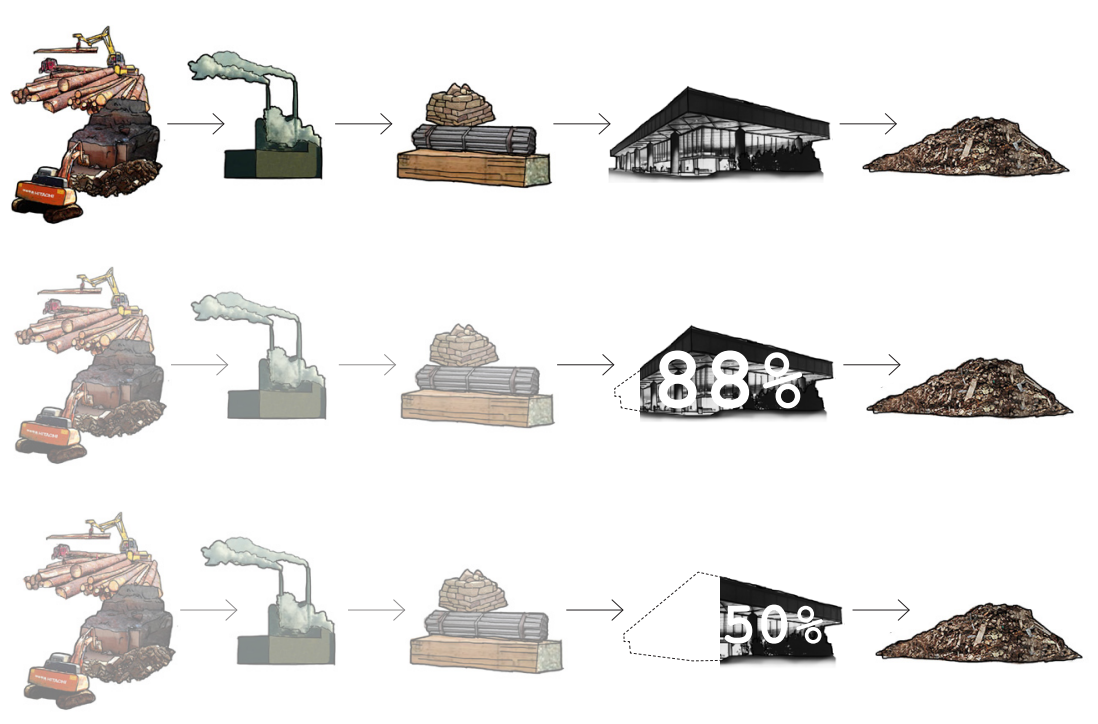

\section{Evaluation}

Fig 4.4.22 The conventional architecture material cycle, where little or no materials are sourced for reuse or recycling

Fig 4.4.23 The material cycle for demolition of an obsolescent building in 2004 , where $88 \%$ of the material volume becomes waste and only $12 \%$ is reused or recycled

Fig 4.4.24 The material cycle for buildings constructed traditionally but disassembled, at least $50 \%$ of materials are reused or recycled in the year 2000
In Canada, 9.3 million tonnes of solid waste are created annually through construction and demolition in Canada (OWMA, 2011). In standard demolition practices, a small amount of materials are salvaged due to their easy removal and reuse, such as windows, doors and lighting fixtures (Frisman, 2004). In the demolition of an obsolescent building only $12 \%$ of material volume is reused or recycled (Frisman, 2004). The current alternative to maximize reuse and recycling of buildings - deconstruction through careful hands-on disassembly - is labor-intensive and time-consuming since buildings are not designed for easy disassembly, however a review of deconstruction case studies by the University of Florida's Powell Center for Construction \& Environment in 2000 found that deconstructed buildings diverted at least $50 \%$ of materials from landfills (Frisman, 2004).

A building constructed from the disassembly system will be infinitely quicker and easier to deconstruct than a permanently detailed building, reducing the excessive time and labor of deconstruction. The material and component design also maximizes recyclable and reusable content, so that the landfill diversion rate approaches $100 \%$. By estimating the volume of material used in the first building iteration, the disassembly system can achieve over $99 \%$ reuse of its components in new iterations. 

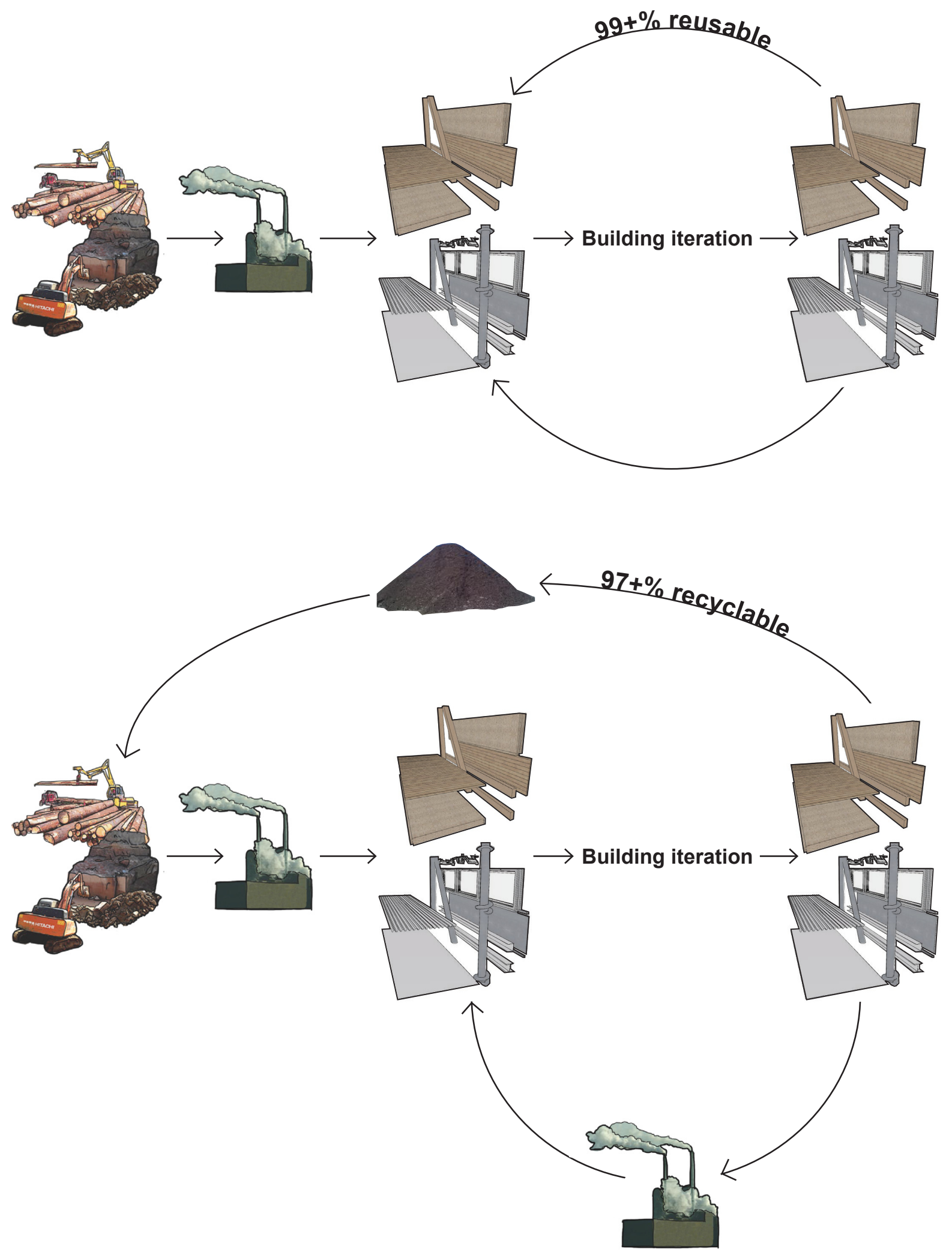
If the system were to obsolesce and the building model discarded - the parts would be over $97 \%$ recyclable to become nutrients for new industrial and natural materials (Appendix 1). The parts that currently hold the system back from reaching its full potential are membranes, gaskets and other materials that are easily damaged and cannot be recycled.

The system proposes a new material lifecycle for an impermanent commercial architecture. Components are selected and combined using

Fig 4.4.25 (Opposite) The new material cycle for reuse and recycling of materials details that allow for their disassembly and reuse in different locations.

When components are worn out they become nutrients - either biological or industrial for the creation of new materials - never wasted. 



\section{Conclusions}



Fig 5.1 (Pages 121-122) worn metal panel
Architecture of disassembly and material life cycle was a worthwhile study to undertake considering the concern for wasted materials and energy in the construction and architectural fields. Placing strict rules upon detail design and material use became a means to urge architectural innovation. It forced a critical look at current assembly methods and a pursuit of improvised solutions. It was evident from the research and early design studies that there would be significant formal limitations to designing for disassembly and cyclical material life. By urging the use of uncut standardized materials, designs could only be composed within dimensional and, typically, orthogonal material limits. There was also a lack of elegance to many standardized materials - such as the proportions of 4' $x$ 8' panels - that made it more difficult to create aesthetically pleasing products and would greatly limit the accessibility of this approach for other designers. The need for reversible connections and avoidance of composite materials were both opportunities for design exploration as well as hindrances. Techniques and efficiencies developed over time in the building trade, often involving material efficiency in the short term, had to be rethought to favor disassembly and durability for the long term (such as the avoidance of adhesives). The concept of layering assemblies so that their maintenance or removal did not compromise still functioning layers, offered a clear and functional diagram, but challenged convention in many circumstances.

The incredibly common misconception that architectural creations are permanent has led architects and the construction industry to ignore the management of the materials that compose them, which has a lasting effect. Selecting materials based upon expected functional lifespan was entirely logical and acceptable, since building a structure to last several months with material that is neither reusable nor recyclable is problematic and short-sighted. It is clear that materials should be clearly suited to the architectural permutation. The functional life of a building should drive the type of materials specified and the method of assembly. 

The design of a disassembly system had its own added challenges. System designs inherently need to find a balance between customized and prefabricated components to achieve efficiency while also creating differentiation. The building iteration at each site needed to be responsive to conditions, but still systematic in approach. It was difficult to conceive an architectural system that would be generic enough to function in different iterations, while also being interesting as a building. The pursuit of expressive assembly, detail design, and use of high quality materials was considered as a means to provide interest where repetitive spatial and formal conditions could not. Small-scale assemblies such as finishes and furnishings were also considered as a method of achieving differentiation between sites, using components and materials that would be appropriate for shortened functional lives and more specific commercial spaces.

The design of reversible assemblies placed an emphasis on connections and detailing, that in traditional works can often be hidden and overlooked. The value of the system design was a thorough study of assembly methods and materials for a holistic understanding of material life. With the system, assemblies could be reused in new configurations or recycled into nutrients for new components. The design of an architectural system offers a very comprehensive study of materials and assembly methods. It incorporates elements of industrial design because it addresses aspects of design that architecture typically underplays, such as production and reusability. The project upholds a position in the field of architecture, however, because each individual part of the system is dependent upon the whole for its significance. The added level of complexity is intended to create a functional building that adds to the economic, cultural, and social structure of its community while performing in a greater material context. The thesis study demanded a more technical approach to design challenges that ensured a deep understanding of how the building would function, be constructed, and perform in a larger context. 

The impermanent nature of the commercial buildings derived in the design project implies a built environment that is constantly changing. A fear associated with that impression is the loss of physical memory of place, culture and history. However, built permanence is not assured even if you build with lasting construction methods. Obsolescence is not foreseeable, as buildings can be slated for removal due to physical factors including material wear and ineffective design, behavioural factors such as change in use and damage by occupants, and finally, by external factors in the surrounding environment. A building that allows for disassembly, in part or in whole, can allow for adaptation and improvements to counter physical factors that threaten its existence. It is nearly impossible to design a lasting building, but designing a solution that is capable of change and adaptation could extend its life. The value of impermanence in architecture is the ability to experiment, adapt, revise, and improve. The design of the system assemblies allows for durable components and materials to be easily removed and replaced as they age, deteriorate or obsolesce. It also permits the layout and arrangement of spaces to be updated to allow the building to adapt to changing needs. A city built for disassembly and cyclical material life would not necessarily reinvent itself from the ground up every decade, but would gradually grow, adapt and change over time in a more sustainable manner than is now offered. Disassembly buildings accept that architecture is impermanent, but materials and resources are long-lasting. Material lives would be considered beyond the single building's existence, and be allowed to provide for changing needs without wasteful use.

For any building, system or component that is impermanent, an architecture of disassembly and cyclical material life is an appropriate response. Buildings designed to last for hundreds of years could easily adopt the flexibility of impermanence in shorter-lasting layers, such as cladding, finishes, services and furnishings in order to be prepared for change. The presence of history and memory in the built environment is a wondrous thing, and the buildings that survive the tests and trials of 

time should be celebrated. However, constructing architecture to make change difficult, with permanent assemblies that are complicated to disassemble and reuse, ignores an honest truth: nothing is static, the world is constantly changing. Architects cannot make permanent marks since buildings need to transform alongside society or they become nothing more than artifacts. All architects can do is attempt to improve the built world while they have the chance, and try to ensure the generations that follow have the same opportunity. 



\section{Appendix 1}

Material volume estimate analysis for Sherbourne St and Wellesley St East building iteration

\begin{tabular}{|lllll|}
\hline & $\begin{array}{l}\text { Approximate } \\
\text { volume of } \\
\text { building }(\mathrm{m} 3)\end{array}$ & $\begin{array}{l}\text { Reuse within } \\
\text { the system }\end{array}$ & $\begin{array}{l}\text { Reuse } \\
\text { beyond the }\end{array}$ & $\begin{array}{l}\text { Recyclable } \\
\text { system }(\mathrm{m} 3)\end{array}$ \\
Component & & &
\end{tabular}

\begin{tabular}{|lrrrr|}
\hline Site & \multicolumn{3}{l|}{ 3.9 } \\
\hline Steel screw piles & 3.9 & 3.9 & & \\
& & & & \\
\hline Structure & & & & \\
\hline Timber posts & 10.79 & 10.79 & 10.79 & 10.79 \\
Steel posts & 19 & 19 & 19 & 19 \\
Steel beams & 11.5 & 11.5 & 11.5 & 11.5 \\
Timber joists (lower) & 42 & 42 & 42 & 42 \\
Steel joists (upper) & 1.04 & 1.04 & 1.04 & 1.04 \\
Metal connectors & & $\checkmark$ & & $\checkmark$
\end{tabular}

\begin{tabular}{|c|c|c|c|c|}
\hline Skin & & & & \\
\hline \multicolumn{5}{|l|}{ Underfloor panels: } \\
\hline Agriboard & 364 & 364 & 364 & 364 \\
\hline Soffit finish & 17.7 & 17.7 & 17.7 & 17.7 \\
\hline Building paper, tape & 0.88 & 0.88 & & \\
\hline \multicolumn{5}{|l|}{ Metal connectors } \\
\hline \multicolumn{5}{|l|}{ Wall panels: } \\
\hline Agriboard & 324.1 & 324.1 & 324.1 & 324.1 \\
\hline Bio/Industrial finishes & 7.96 & 7.96 & 7.96 & 7.96 \\
\hline Precast concrete firewall & 34.27 & 34.27 & & \\
\hline Building paper, tape & 0.6 & 0.6 & & \\
\hline Metal connectors & & $\checkmark$ & $\checkmark$ & $\checkmark$ \\
\hline \multicolumn{5}{|l|}{ Roof panels: } \\
\hline Agriboard & 310.5 & 310.5 & 310.5 & 310.5 \\
\hline Metal roofing & 12.4 & 12.4 & 12.4 & 12.4 \\
\hline Building paper, tape & 1.2 & 1.2 & & \\
\hline \multicolumn{5}{|l|}{ Metal connectors } \\
\hline \multicolumn{5}{|l|}{ Glazing: } \\
\hline Curtain wall frame and glass & 27.7 & 27.7 & 27.7 & 27.7 \\
\hline Gaskets & & $\checkmark$ & & \\
\hline Exterior doors and hardware & 3.9 & 3.9 & 3.9 & 3.9 \\
\hline Metal flashing & & $\checkmark$ & & $\checkmark$ \\
\hline
\end{tabular}





\begin{tabular}{|c|c|c|c|c|}
\hline \multicolumn{5}{|l|}{ Services } \\
\hline \multicolumn{5}{|l|}{ Washroom/service core: } \\
\hline Mechanically fastened pipes & & $\sqrt{ }$ & $\sqrt{ }$ & $\sqrt{ }$ \\
\hline Fixtures (metal) & & $\checkmark$ & $\checkmark$ & $\checkmark$ \\
\hline Steel frame & & $\checkmark$ & $\checkmark$ & $\checkmark$ \\
\hline Box finish enclosure (metal) & 1.5 & 1.5 & & 1.5 \\
\hline Metal connectors & & $\checkmark$ & $\checkmark$ & $\checkmark$ \\
\hline \multicolumn{5}{|l|}{ Elevator core: } \\
\hline Mechanics & & $\checkmark$ & $\checkmark$ & $\checkmark$ \\
\hline Steel frame & & $\checkmark$ & $\checkmark$ & $\checkmark$ \\
\hline Core finish enclosure & 3.5 & 3.5 & 3.5 & 3.5 \\
\hline Lighting fixtures & & $\checkmark$ & $\checkmark$ & $\checkmark$ \\
\hline
\end{tabular}

\begin{tabular}{|lcccc|}
\hline Finishes & & & & \\
\hline Floor panels: & & & & \\
\hline Bio/Industrial finish & 28 & 28 & & \\
Metal access panels & 0.87 & 0.87 & & 0.87 \\
Metal connectors & & $\checkmark$ & $\checkmark$ & $\checkmark$ \\
Exterior wood deck & 9.3 & 9.3 & 9.3 & 9.3 \\
Metal connectors & & $\checkmark$ & $\checkmark$ & $\checkmark$ \\
\hline Interior partitions & & & & \\
\hline Bio/Industrial finish & 4.6 & 4.6 & 4.6 & 4.6 \\
Metal frame & & $\checkmark$ & $\checkmark$ & $\checkmark$ \\
Metal connectors & & $\checkmark$ & $\checkmark$ & $\checkmark$ \\
Interior doors and hardware & & $\checkmark$ & $\checkmark$ & $\checkmark$
\end{tabular}

\begin{tabular}{|c|c|c|c|c|}
\hline \multirow{2}{*}{\multicolumn{5}{|c|}{\begin{tabular}{|l} 
Furnishings: \\
Planters and furniture:
\end{tabular}}} \\
\hline & & & & \\
\hline Custom metal frames & \multicolumn{3}{|c|}{$\checkmark$} & $\sqrt{ }$ \\
\hline Bio/Industrial finish panels & \multicolumn{3}{|c|}{$\checkmark$} & $\checkmark$ \\
\hline Plant sacks & \multicolumn{3}{|c|}{$\checkmark$} & \\
\hline Metal canopies & & $\mathrm{N} / \mathrm{A}$ & $\mathrm{N} / \mathrm{A}$ & $\mathrm{N} / \mathrm{A}$ \\
\hline \multicolumn{5}{|l|}{ Staircases: } \\
\hline Metal frames & \multicolumn{3}{|c|}{$\sqrt{ }$} & $\sqrt{ }$ \\
\hline Bio/Industrial finishes & 0.75 & 0.75 & 0.75 & 0.75 \\
\hline Metal connectors & \multicolumn{3}{|c|}{$\checkmark$} & $\checkmark$ \\
\hline Total estimable material volume & 1241.96 & & & \\
\hline Total estimable reusable volume & & 1241.96 & & \\
\hline Total estimable recyclable volume & & & & 1205.01 \\
\hline Total reusable ratio & & $100 \%$ & & \\
\hline Total recyclable ratio & & & & $97 \%$ \\
\hline
\end{tabular}





\section{References}

Addis, Bill. (2006) Building With Reclaimed Components and Materals: A Design Handbook for Reuse and Recycling. Sterling, VA: Earthscan.

Alfred, Randy. (2009, July 31) Aug. 2, 1803: Crystal Palace Architect Born, In Wired Magazine. Retrieved from www.wired.com, Dec 7, 2011.

Ander, Gregg D (2012) Daylighting. National Institute of Building Sciences, retrieved from http://www.wbdg.org/resources/ daylighting.php?r=joint_re-tail, Feb 2, 2012.

Anderson, Mark \& Anderson, Peter. (2007) Prefab Prototypes: site-specific design for offsite construction, New York: Princeton Architectural Press.

Architecture 2030. (2011) retrieved from www.architecture2030.org/ home/html, Mar 142011.

Architecture, Modern Home \& Interior Design, Furniture. (2010, Nov) Outdoor Bamboo Restaurant. Retrieved from www.arch planner.com, Nov 28, 2011.

Ashby, Michael F. (2009) Materials and Environment: Eco-In formed Material Choice. Burlington, MA: Elsevier Inc.

Bahamon, Alejandro \& Sanjines, Maria Camila. (2010) Rematerial: From Waste to Architecture. WW Norton \& Co.

Barreneche, Raul D. (2005) New Retail. New York: Phaidon Press Limited.

Bell, Victoria and Rand, Patrick. (2006) Materials for Design. New York: Princeton Architectural Press.

Berge, Bjorn. (2009) The Ecology of Building Materials: Second Edition. Massachusets: Elsevier Ltd.

Brand, Stewart. (1994) How Buildings Learn: What happens after they're built. London: Viking.

Carr-Smith, David. (2009) Temporary Architecture. Retrieved from http://davidcarrsmith.co.uk/_D-WW_TMP-ARC_CAF1.htm , Nov 20, 2011.

CBC. (2011) Throw-away buildings: The slow-motion failure of Toronto's glass condos. Retrieved from http://www.cbc.ca/ toronto/features/condos/index.html, Nov 22, 2011.

Cho, Minsuk. (2010) Best Used Before: The Asian City and the Quest for a Time-specific Architecture, In Ruby, Ilka \& Andreas (Ed.) Re-inventing Construction. Berlin: Ruby Press, 201-216.

Christensen, Julia. (2008) Big Box Reuse. Cambridge: MIT Press.

Citizendium. (2010) Crystal Palace. Retrieved from http:// en.citizendium.org, Dec 7, 2011. 

Cowling, Dan. (2010) Mountain Equipment Co-op: New store tests design for recoverability, In SAB Magazine, retrieved from www.sabmagazine.com, Nov 30, 2011.

Daniels, Yolande. (2003) Detail and Articulation, In The State of Architecture at the Beginning of the 21st Century. New York: The Monacelli Press. 48.

Design4deconstruction. (2011) Case Studies. Retrieved from http:// www.design-4deconstruction.org/, Nov 22, 2011.

Dezeen magazine. (2011, Nov 17) Taichung Infobox by Stan Allen, In dezeen magazine. Retrieved from www.dezeen.com, Nov 28, 2011.

Dickinson, Duo. (1996) Expressive Details. New York: McGraw-Hill.

Duerksen, Chris (2008) Saving the World Through Zoning, American Planning Association, retrieved from http://law.du.edu/ documents/rmlui/saving-the-world-through-zoning.pdf, Feb 2, 2012.

Durmisevic, Elma \& Brouwer, Jan. (2002) Dynamic Versus Static Building Structures, Netherlands: Delft University of Technology.

Durmisevic, Elma \& Yeang, Ken. (2009) Designing for Disassembly (DfD), In Architectural Design, 79 (6), 134-137.

Durmisevic, Elma \& Linthorst, Patrick. (2000) Industrialization of Housing (Building with systems) The Netherlands: Delft University of Technology,

Ermanno, Ranzani. (1990, Feb) Ampliamento dell'IRCAM a Parigi: Renzo Piano Building Workshop, In Domus, [38] 47.

Fleishman, Gregg, (2011) Humanizing the Factory Produced House. Retrieved from www.greggfleishman.com, Nov 28, 2011.

Ford, Edward R. (2009) Five Houses, Ten Details, New York: Princeton Architectural Press.

Frampton, Kenneth. (2008) Rappel à L'Ordre: A Case for the Tectonic, In Mallgrave, Harry Francis and Contandriopoulos, Christina (Ed.) Architectural Theory: Volume II An Anthology from 18712005. USA: Blackwell Publishing. 565-571.

Frampton, Kenneth. (2001) Studies in Tectonic Culture: The Poetics of Construction in Nineteenth and Twentieth Century Architecture. MIT Press.

Frascari, Marco. (2008) The Tell-the-tale Detail, In Mallgrave, Harry Francis and Contandriopoulos, Christina (Ed.) Architectural Theory: Volume II An Anthology from 1871-2005. USA: Blackwell Publishing. 500-508.

Frisman, Paul. (2004) Building Deconstruction, In OLR Research Report. retrieved from http://www.cga.ct.gov/2004/rpt/ 2004-R-0911.htm, April 102012. 

GEDA USA (2012) Rack and Pinion Elevators, retrieved from http://www.gedausa.com/rack-and-pinion-elevators.html, May 1, 2012.

Hubei Fotma Machinery Co. (2010) Truck Mounted Crane, retrieved from www.cmec-hb.com, Mar 31, 2012.

Hulchanski, J. David. (2010) The Three Cities Within Toronto: Income Polarization Among Toronto's Neighbourhoods, 1970-2005. Toronto: Cities Centre, University of Toronto.

Iwamoto, Lisa. (2009) Digital Fabrications: Architectural and Material Techniques. New York: Princeton Architectural Press.

Kernan, Paul. (2002) Old to New: Design Guide: Salvaged Building Materials in New Construction, 3rd Edition. Greater Vancouver Regional District, Policy and Planning Dept.

Kieran, Stephen and Timberlake, James. (2002) Manual. New York: Princeton Architectural Press.

Kieran, Stephen and Timberlake, James. (2008) Loblolly House: Elements of a New Architecture. New York: Princeton Architectural Press.

Killingsworth, R., \& Farrow, B. (2007) Adaptive reuse of large singletenant retail facilities (Case study). Auburn University, Auburn, AL: Department of Building Science. Retrieved from http:// www.rics.org/site/download_feed-.aspx?filelD $=3329 \&$ file Extension=PDF, Jan 31, $20 \overline{1} 2$.

Knecht, Barbara. (2004, Oct) Designing for Disassembly and Deconstruction, Architectural Record, Vol 192 Issue 10, 181-188.

Kronenberg, Robert. (2000) Portable Architecture, Second Edition. Oxford: Architectural Press.

Krytiuk Specialty Contracting. (2012) Intumescent Paint, retrieved from www.ksccanada.com, Mar 26, 2012.

Laubin, Reginald \& Gladys. (1977) The Indian Tipi: Its History, Construction and Use, Second Edition. University of Oklahoma Press.

Levesque, Carole. (2008, May) Actions in indeterminability: exploring the possibilities of temporary architecture, In Reconciling Poetics and Ethics in Architecture retrieved from www.arch. mcgill.ca/theory/conference/papers/Levesque_Carole.doc, Nov 10, 2011.

Marble Fairbanks. (2011) Flatform, Home Delivery: Fabricating the Modern Dwelling. Retrieved from www.marblefairbanks.com, Oct 27, 2011.

McDonough, William \& Braungart, Michael. (2002) Cradle to Cradle. North Point Press.

Melet, Ed. (2002) The Architectural Detail: Dutch Architects Visualise 

their Concept. Rotterdam: NAI Publishers.

Miller, Stephen G. (Ed.) (1990) Nemea: A Guide to the Site and Museum. Berkeley: University of California Press.

retrieved from http://publishing.cdlib.org/ucpressebooks/ view?docld=ft1q2nb0x1; chunk.id=d0e5888;doc.view=print, Dec 7, 2011.

Mori, Toshiko. (2003) Materiality and Culture, In (Ed.?) The State of Architecture at the Beginning of the 21st Century. New York: The Monacelli Press. 30-31.

Muslimin, Rizal. (2010) Bead Brick, retrieved from http://www. brickstainable.com/current-winners/technical-design.html, Dec 9, 2011.

NAHB Research Center (2001) Strawboard Panels. Retrieved from http://www.toolbase.org/Technology-Inventory/Whole-HouseSystems/-strawboard-panels, Feb 12, 2012.

National Institute of Building Sciences (2012) Building Envelope Design Guide - Curtain Walls, in Whole Building Design Guide, retrieved from http://www.wbdg.org/design/env_ fenestration_cw.php, April 11, 2012.

Ontario Farmland Trust (2012) Saving Farmland, retrieved from http:// www.ontariofarmlandtrust.ca/issues-and-programs/ saving-farmland, Jan 31, 2012.

Ontario Waste Management Association. (2005) A Landfill Story: Capacity, Export \& EA. Retrieved from www.owma.org/ db/db2file.asp?fileid=457, March 272011.

Panchapakesan, Charisma. Sustainable Building Design: Case Study, Wal-Mart Eco-Store, William McDonough Architects. University of Waterloo. retrieved from http://www.architecture.uwaterloo. ca/faculty_projects/terri/125_W03/Panchapakesan_ walmart.pdf, Feb 12, 2012.

Pearson, Clifford A. (2007) On a wooded site on Taylors Island, Maryland, Kieran Timberlake tested a new way of building with the LOBLOLLY HOUSE, In Architectural Record. p140-146.

Prussin, Labelle. (1995) African Nomadic Architecture: Space, Place and Gender, Smithsonian Institution Press and The National Museum of African Art: Washington and London.

Remodelista. (2011, March 21) Architect Visit: Suyama Peterson Deguchi Architects in Seattle, retrieved from www.remodelista. com, Nov 28, 2011.

Saieh, Nico. (2008, Aug 14) Kunsthaus Art House Extension/ssm Architekten, In archdaily. Retrieved from www.archdaily.com, Nov 28, 2011.

Sobek, Werner. (2010) Architecture Isn't Here to Stay, In Ruby, Ilka \& Andreas (Ed.) Re-inventing Construction. Berlin: Ruby Press, 34-45. 

Sober, Werner. (2011) Station Z, retrieved from www.wernersobek.de, Dec 9, 2011.

Stang, Alanna and Hawthorne, Christopher. (2005) The Green House: New Directions in Sustainable Architecture. New York: Princeton Architectural Press.

Steel Recycling Institute. (2011) Steel Recycling Rates, retrieved from www.recycle-steel.org, Mar 26, 2012.

Superuse. (2007) Cable Reel Reality, retrieved from www.superuse. org, Oct 27, 2011

Thomsen, André and van der Flier, Kees. (2011) Understanding Obsolescence: A Conceptual Model for Buildings, BRI Building Research \& Information, 39 (4), 352-362.

Triumph Modular (2012) Building Foundations, retrieved from www.triumphmodular.com/building-foundations.php, Feb 10, 2012

Universitat Stuttgart, Institut fur Leichte Flachentragwerke. (1975) Anpassungsfahig Bauen $=$ Adaptable Architecture, Stuttgart: Universitat Stuttgart.

University of Virginia (2012) ecoMOD 3: Design for Deconstruction, retrieved from http://ecomod.virginia.edu/wp-content/ uploads/2010/02/dfd-060407-.pdf, Feb 10, 2012

US Department of Energy (2011) Natural Fiber Insulation Materials, retrieved from http://www.energysavers.gov/your_home/ insulation_airsealing/index.cfm/mytopic=11560, Feb 122012.

Vitra Design Museum, (2002) Living in Motion: Design and Architecture for Flexible Dwelling. Vitra Design Stiftung gGmbH and contributors.

Weston, Richard. (2003) Materials, Form and Architecture. London: Laurence King Publishing Ltd.

Woodwork Details. (2007-2009) Mortise and Tenon Frame Joints. Retrieved from www.woodworkdetails.com, Nov 28, 2011. 